\title{
WestVirginiaUniversity
}

THE RESEARCH REPOSITORY @ WVU

Graduate Theses, Dissertations, and Problem Reports

1999

\section{Designing and modeling a torque and speed control transmission (TSCT)}

John Allen Anderson

West Virginia University

Follow this and additional works at: https://researchrepository.wvu.edu/etd

\section{Recommended Citation}

Anderson, John Allen, "Designing and modeling a torque and speed control transmission (TSCT)" (1999). Graduate Theses, Dissertations, and Problem Reports. 984.

https://researchrepository.wvu.edu/etd/984

This Thesis is protected by copyright and/or related rights. It has been brought to you by the The Research Repository @ WVU with permission from the rights-holder(s). You are free to use this Thesis in any way that is permitted by the copyright and related rights legislation that applies to your use. For other uses you must obtain permission from the rights-holder(s) directly, unless additional rights are indicated by a Creative Commons license in the record and/ or on the work itself. This Thesis has been accepted for inclusion in WVU Graduate Theses, Dissertations, and Problem Reports collection by an authorized administrator of The Research Repository @ WVU. For more information, please contact researchrepository@mail.wvu.edu. 
Designing and Modeling a Torque and Speed Control Transmission (TSCT)

\author{
John A. Anderson \\ Thesis submitted to the \\ College of Engineering and Mineral Resources \\ at West Virginia University \\ in partial fulfillment of the requirements \\ for the degree of \\ Master of Science \\ in \\ Mechanical Engineering \\ Chris M. Atkinson, Sc.D., Chair \\ Nigel N. Clark, Ph.D. \\ Victor H. Mucino, Ph.D. \\ Department of Mechanical and Aerospace Engineering
}

Morgantown, West Virginia

1999

Keywords: CVT, Transmission, Hybrid, Power Split 


\title{
Abstract \\ Designing and Modeling a Torque and Speed Control Transmission (TSCT)
}

\author{
By John A. Anderson
}

Near term Hybrid Electric Vehicles (HEVs) generally employ current automotive transmissions. These automatic and manual transmissions are based on designs that are many years old. These older transmission designs do not allow multiple power inputs/outputs to be connected to the transmission. These types of designs significantly limit the flexibility in terms of overall function and component packaging for hybrid vehicles. This study was conducted to determine the feasibility of creating a transmission for hybrid vehicle applications with multiple power inputs/outputs.

The Torque and Speed Control Transmission (TSCT) is a combination of a planetary geartrain and a Continuously Variable Transmission (CVT). By combining these two types of power transmission devices, a new transmission is created that has much greater flexibility. This combination of a planetary geartrain with a CVT allows for a power split operation under certain conditions. This type of operation is beneficial as it allows for the power through the CVT to be varied independently of engine power and vehicle speed.

The TSCT was studied to determine the most beneficial mechanical layout of components. Six possible drivetrain layouts were analyzed. A final drivetrain configuration was chosen that allows six distinct modes of operation. This configuration was chosen for correct component rotations throughout all modes and ease of control. A common shaft from the engine is connected to both the CVT input and the sun gear of the planetary geartrain. A high power electric motor is attached to the planetary carrier and the output from the CVT is connected to the ring gear and a high power alternator. Vehicle propulsive power is extracted from a geared connection to the ring gear. This mechanical layout allows for Convention Vehicle, Electric Vehicle, Series HEV, Geared Neutral, and two Parallel HEV modes. 


\section{Table of Contents}

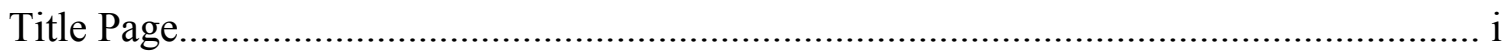

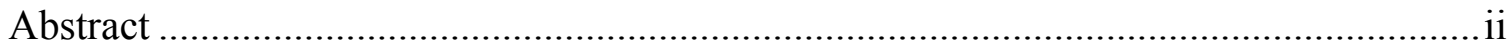

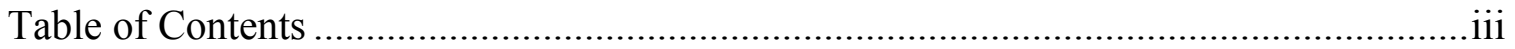

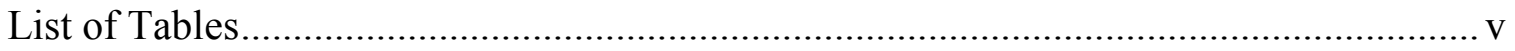

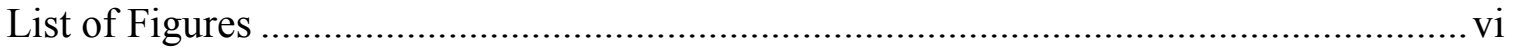

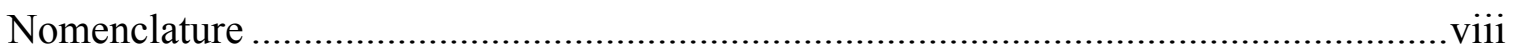

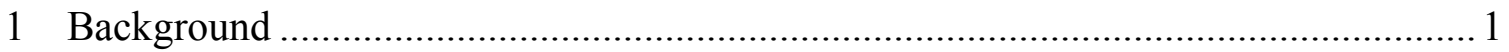

1.1 Current Automotive Transmission Technologies ...........................................

1.1.1 Manual Transmission Operation .................................................................

1.1.2 Automatic Transmission Operation ......................................................... 4

1.1.3 Continuously Variable Transmission Operation ............................................. 5

1.1.4 Automatically Shifted Manual Transmission Operation.................................... 6

1.1.5 Manually Shifted Automatic Transmission Operation...................................... 7

1.1.6 Planetary Gear Drive Transmission Operation ............................................ 8

1.2 Current Hybrid Electric Vehicle Transmission Design....................................... 9

1.2.1 The Advantages and Disadvantages of Series Hybrid Vehicles ..................... 10

1.2.2 The Advantages and Disadvantages of Parallel Hybrid Vehicles.................... 11

1.2.3 The Advantages and Disadvantages of Combination Hybrid Vehicles ...........13

1.3 Combining Two Different Types of Transmissions............................................. 13

1.4 Multiple Transmission Combinations for Hybrid Vehicle Applications .............. 14

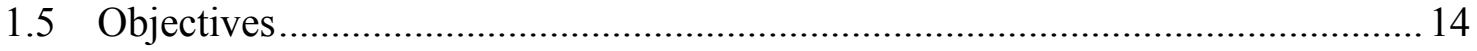

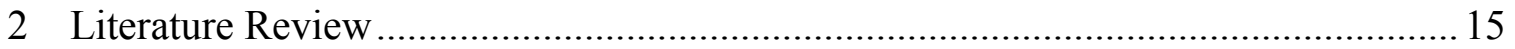




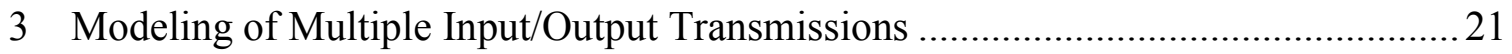

3.1 Toyota Prius Hybrid Electric Drivetrain ........................................................ 21

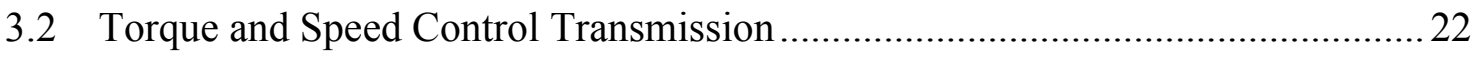

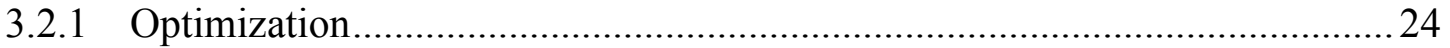

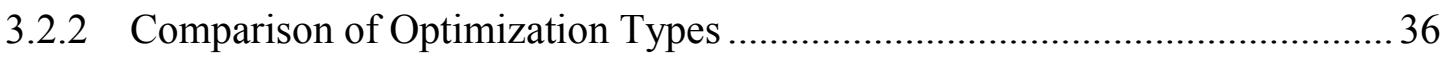

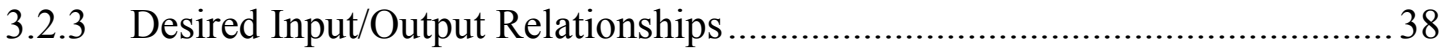

3.2.4 Desired CVT Operating Range .............................................................. 39

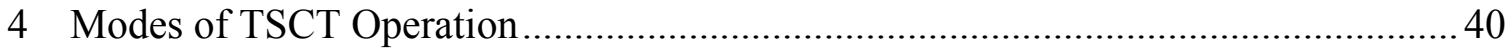

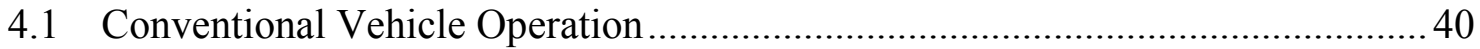

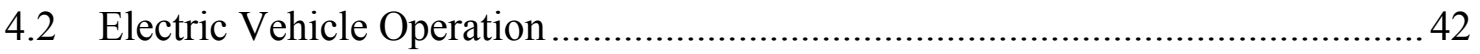

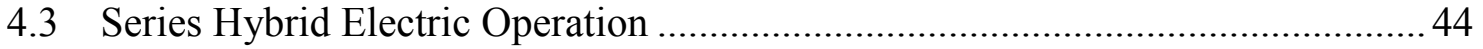

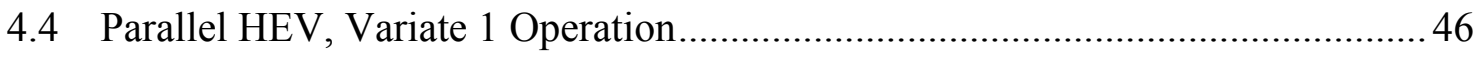

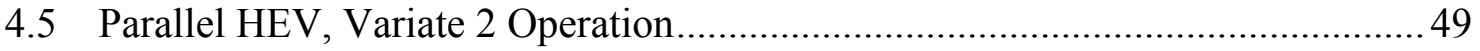

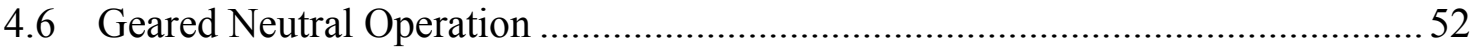

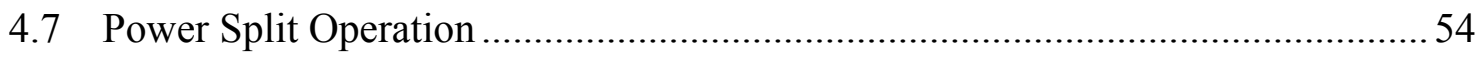

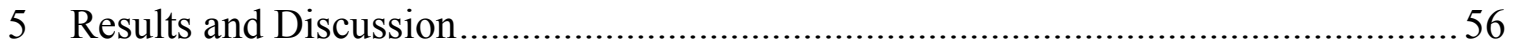

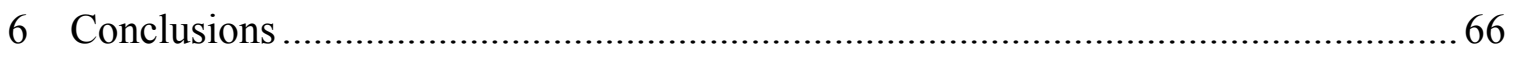

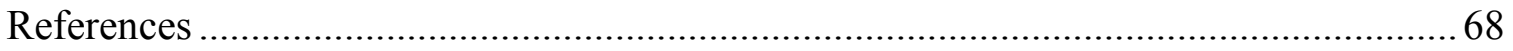

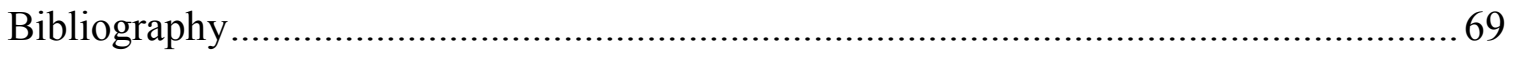




\section{List of Tables}

Table 3.1.1: $\quad$ Toyota Prius Planetary Geartrain Connections

Table 3.2.1: $\quad$ Mode Switching Strategy for the TSCT for a Multi-Mode Hybrid Vehicle

Table 3.2.2.1: $\quad$ Component Connection for Each Type Examined

Table 3.2.2.2: $\quad$ Advantages and Disadvantages of Each Type Examined

Table 3.2.3.1: $\quad$ Required Components and Function for Each Mode of Operation 


\section{List of Figures}

Figure 1.2.1.1: $\quad$ Power Flow Diagram for a Typical Series HEV

Figure 1.2.2.1: $\quad$ Power Flow Diagram for a Typical Parallel HEV

Figure 3.1.1: $\quad$ Power Flow Diagram for the Toyota Prius

Figure 3.2.1: $\quad$ Block Diagram of TSCT Components and Power Flow

Figure 3.2.2: Mechanical Design for the Torque and Speed Control

Transmission

Figure 3.2.1.1: $\quad$ Component Schematic for Type 1 Analysis

Figure 3.2.1.2: $\quad$ Planetary Geartrain Component Rotation Speed as a Function of

Variator Ratio

Figure 3.2.1.3: $\quad$ Component Schematic for Type 2 Analysis

Figure 3.2.1.4: $\quad$ Planetary Geartrain Component Rotation Speed as a Function of

Variator Ratio

Figure 3.2.1.5: $\quad$ Component Schematic for Type 3 Analysis

Figure 3.2.1.6: $\quad$ Planetary Geartrain Component Rotation Speed as a Function of

Variator Ratio

Figure 3.2.1.7: $\quad$ Component Schematic for Type 4 Analysis

Figure 3.2.1.8: $\quad$ Planetary Geartrain Component Rotation Speed as a Function of

Variator Ratio

Figure 3.2.1.9: $\quad$ Component Schematic for Type 5 Analysis

Figure 3.2.1.10: $\quad$ Planetary Geartrain Component Rotation Speed as a Function of Variator Ratio

Figure 3.2.1.11: $\quad$ Component Schematic for Type 6 Analysis

Figure 3.2.1.12: $\quad$ Planetary Geartrain Component Rotation Speed as a Function of Variator Ratio

Figure 4.1.1: $\quad$ Conventional Vehicle Operation

Figure 4.1.2: $\quad$ Power Flow Diagram for Conventional Vehicle Operation

Figure 4.2.1: $\quad$ Electric Vehicle Mode

Figure 4.2.2: $\quad$ Power Flow Diagram for Electric Vehicle Operation

Figure 4.3.1: $\quad$ Series HEV Operation 
Figure 4.3.2: $\quad$ Power Flow Diagram for Series HEV Operation

Figure 4.4.1: $\quad$ Parallel HEV, Variate 1

Figure 4.4.2: $\quad$ Power Flow Diagram for Parallel HEV, Variate 1 Operation

Figure 4.5.1: $\quad$ Parallel HEV, Variate 2

Figure 4.5.2: $\quad$ Power Flow Diagram for Parallel HEV, Variate 2 Operation

Figure 4.6.1: $\quad$ Geared Neutral Operation

Figure 4.6.2: $\quad$ Power Flow Diagram for Geared Neutral Operation

Figure 4.7.1: $\quad$ Power Split in CVT as a Function of Motor Torque

Figure 5.1: $\quad$ TSCT Operation vs Manual Transmission

Figure 5.2: $\quad$ Engine Operation as a Function of Vehicle Speed and Variator

Ratio

Figure 5.3: $\quad$ Planetary Geartrain Rotation as a Function of Vehicle Speed

Figure 5.4: $\quad$ Engine and Planetary Geartrain Speed vs Vehicle Speed

Figure 5.5: $\quad$ Planetary Geartrain Speeds vs Vehicle Speed

Figure 5.6: $\quad$ Planetary Geartrain Speeds vs Vehicle Speed 


\section{Nomenclature}

\begin{tabular}{|c|c|}
\hline PNGV & $=$ Partnership for a New Generation of Vehicles \\
\hline EPA & $=$ Environmental Protection Agency \\
\hline HWFET & $=$ Highway Fuel Efficiency Test \\
\hline FTP & $=$ Federal Test Procedure \\
\hline $\mathrm{HEV}$ & $=$ Hybrid Electric Vehicle \\
\hline $\mathrm{EV}$ & $=$ Electric Vehicle \\
\hline ZEV & $=$ Zero Emissions Vehicle \\
\hline ICE & $=$ Internal Combustion Engine \\
\hline SI & $=$ Spark Ignited \\
\hline SoC & $=$ State of Charge \\
\hline $\mathrm{TSCT}$ & $=$ Torque and Speed Control Transmission \\
\hline THS & $=$ Toyota Hybrid System \\
\hline CVT & $=$ Continuously Variable Transmission \\
\hline mpg & $=$ Miles per gallon \\
\hline $\mathrm{mph}$ & $=$ Miles per hour \\
\hline $\mathrm{rpm}$ & $=$ Revolutions per minute \\
\hline $\mathrm{AC}$ & $=$ Alternating current \\
\hline $\mathrm{kW}$ & $=$ Kilowatt \\
\hline $\mathrm{N}_{\mathrm{r}}$ & $=$ Number of teeth of ring gear \\
\hline $\mathrm{N}_{\mathrm{s}}$ & $=$ Number of teeth of sun gear \\
\hline $\mathrm{W}_{\mathrm{c}}$ & $=$ Rotation of ring gear \\
\hline $\mathrm{W}_{\mathrm{o}}$ & $=$ Rotation of CVT output \\
\hline$\gamma_{\mathrm{g}}$ & $=$ Ratio of ring gear to sun gear \\
\hline$\gamma_{c}$ & $=\mathrm{CVT}$ to ring gear ratio \\
\hline $\int_{\mathrm{v}}$ & $=$ Instantaneous CVT ratio \\
\hline
\end{tabular}




\section{Background}

The Partnership for a New Generation of Vehicles (PNGV) was formed between the Federal Government, Ford Motor Company, General Motors Corporation, and Chrysler Corporation. The goal of this partnership was to allow the major U.S. automotive manufactures to collaborate with each other and produce high fuel efficiency, low emissions vehicles for sale to the general public. The performance objective for these manufacturers was to create mid-sized passenger cars capable of attaining an $80 \mathrm{mpg}$ (gasoline) composite fuel economy rating on the Environmental Protection Agency (EPA) city and highway cycles.

Hybrid vehicle technology has shown great promise in attaining the goals set forth by the PNGV. Hybrid electric vehicles (HEVs) employ technology that helps bridge the gap between the future hope of an electric vehicle (EV) and today's current vehicles. Within the past year hybrid electric vehicles have gained an important place in the vehicle market. American Honda Motor Company, Inc. is currently releasing their first generation HEV, the Insight. The Insight is a compact, two passenger, parallel HEV which achieves more than $65 \mathrm{mpg}$ (composite) on the EPA test cycles: the highest of any production vehicle ever tested. Toyota Motor Corporation has also released a hybrid vehicle for sale to the general public. The Toyota Prius is currently for sale in Japan and will come the United States in the beginning of the year 2000. The Prius is a four passenger combination hybrid employing an a gasoline engine, high power electric motor, and an electromechanical continuously variable transmission (CVT) comprised of a planetary geartrain and a high power alternator/motor. It is through technology 
incorporated in vehicles such as the Prius that automotive transmission design and operation will make significant new advances.

\subsection{Current Automotive Transmission Technologies}

With the advent of the automobile also came the creation of the automotive transmission. Early vehicles were simple with manual controls for all functions including the transmission. As advances have been made in vehicles over the past several decades, transmission technology has also advanced. The automatic transmission has nearly replaced the manual transmission in all but economy and performance cars. This trend can be attributed to ease of use, higher power engines becoming available, and congestion in urban areas. Another new transmission technology beginning to see application particularly in foreign markets is the continuously variable transmission that offers continuous operation without shifting between a high and low gear ratio.

These three types of transmissions are all similar in function though their objectives are accomplished in different ways. The capabilities of these transmissions are limited to decoupling the engine speed from the speed of wheels and thereby providing one of several forward or reverse gear ratios. Each transmission is also a single input (engine) and single output (drive device). There are typically no provisions for attaching multiple power sources or for extracting power from more than one point. The exception to this is heavy-duty transmissions equipped with provisions for a power take off for driving auxiliary mechanical equipment. Single input, single output 
operation limits drivetrain flexibility for newer systems employing multiple power sources such as those used in the next generation of hybrid vehicles.

\subsubsection{Manual Transmission Operation}

Manual transmissions are the least complex and oldest design of power transmission available. In simplest form, a manual transmission is a linear combination of a clutch and a directly geared connection. More sophisticated examples rely on this design but add the ability to select other gear ratios to allow different output speeds for the same input speed. Of these types of transmissions, there are two variations: synchronized and unsynchronized. Synchronized manual transmissions are typically used for light duty applications. Coupled to each gear is a synchronizer that allows the operator to disengage the clutch and select whatever gear necessary. The selection of a different gear engages the synchronizer, which then matches engine input speed and transmission output speed before the gears are engaged.

Unsynchronized manual transmissions are more robust by nature. The operator must double-clutch between shifts to match engine and transmission speed manually. However, this allows a transmission of a given size to handle greater load as space previously occupied by the synchronizers can now be dedicated to the use of wider gears. Applications of these types of manual transmissions are for over-the-road trucks and up to larger equipment with total vehicle weights over 100 tons. [1] 


\subsubsection{Automatic Transmission Operation}

Automatic transmissions are a complex assembly of many components that allow for seamless power transmission. Those currently available in production vehicles use torque converters, clutches, and planetary gear sets for the selection of different output ratios. The engine is connected to the torque converter that acts very much like a clutch under some conditions while more like a direct connection in others. The torque converter is a hydraulic coupling that will slip under light load (idle), but engage progressively under higher load. While the torque converter transmits power to the transmission there is a speed reduction across the unit during low speed operation. This reduction is typically between $2.5: 1$ to $3.5: 1$. Once higher vehicle speeds are attained, the torque converter input and output may be locked together to achieve a direct drive though the unit. The output of the torque converter is typically connected to a hydraulic pump that provides the necessary pressure to engage different clutches within the transmission and the planetary drive. Different gear ratios are created through the use of two or more planetary gearsets. These gearsets are combined with clutches on different elements. By clutching and declutching different elements, multiple gear ratios are possible.

Basic automatic transmissions are equipped with a single control input that is throttle position. The combination of this with the hydraulic pressure created within the transmission allows for mechanical open loop control of all gear selections. Newer variations of the automatic transmission are equipped with electronic feedback controls. Shift logic is dependent on many more variables such as engine speed, temperature, current driving trend, throttle position, vehicle accelerations, etc. This allows the 
transmission controller to monitor vehicle operation and using a rule-based control strategy decide which gear is best suited to the current driving conditions. Newer systems are also integrated with the engine controller such that a vehicle control computer has authority over engine and transmission operation simultaneously. This allows for such features as increasing engine speed during high-speed downshifts to match engine and transmission speed for smoother shifting and retarding fueling and ignition timing during high power upshifts to reduce 'jerk'. Previously, transmission control was much simpler because overrunning clutches were employed in higher gears that only allowed for coasting to conserve fuel. [1]

\subsubsection{Continuously Variable Transmission Operation}

Continuously variable transmissions are one of the emerging transmission technologies of the last twenty years. This type of transmission allows power transmission over a given range of operation with infinitely variable gear ratios between a high and low extreme. These transmissions are constructed using two variable diameter pulleys with a belt connecting the two. As one pulley increases in size, the other decreases. This is accomplished by locating on one shaft a stationary sheave and a movable sheave. For automotive applications, a hydraulic actuator controls movement of the sheave. However, centrifugal systems along with high power electronic solenoids may be used. A second shaft in the CVT contains the other stationary sheave and movable sheave also controlled hydraulically. A flexible metal belt is fitted around these two pulleys and the movable sheaves are located on opposite sides of the belt. 
There are two variations of this type of transmission: push belt and pull belt. Pull belt CVTs were the first type to be manufactured due to simplicity. A clutch is attached between the first pulley and the engine while the output of the second pulley was connected to a differential and thus the wheels. A hydraulic pump is used to control the diameter of the two different pulleys. As power is applied the first pulley creates a torque that is transmitted through the belt (under tension) to the second pulley. Control of the transmission ratio is usually a direct relationship dependent upon throttle position. Push belt CVTs, similar in design to the Van Doorne, are much the same as pull belt CVTs, except that power is transmitted through the belt while under compression. This provides a higher overall efficiency due to the belt being pushed out of the second pulley and lowering frictional losses. Current work with these transmissions is being focused on creating larger units capable of handling more torque.

Efficiency of the CVT is directly related to how much tension is in the belt between the two pulleys. CVT torque handling capacity increases as tension in the belt increases. However, this increased tension lowers power transmission efficiency. The belt must slide across the faces of each pulley as it enters and exits upon each half rotation. This sliding of the belt creates frictional losses within the system. In addition, there may be significant parasitic losses associated with raising the hydraulic pressure required to move or maintain the position of the sheaves in each pulley. [2]

\subsubsection{Automatically Shifted Manual Transmission Operation}

Automatically shifted manual transmissions are a fairly recent innovation. The benefit of the manual transmission is that (due to the direct mechanical connection 
through fixed gears) efficiency is very high. The drawback is that there must be some interaction with the user in the selection and changing of gears. Automatically shifted manuals were created to address this issue. These types of transmissions are traditionally synchronized manual transmissions with the addition of automation of the gear selection and control of the clutch. A logic controller is also employed to decide when and how to shift. Automatic shifting is usually accomplished through the use of electro-hydraulics. A high-pressure electric pump supplies pressure to hydraulic solenoids that are used to shift the transmission. A hydraulic ram is also used to engage and disengage the clutch. Current versions of these transmissions also employ unsynchronized gears. This allows for overall smaller packaging to accomplish the same task. Input speed of the engine is monitored along with layshaft speed. When a gear change is initiated, the controller opens the clutch, shifts to the desired gear while matching engine and layshaft speed, and then closes the clutch again. This shifting operation can all be achieved in less than one third of a second. Automatically shifted manual transmissions shift gears faster than humanly possible. [3]

\subsubsection{Manually Shifted Automatic Transmission Operation}

Manually shifted automatic transmissions are a variation on control of the transmission. The user is allowed to select either automatic or manual shifting modes. During automatic mode, the transmission functions identically to an automatic transmission. While in manual shift mode however, the transmission controller allows the user full authority over gear changes as long as the gear change will not overspeed the engine. This mode of operation traditionally offers the user tighter, more positive 
shift feel. The only requirement of an automatic transmission for manual shifting is that shifts must be accomplished rapidly enough to allow the user a feeling of fluidity. The act of shifting must provide the immediate desired response. [3]

\subsubsection{Planetary Gear Drive Transmission Operation}

Planetary gear sets are unique in that the combination of gears creates a two degree-of-freedom system. The gear sets are comprised of a ring gear, a sun gear in the center, and planetary gears that contact both the ring and the sun gears. Motion of the planetary gears is controlled by the carrier on which each of the planetary gears rotate. The carrier maintains the position of the planets in relation to each other but allows rotation of all planets freely. Inputs (or outputs) to the geartrain are the ring gear, sun gear, and planetary carrier. By prescribing the motion of any two of these parameters, the third is fixed in relation to the other two. By employing one planetary geartrain, a fixed ratio between input and output is created. Increasing or decreasing the number of teeth on the sun and ring gears can change this ratio. This in turn changes the number of teeth on the planetary gears, which has no other effect as these gears act as idlers.

When combining more than one planetary geartrain at one time, braking or allowing the movement of different elements can create a wide range of effective operation in terms of relative speeds, torque transfer, and direction of rotation. This is the type of system that is used in automatic transmissions described above. These systems are also employed in large stationary power transmission applications. [1] 


\subsection{Current Hybrid Electric Vehicle Transmission Design}

Hybrid vehicles are vehicles that utilize more than one power source. Current propulsion technologies being favored are compression ignition (CI) engines, spark ignition(SI) engines, hydrogen-fueled engines, fuel cells, gas turbines, and high power electric drives. Energy storage devices include batteries, ultra-capacitors, and flywheels. Hybrid powertrains can be any combinations of these technologies. The aim of these vehicles is to use cutting edge technology combined with current mass-produced components to achieve much higher fuel economy combined with lower emissions without raising consumer costs appreciably. These vehicles are targeted to bridge the gap between current technology and the future hope of a Zero Emission Vehicle (ZEV), presumably a hydrogen-fueled fuel cell vehicle. The operation of these systems must also be transparent to the user to enhance consumer acceptability and the vehicle must still maintain all required safety features with comparable dynamic performance all at an acceptable cost.

By combining multiple power sources, overall vehicle efficiency can be improved by the ability to choose the most efficient power source during the given operating conditions. This is key in improving vehicle efficiency because current battery technology dictates that nearly all total energy used by the vehicle across a reasonable range of driving comes from the on-board fuel. Highly adaptive control strategies that may be employed in the next generation of HEVs may monitor vehicle speed, desired torque, energy available, and recent operating history to choose which mode of operation is most beneficial. These advanced control schemes will maximize the usage of the fuel energy available by choosing the most efficient means of power delivery at 
any instant. The reduced usage of energy for a given amount of work may also result in lower exhaust emissions due to a reduction in fuel energy used.

\subsubsection{The Advantages and Disadvantages of Series Hybrid Vehicles}

Series hybrid vehicles typically have an internal combustion engine (ICE) that is coupled directly to an electric alternator. The vehicle final drive is supplied entirely by an electric traction motor that is supplied energy by the battery pack or combination of engine and alternator. The benefit of this type of operation is the engine speed and torque are decoupled from the instantaneous vehicle load and the engine needs only to run when battery state of charge (SoC) has dropped below some lower level. This allows engine operation to be optimized for both fueling and ignition timing in the case of a spark ignited engine, or fueling and injection timing for a compression ignition engine. The engine is also operated in the most efficient speed and torque without encountering transient operation regardless of load. The result is excellent fuel economy and low emissions. Series HEV operation is exceptionally well suited to highly transient vehicle operation which is prevalent in highly urban areas and city driving. The disadvantage to series hybrid operation is the efficiency losses associated with converting mechanical to electrical and then electrical to mechanical energy. Further losses in system efficiency are realized when the energy is stored in the battery pack for later use. Only a fraction of the energy put into the batteries can be returned due to the internal resistance of the batteries. The mechanical energy of the engine is directly converted to electricity by an alternator that has losses both in internal resistance and eddy currents present. Further losses are incurred when this electrical energy is 
converted back to mechanical energy by the traction motor and controller. Dynamic performance is also limited, as the engine cannot supplement the traction motor in powering the vehicle.

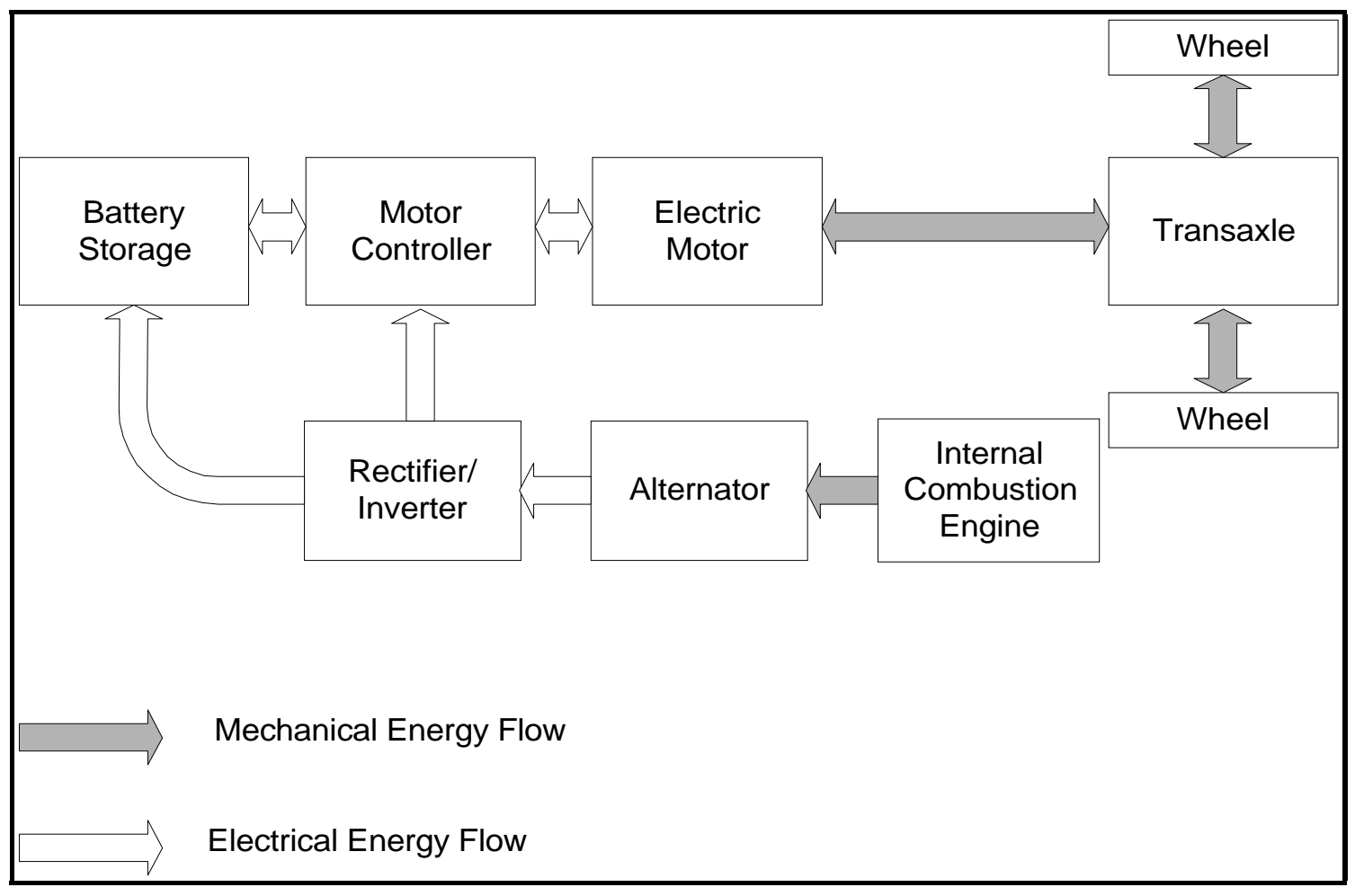

Figure 1.2.1.1: Power Flow Diagram for a Typical Series HEV

\subsubsection{The Advantages and Disadvantages of Parallel Hybrid Vehicles}

Parallel systems also employ two power sources, typically an engine and a traction motor with both directly coupled to the wheels typically through a multi-speed transmission. This requires that the engine see substantial transient operation. However, the motor can act as a load-leveling device allowing the engine to operate in a more efficient operating region. When the vehicle is operating in a low load state the engine can be decoupled from the drivetrain and shut off, or the motor can be used to charge while driving creating a greater power demand for the engine and storing energy in the 
battery pack. The disadvantage of parallel hybrids is that direct connection of the engine to the wheels requires transient engine operation. This operation lowers fuel economy and increases exhaust emissions especially when employing SI engines. Ignition timing and fueling cannot be optimized for a single region of operation either. However, dynamic performance of parallel hybrids is much better than that of series hybrids using the same components. Much more power is available as both the engine and motor can provide power to the wheels simultaneously. These characteristics lend parallel HEVs to excel in higher load, less transient situations and when using high efficiency engines such as $\mathrm{CI}$ engines.

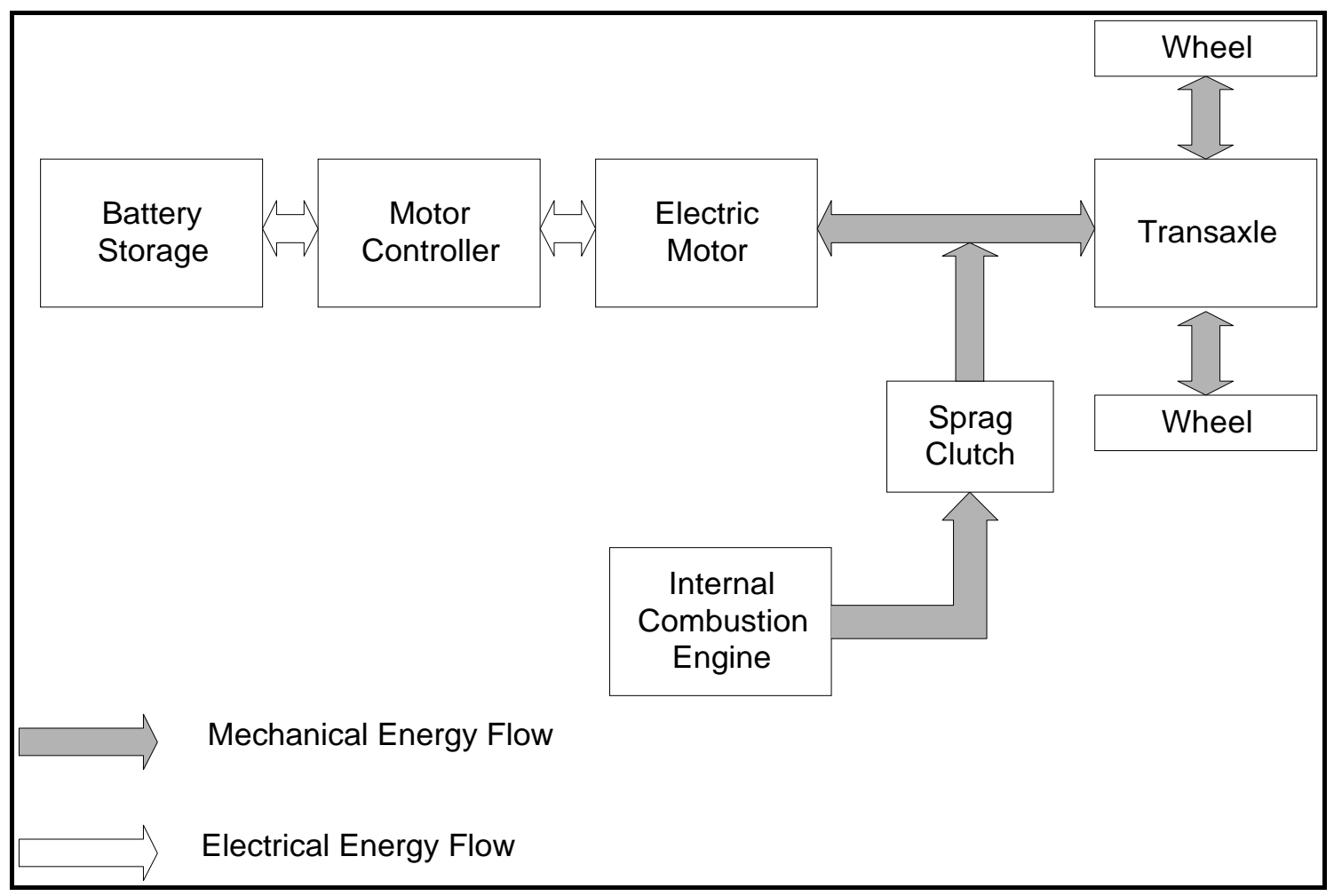

Figure 1.2.2.1: Power Flow Diagram for a Typical Parallel HEV 


\subsubsection{The Advantages and Disadvantages of Combination Hybrid Vehicles}

The third variation of hybrid vehicle drivetrains is the combination, which is a system that can function both as a series and parallel hybrid. Complex combinations of engines, alternators, and motors can accomplish this with geared connections and multiple clutches. By clutching and declutching different elements, a combination can be designed to function as a series hybrid under low speed transient conditions and then as a parallel hybrid under higher speed and load. This allows for increased efficiency as each mode of operation is employed under the ideal operating conditions. Drawbacks to these systems are increased mechanical and drivetrain control complexity along with higher weight associated with more components. Controlling these types of systems is much more difficult than either a series or parallel HEV. The system must first be capable of operating as a series or parallel and then be able to choose which mode is optimum and switch between the two seamlessly during vehicle operation.

\subsection{Combining Two Different Types of Transmissions}

All current automotive transmissions in production are single input, single output meaning that one power source is connected to the wheels. This design is acceptable for most situations, but to achieve the highest possible efficiency in a hybrid vehicle it would be beneficial to combine different types of transmissions. Under different conditions some transmissions are more efficient than others are. By using multiple transmissions, it is possible to combine each in a way that the area of operation for each transmission is moved toward a more efficient region than normally possible. This 
combination of multiple transmissions can also provide the ability to connect more than one power source and have more than one output.

\subsection{Multiple Transmission Combinations for Hybrid Vehicle Applications}

Hybrid vehicles posses more than one power source such as an engine and one or more motors. These sources can be distinctly different from each other in operating speed, power output, and control strategy. When combining multiple power source inputs into a single transmission, operation is limited by creating a transmission that cannot be optimized for either. By utilizing a combination of transmissions with a combination of power sources, the transmission for each source can be optimized for the desired area of operation increasing overall system efficiency. The total system can be tailored to couple the most efficient means of power with the most efficient way to channel the power to the wheels.

\subsection{Objectives}

West Virginia University is proposing the design of the Torque and Speed Control Transmission (TSCT), a multiple input, multiple output transmission. This design will allow for much more freedom in powertrain configurations. Multiple power sources may be connected to the TSCT and power can be removed from the transmission either by a motor (acting as a alternator), an alternator, or the drive wheels of the vehicle. This transmission design also will employ a CVT and a planetary geartrain. The combination of these two transmission types allows for six distinct modes of operation. These modes are Conventional Vehicle, Electric Vehicle, Series HEV, Parallel HEV variate 1, Parallel 
HEV variate 2, and a Geared Neutral mode. The purpose of this study is to determine the feasibility of such a transmission. Several of the possible combinations will be analyzed and the most beneficial design will be reviewed further in depth.

\section{Literature Review}

Automotive manufacturers and private companies alike have created alternative transmission designs as a means to achieve greater fuel economy and lower vehicle emissions. A brief review of those transmissions and powertrains that are similar in design and operation to the TSCT follows.

\section{Results of the ETH Hybrid III-Vehicle Project}

The ETH-Hybrid III is a parallel hybrid drivetrain built by the Swiss Federal Institute of Technology. The ETH-Hybrid III drivetrain incorporates a spark ignited internal combustion engine, an asynchronous electric motor, a flywheel, a continuously variable transmission, and a battery pack. Under light load conditions, the electric motor is used to power the vehicle with the flywheel providing power for peak power demands through the CVT. As energy is lost from the flywheel, the engine is started and operated at full load for a short time to recharge the flywheel. Under moderate and high load conditions, the engine powers the vehicle with the flywheel acting as a load-leveling device. Engine operation is moved to a more efficient regime by selecting the proper ratio across the CVT operating range. A regenerative braking mode is also possible with the motor recharging the batteries or the energy being imparted into the flywheel. When these two storage devices are at full capacity, a latent heat energy storage device 
converts the energy to raise the operating temperature of the oil and coolant. However, it is unclear what real benefit is gained from adding heat to the lubrication and cooling systems other than to reduce cold or warm start emissions. Furthermore, the use of flywheels has not been proven as an effective or efficient means of energy storage. [4]

\section{A Charge Sustaining Parallel HEV Application of the Transmotor}

The transmotor was developed by Texas A\&M University. Operation of the transmotor is characterized as an electromechanical CVT with three degrees of freedom: input, output, and an electronic connection. The transmotor is an electric motor with the input shaft connected to the stator and the output shaft connected to the rotor. This allows the transmotor to function in the place of a mechanical transmission. To accomplish speed reduction relative to the input speed, electric energy is extracted from the motor. Direct drive through the transmotor is possible by shorting the leads of the motor together and a speed increase across the transmotor is accomplished by consuming electric energy. Combination HEV operation can be achieved by employing the transmotor in conjunction with another electric motor. By combining the transmotor in series between an engine and an electric motor, operation of the engine can occur at a constant speed and torque during transient conditions. This combination of the transmotor in conjunction with another motor also requires more complex control. Also, to achieve an given speed ratio, power must always be flowing in the transmotor system. This can lead to a loss in efficiency due to the resistance and inefficiencies of the electrical components involved. [5] 


\section{Functional Design of a Motor Integrated CVT for a Parallel HEV Nissan Parallel}

HEV

Nissan Motor Company has created a parallel, charge sustaining HEV. Basic components of the system are a high power four cylinder spark ignited engine, electronically engaged clutch, low power electric motor, and a continuously variable transmission. This drivetrain is capable of three main modes of operation: conventional vehicle, electric vehicle, and charge while driving. For conventional vehicle operation, the clutch is engaged and power from the engine is sent through the CVT to the wheels. In electric only operation, $\mathrm{EV}$ or $\mathrm{ZEV}$, the clutch between the engine and motor is opened and power from the motor is transmitted to the wheels through the CVT. For parallel HEV operation, the clutch is closed between the engine and motor and all power is sent through the CVT. Under lighter load conditions the motor can act as a loadleveling device and create higher load on the engine by charging the batteries.

The advantages of this system are simplicity and CVT operation allows for the engine to operate in more efficient regimes than possible with an automatic or manual transmission. However, power from the electric motor must be sent through the CVT during pure electric operation incurring high efficiency losses unnecessarily. The motor could be placed downstream of the transmission taking advantage of the inherent high torque characteristics of the motor. [6]

\section{A Continuously Variable Power Split Transmission for Automotive Applications}

West Virginia University and CK Engineering have proposed a continuously variable power split transmission for an automotive application. This transmission is a 
combination of a CVT and a planetary geartrain with a single power input/single power output. This transmission has a higher load carrying capacity than the typical shaft-toshaft arrangement of CVTs due to only a fraction of engine power being sent through the CVT.

In this power split transmission the engine output is taken directly from a shaft which is common to both the CVT and sun gear. The output from the CVT is then connected the ring gear of the planetary geartrain. The power from the engine is then sent to the drive wheels via the planetary carrier. This configuration offers the benefit of varying the power sent through the CVT across the entire operating range. During low speed vehicle operation (typically high torque), less power is sent through the CVT making the belt much less likely to slip. Then as the vehicle speed increases, a greater percentage of the engine power is sent through the CVT belt. Typically for a given amount of power at higher vehicle speeds the torque in the transmission is lower due to higher engine speed. However, in this transmission the engine torque transmitted through the belt does not decrease as dramatically because of the power split capability. This increase in the percentage of power sent through the CVT is beneficial because this allows the CVT to operate in a more efficient area than normally possible. [7] 


\section{Toyota Hybrid System}

The Toyota Hybrid System, THS, is a combination hybrid electric drivetrain. As installed in the Prius, the major components of the system are a 1.5L spark ignited engine, a high power AC synchronous electric alternator, a high power AC synchronous electric motor, and a planetary geartrain. The engine is directly connected to the planetary carrier while the motor is connected to the ring gear that serves as the output to the differential. The alternator is connected to the sun gear. Sophisticated control of the alternator allows the system to act as an electronically controlled CVT. This further enhances hybrid operation by allowing for series, parallel, or combination operation. By controlling the speed and power flow in the alternator, engine efficiency is greatly increased by moving engine operation into higher torque and lower speed regimes. Using a modified Atkinson cycle further increases engine efficiency by allowing different compression and expansion ratios. Variable inlet camshaft timing is also utilized and has a range of authority of forty degrees of rotation. This engine and drivetrain technology helped the Prius to have a much publicized fuel efficiency of 66 mpg. However, it was later discovered that this number was recorded over the Japanese 10-15 cycle. This is a much less aggressive cycle than the city (FTP) and highway (HWFET) employed by the EPA. Subsequent testing in the United States by the EPA aided by Toyota found the Prius capable of approximately $48 \mathrm{mpg}$ city and $53 \mathrm{mpg}$ highway with a composite of approximately $50 \mathrm{mpg}$. [8] 


\section{Dual System}

The Dual-System was developed by Equos Research Co., Ltd. The Dual-System is a hybrid transaxle that can function similar both to a series or parallel HEV. The mechanical layout consists of a planetary geartrain, a spark ignited internal combustion engine, and two generator/motors. The output of the engine is directly connected to the planetary carrier. The first low power generator motor is connected to the sun gear. Output of the planetary geartrain is then transmitted through an idler that connects to the second higher power alternator/motor. Final drive is then taken from this second motor.

The first motor attached to the sun gear of the planetary gear train functions as the starter for the engine, an alternator under low to medium load, and as a power source under high load. The second motor provides power to supplement the engine and to increase efficiency. Engine operation always occurs with the first motor either charging the batteries or powering the vehicle and the main motor supplementing engine operation or charging the batteries through regenerative braking. [9]

\section{Two-mode, input-split, parallel, hybrid transmission}

General Motor Corporation was awarded United States Patent 5,558,588 for a multiple input transmission for a parallel hybrid electric vehicle employing multiple motors, clutches, brakes, and planetary geartrains. The transmission has an input shaft receiving power directly from an engine. The input shaft is then connected to one of any three members of a planetary geartrain. A second member of this planetary geartrain is then connected to an electric motor. The third member is then connected to any member of a second planetary geartrain. Another motor is connected to the second member of 
this geartrain, and the third member is taken as the output of the transmission. This combination of an engine with multiple planetary geartrains and motors allows for parallel HEV operation with each motor either providing power or acting as a generator and charging a battery pack. Multiple clutches and brakes may also be added to this system to allow for series HEV operation. However, this design requires a very complex mechanical layout. Similar hybrid operation may be attained with much less mechanical and electrical complexity. [10]

\section{Modeling of Multiple Input/Output Transmissions}

\subsection{Toyota Prius Hybrid Electric Drivetrain}

This system utilizes a $1.5 \mathrm{~L}$ four cylinder spark ignited engine ( $43 \mathrm{~kW})$, a high power AC synchronous electric motor $(30 \mathrm{~kW})$, and a high power alternator/motor (21 $\mathrm{kW}$ ) all connected to a planetary geartrain. The engine is connected to the planetary carrier while the motor is connected to the ring gear that also serves as the output to the differential and thus the wheels. The sun gear is the connection for the alternator/motor to the geartrain. Control of the system is very complex and allows any two of the three components to be the input degrees-of-freedom. Under light load operation the motor provides all initial propulsive power until approximately $20 \mathrm{mph}$ when the engine is started and powers the vehicle and charges the batteries through the alternator. Higher load operation requires that both the motor and engine power the vehicle while the alternator acts as a flywheel only and energy from the batteries is depleted. When maximum power is desired the engine, motor, and alternator/motor all can supply power until the battery SoC is depleted below an acceptable limit. The engine is never 
completely decoupled from the load as in series hybrid operation and limited parallel operation occurs due to an undersized battery pack (approximately $3 \mathrm{kWhr}$ usable). [11]

\begin{tabular}{|l|l|}
\hline Component & Input \\
\hline Alternator/Motor & Sun Gear \\
\hline Engine & Planetary Carrier \\
\hline Motor and Differential Output & Ring Gear \\
\hline
\end{tabular}

Table 3.1.1: Toyota Prius Planetary Geartrain Connections

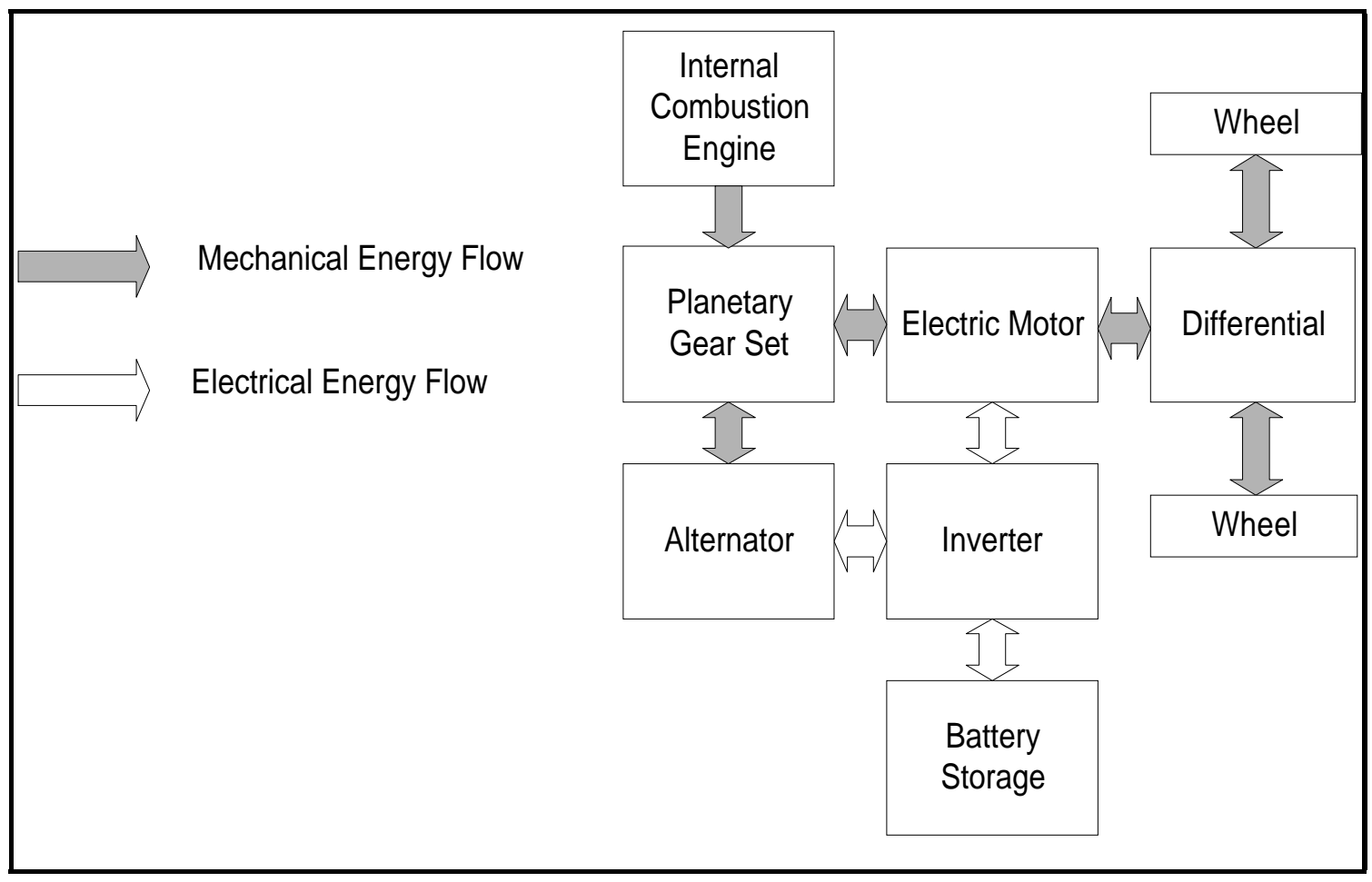

Figure 3.1.1: Power Flow Diagram for the Toyota Prius

\subsection{Torque and Speed Control Transmission}

The TSCT developed by West Virginia University is a continuously variable final gear ratio, multiple input, multiple output transmission. By utilizing a CVT and a planetary geartrain in conjunction with an engine, a high power electric motor, and an 
alternator, large increases in fuel efficiency and emissions can be achieved over current production vehicles. The wheels are connected directly to the ring gear (through a differential), the electric drive motor is connected to the planetary carrier, the alternator is attached to the output side of the CVT, and the engine is connected to the sun gear. The ring gear (and hence the wheels) and attached gear set is also connected through a clutch (C) to the output pulley of the CVT. Reverse gear operation is possible both through reversing the electric motor in EV mode and the geared neutral mode.

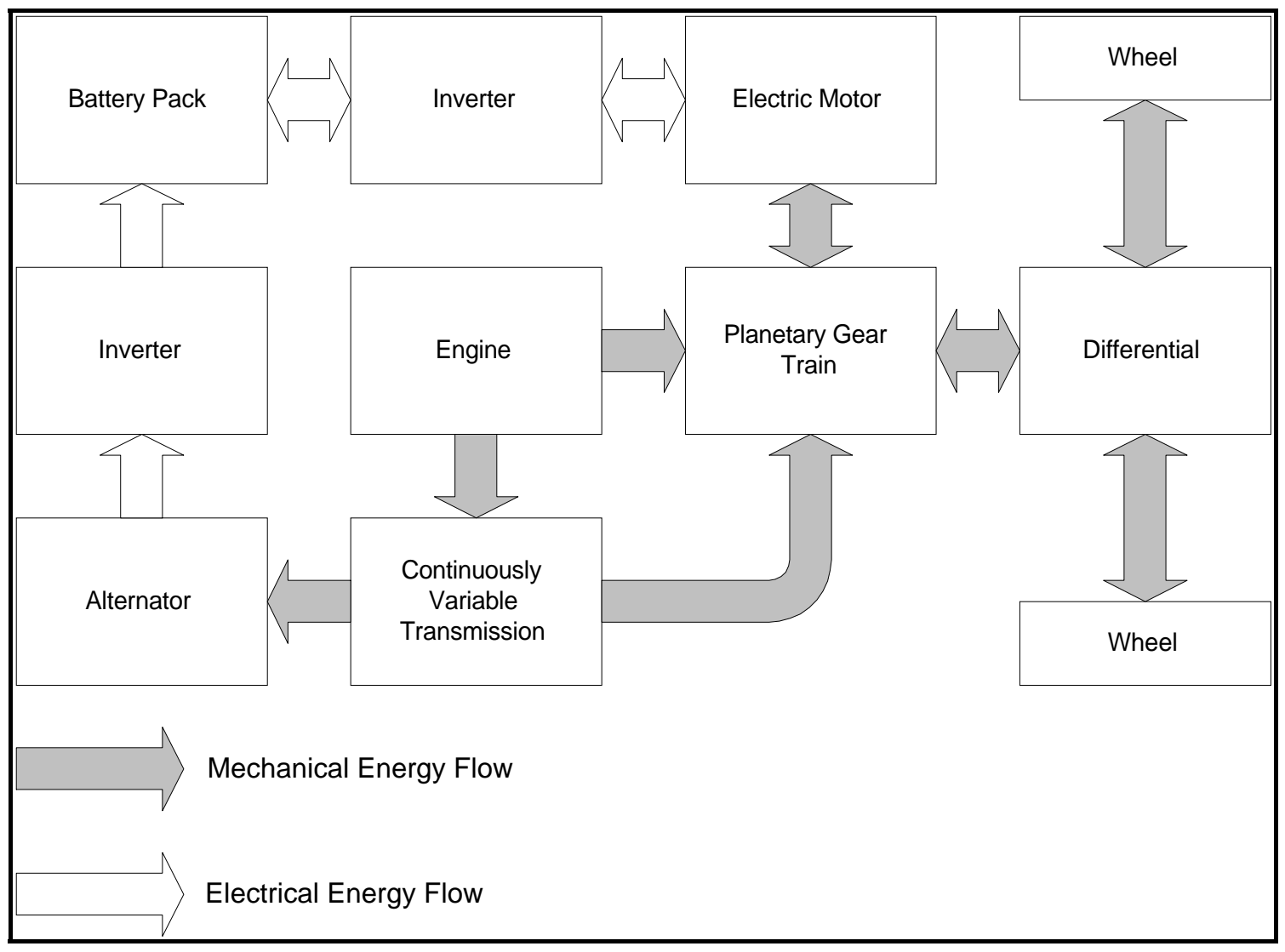

Figure 3.2.1: Block Diagram of TSCT Components and Power Flow 


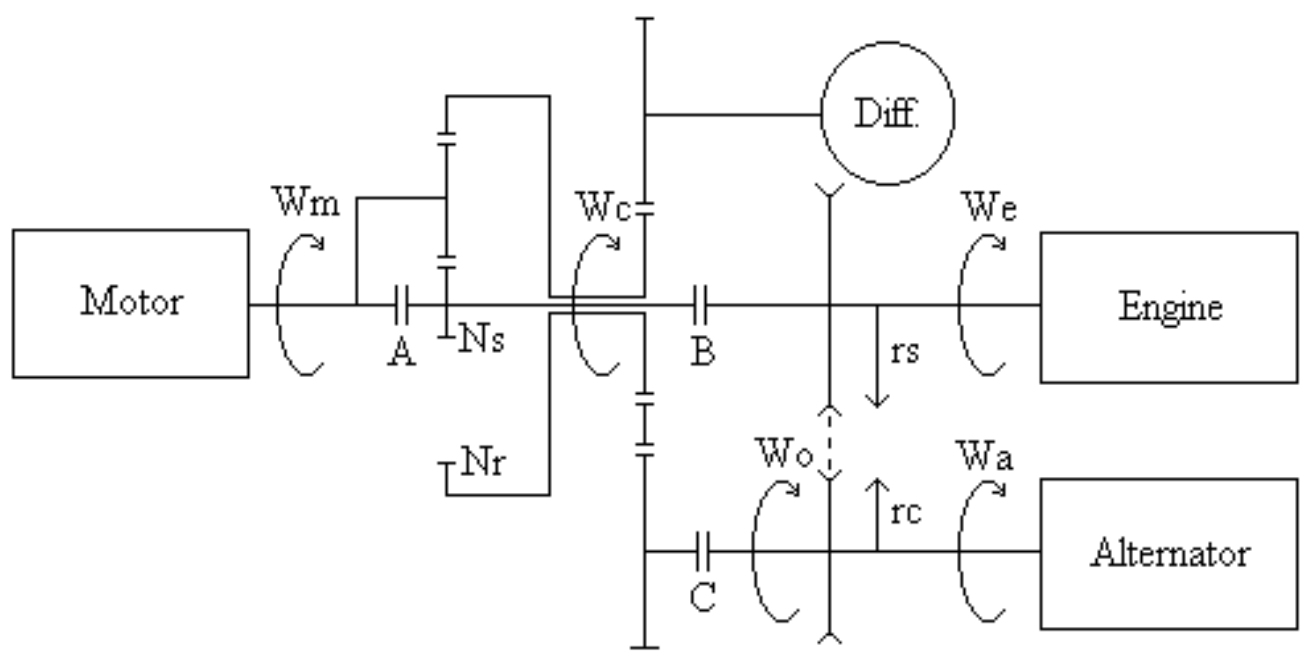

Figure 3.2.2: Mechanical Design for the Torque and Speed Control Transmission

\begin{tabular}{|c|c|c|c|c|c|c|c|}
\hline Mode & & Engine & Motor & Alternator & Clutch A & Clutch B & Clutch C \\
\hline Conventional & (with CVT) & On & Off & Off & $\mathrm{O}$ & $\mathrm{X}$ & $\bar{X}$ \\
\hline Electric & (w/o CVT) & Off & On & Off & $\bar{X}$ & $\mathrm{O}$ & $\mathrm{O}$ \\
\hline Series HEV & (with CVT) & On & On & On & $\mathrm{X}$ & $\mathrm{O}$ & $\mathrm{O}$ \\
\hline Parallel HEV var. 1 & (with CVT) & On & On & Off & $\mathrm{O}$ & $\mathrm{X}$ & $\mathrm{X}$ \\
\hline Parallel HEV var. 2 & (with CVT) & On & On & Off & $\mathrm{X}$ & $\mathrm{O}$ & $\mathrm{X}$ \\
\hline Geared Neutral & (w/o CVT) & On & On & Off & $\bar{X}$ & $\mathrm{X}$ & $\mathrm{O}$ \\
\hline
\end{tabular}

Note: $X$ : CLOSED, O: OPEN

Table 3.2.1: Mode Switching Strategy for the TSCT for a Multi-Mode Hybrid Vehicle

\subsubsection{Optimization}

For the initial design of the Torque and Speed Control Transmission all possible planetary geartrain configurations were analyzed. This provided the necessary background information as to what design is the best and how different variables affect the system. The design of the TSCT centers around the combination of a CVT and a planetary geartrain. This creates a system with multiple possible inputs and outputs. The engine can provide any two of the degrees-of-freedom for the planetary geartrain due to the use of the CVT and a direct-geared connection while the rotation of the motor provides the third connection. This leads to the possibility of three configurations. 
However, when an idler is added after the variator, the total becomes six. All six of these possible types of operation were analyzed with the drivetrain operating in Parallel HEV variate 1 . This was assumed to be the normal mode of operation of the drivetrain.

Parallel HEV variate 1 is considered the main mode of operation for the TSCT because current battery technology is not advanced enough to support EV operation for extended ranges. Furthermore, hybrid operation is more efficient in terms of total onboard fuel used. Of the three modes of hybrid operation available, a properly controlled parallel HEV can be nearly as fuel efficient and provide much better dynamic performance to the user than a series HEV.

The TSCT is capable of two different modes of parallel HEV operation. Parallel HEV variate 1 is the most likely mode of parallel HEV operation. This is necessitated by the motor operating in more efficient regimes during both high and low speed operation. Therefore, this is the mode of operation used to evaluate each of the different types to determine the most beneficial mechanical layout of the TSCT.

During the evaluation of each of the six different types a medium vehicle acceleration is simulated. The engine operation is held at $2000 \mathrm{rpm}$ while the variator ratio is changed from maximum gear reduction at slow speed to maximum overdrive at higher speed. As the variator ratio is swept across the extremes of the possible operating area, the speed of the ring gear, sun gear, and planetary carrier can all be studied. These figures provided graphically illustrate the rotational trends of each planetary geartrain component. It is through these trends that the most viable types are chosen. These three types are then further evaluated to find the final design for the TSCT. 


\section{Type 1:}

The first combination analyzed has the engine connected to both the sun and ring gears and employs an idler between the CVT and ring gear. The motor is connected to the planetary carrier. The system was studied with the engine rotating at a constant speed of $2000 \mathrm{rpm}$ while the variator ratio was changed. These relationships are shown in Figure 3.2.1.2. The variables $\gamma_{c}$, diameter of ring gear divided by diameter of the sun gear, and $\gamma_{\mathrm{g}}$, the output rotational speed of the CVT divided by rotational speed of the ring gear, were also varied to find the effect on component rotational speeds. By varying variator ratio, $\gamma_{\mathrm{c}}$, and $\gamma_{\mathrm{g}}$ individually, general performance trends were identified. It was determined that as $\gamma_{c}$ increases, motor speed increases and the effect on the lower total gear reduction is negligible. Further, $\gamma_{\mathrm{g}}$ has an inverse relationship with the motor speed: as $\gamma_{\mathrm{g}}$ decreases the motor speed increases. This combination also has the desirable characteristic of motor speed and variator ratio being proportional. While at lower vehicle speeds the motor turns slowly and as speed increases so does motor speed.

- $\gamma_{\mathrm{g}}=$ Ratio of ring gear to the sun gear $\left(\mathrm{N}_{\mathrm{r}} / \mathrm{N}_{\mathrm{s}}\right)$

- $\gamma_{\mathrm{c}}=$ Variator output to ring gear ratio $\left(\mathrm{W}_{\mathrm{c}} / \mathrm{W}_{\mathrm{o}}\right)$ 


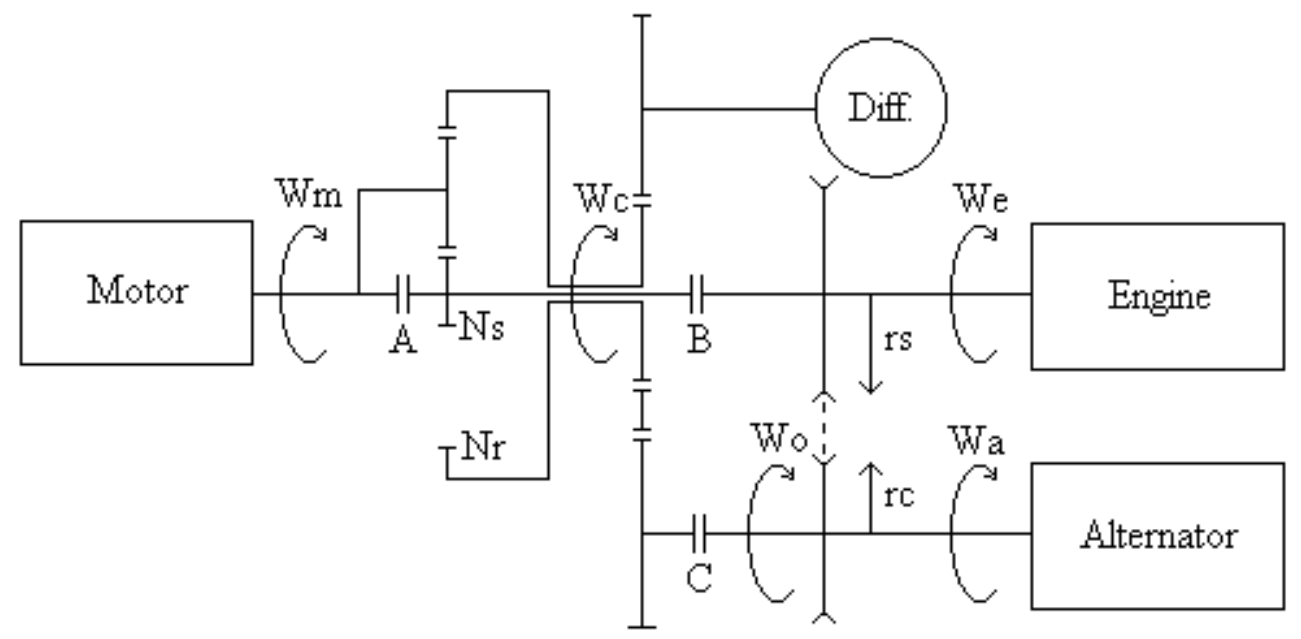

Figure 3.2.1.1: Component Schematic for Type 1 Analysis

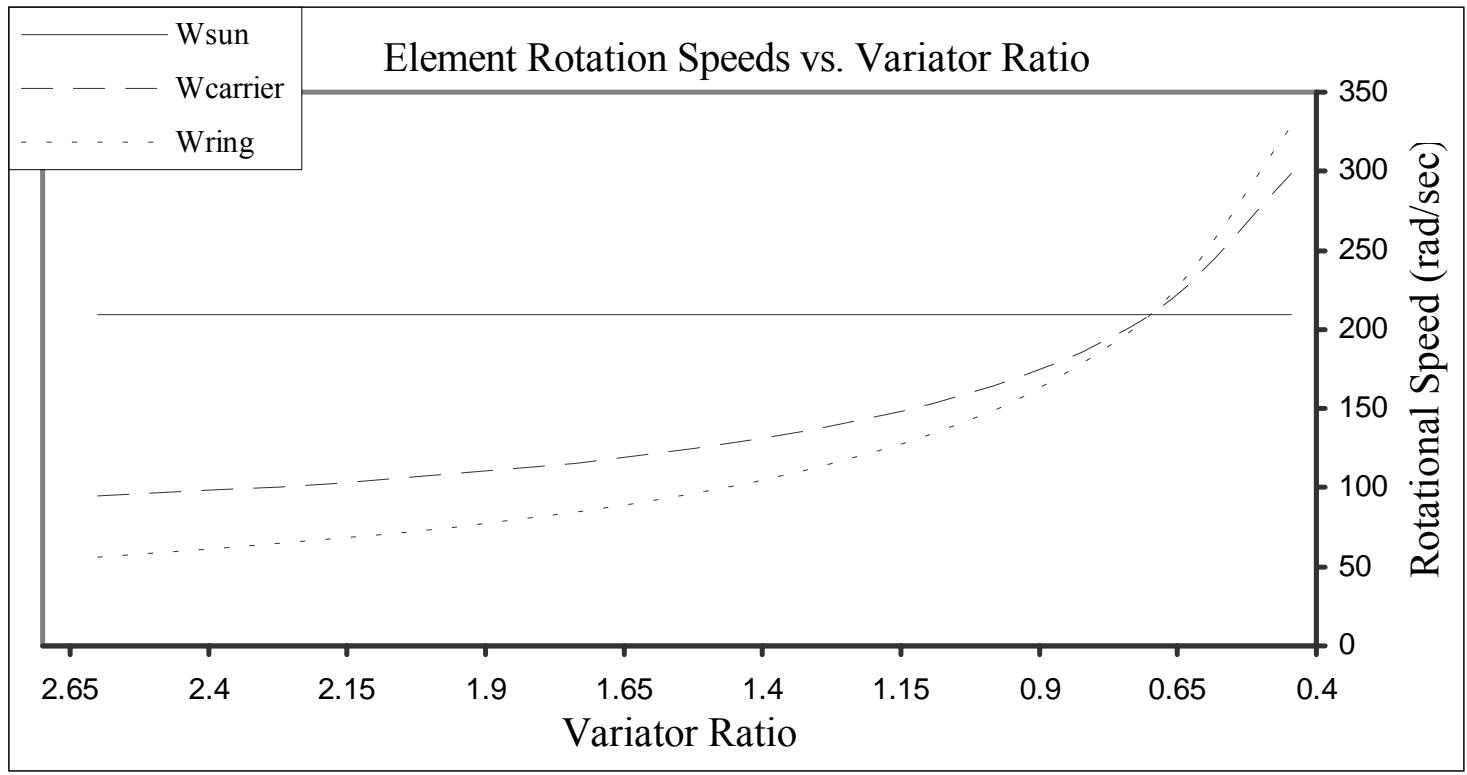

Figure 3.2.1.2: Planetary Geartrain Component Rotation Speed as a Function of Variator Ratio

\section{Type 2:}

The second combination analyzed has the engine connected to both the sun and ring gears and does not employ an idler between the variator and ring gear. The motor is connected to the planetary carrier. The system was studied with the engine rotating at a 
constant speed of $2000 \mathrm{rpm}$ while the variator ratio was changed. These relationships are shown in Figure 3.2.1.4. The variables $\gamma_{c}$, diameter of ring gear divided by diameter of the sun gear, and $\gamma_{\mathrm{g}}$, the output rotational speed of the CVT divided by rotational speed of the ring gear, were also varied to find the effect on component rotational speeds. By varying variator ratio, $\gamma_{c}$, and $\gamma_{g}$ individually, general performance trends were identified. It was determined that as $\gamma_{c}$ increases, motor speed increases but in the opposite direction of the engine rotation and lower total gear reduction is negligible.

During operation at values of $\gamma_{c}$ less than 0.7 and $\gamma_{\mathrm{g}}$ less than 4 , motor rotation occurs in both directions depending on variator ratio. Further, as $\gamma_{\mathrm{g}}$ increases so does motor speed, but in the opposite direction to the engine. This combination also has the desirable characteristic of motor speed and variator ratio being proportional. While at lower vehicle speeds the motor turns slowly and as speed increases so does motor speed.

- $\gamma_{\mathrm{g}}=$ Ratio of ring gear to the sun gear $\left(\mathrm{N}_{\mathrm{r}} / \mathrm{N}_{\mathrm{s}}\right)$

- $\gamma_{\mathrm{c}}=$ Variator output to ring gear ratio $\left(\mathrm{W}_{\mathrm{c}} / \mathrm{W}_{\mathrm{o}}\right)$

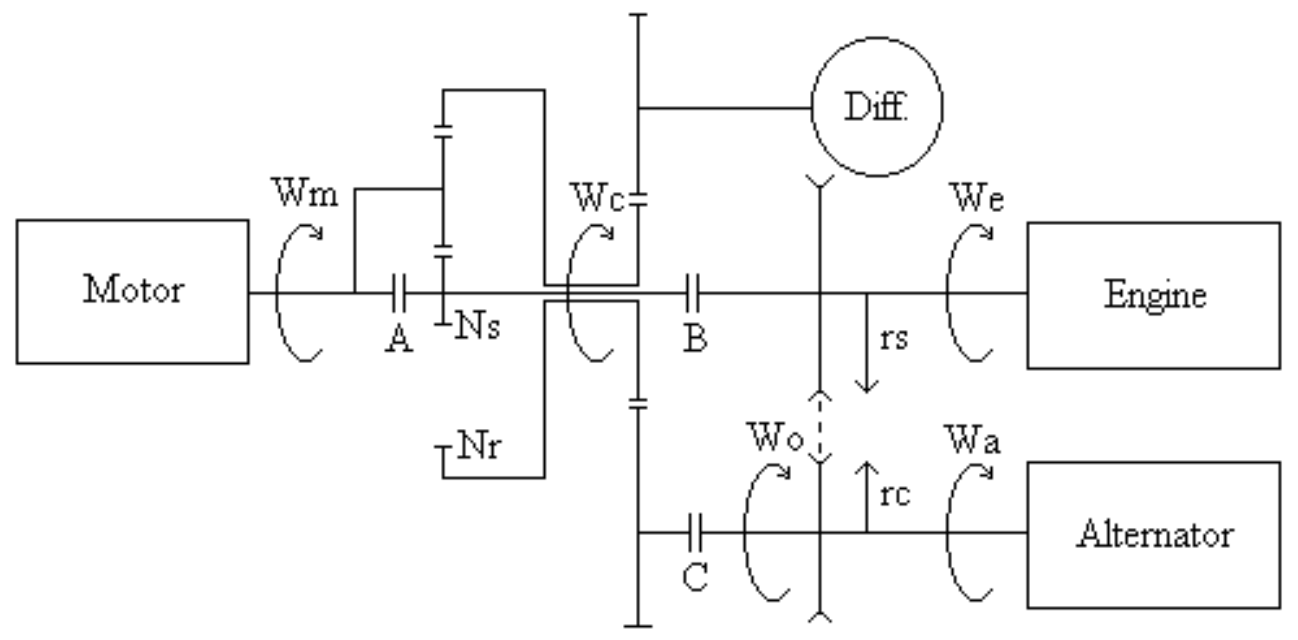

Figure 3.2.1.3: Component Schematic for Type 2 Analysis 


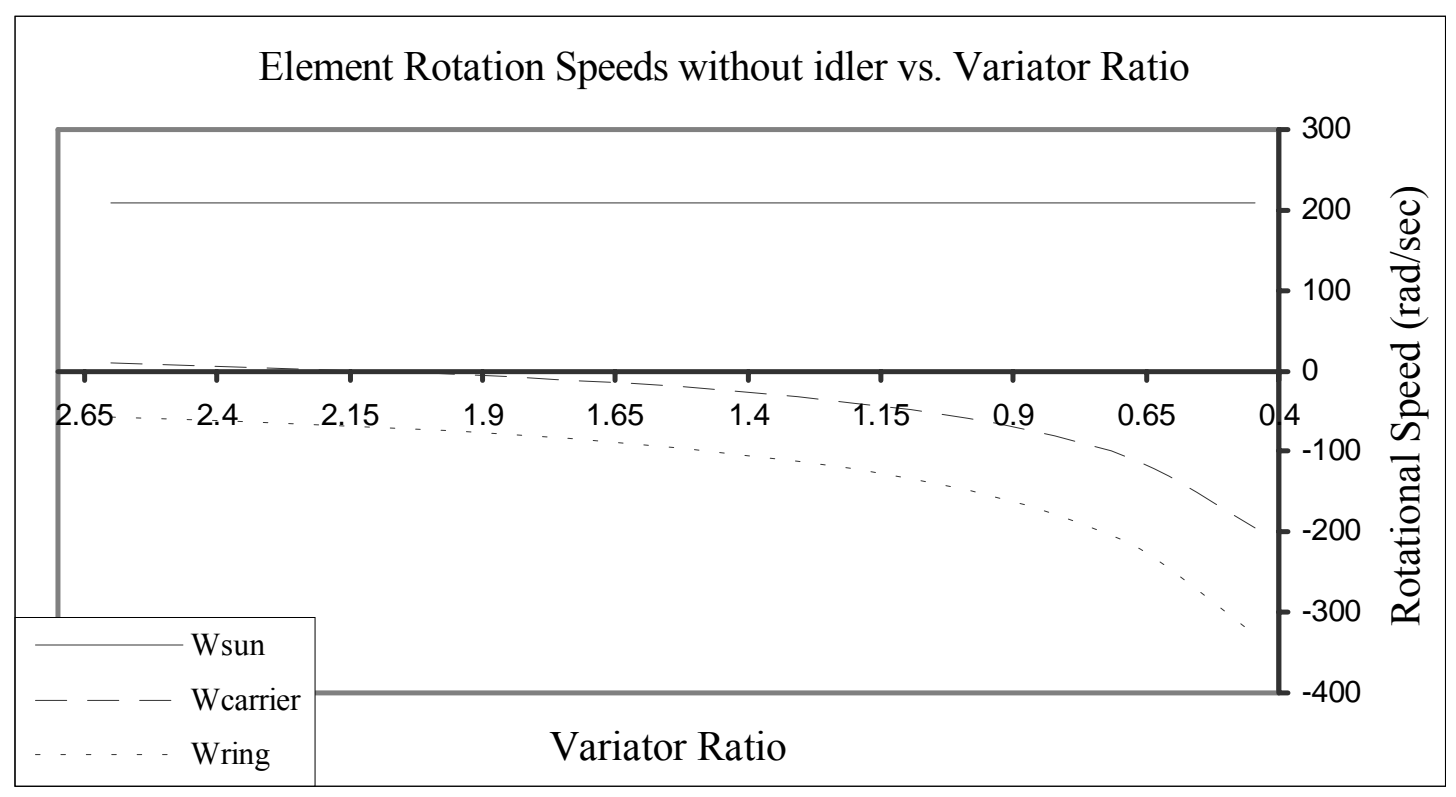

Figure 3.2.1.4: Planetary Geartrain Component Rotation Speed as a Function of Variator Ratio

\section{Type 3:}

The third combination analyzed has the engine connected to both the sun gear and planetary carrier and employs an idler between the variator and planetary carrier. The motor is connected to the ring gear. The system was studied with the engine rotating at a constant speed of $2000 \mathrm{rpm}$ while the variator ratio was changed. These relationships are shown in Figure 3.2.1.6. The variables $\gamma_{c}$, diameter of ring gear divided by diameter of the sun gear, and $\gamma_{\mathrm{g}}$, the output rotational speed of the CVT divided by rotational speed of the ring gear, were also varied to find the effect on component rotational speeds. By varying variator ratio, $\gamma_{\mathrm{c}}$, and $\gamma_{\mathrm{g}}$ individually, general performance trends were identified. It was determined that as $\gamma_{c}$ increases, motor speed increases and lower total gear reduction is achieved. Further, $\gamma_{\mathrm{g}}$ has an inverse relationship with the motor speed: as $\gamma_{\mathrm{g}}$ decreases the motor speed increases. This combination also has the 
undesirable characteristic of motor speed slowing as vehicle speed increases. While at lower speeds the motors has high rotational speed and as vehicle speed increases motor rotation slows. During operation at values of $\gamma_{\mathrm{c}}$ less than 1.7 and $\gamma_{\mathrm{g}}$ greater than 4 , motor rotation reverses direction at high vehicle speed.

- $\gamma_{\mathrm{g}}=$ Ratio of ring gear to the sun gear $\left(\mathrm{N}_{\mathrm{r}} / \mathrm{N}_{\mathrm{s}}\right)$

- $\gamma_{\mathrm{c}}=\mathrm{CVT}$ output to planetary carrier ratio $\left(\mathrm{W}_{\mathrm{c}} / \mathrm{W}_{\mathrm{o}}\right)$

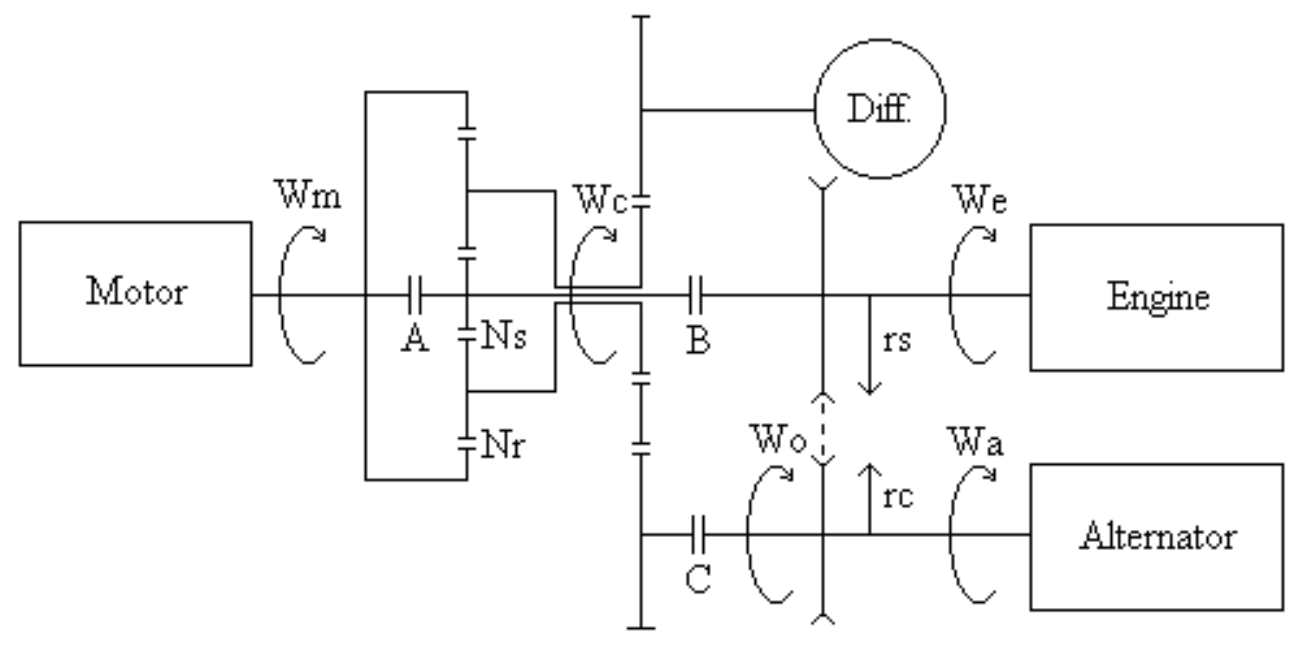

Figure 3.2.1.5: Component Schematic for Type 3 Analysis 


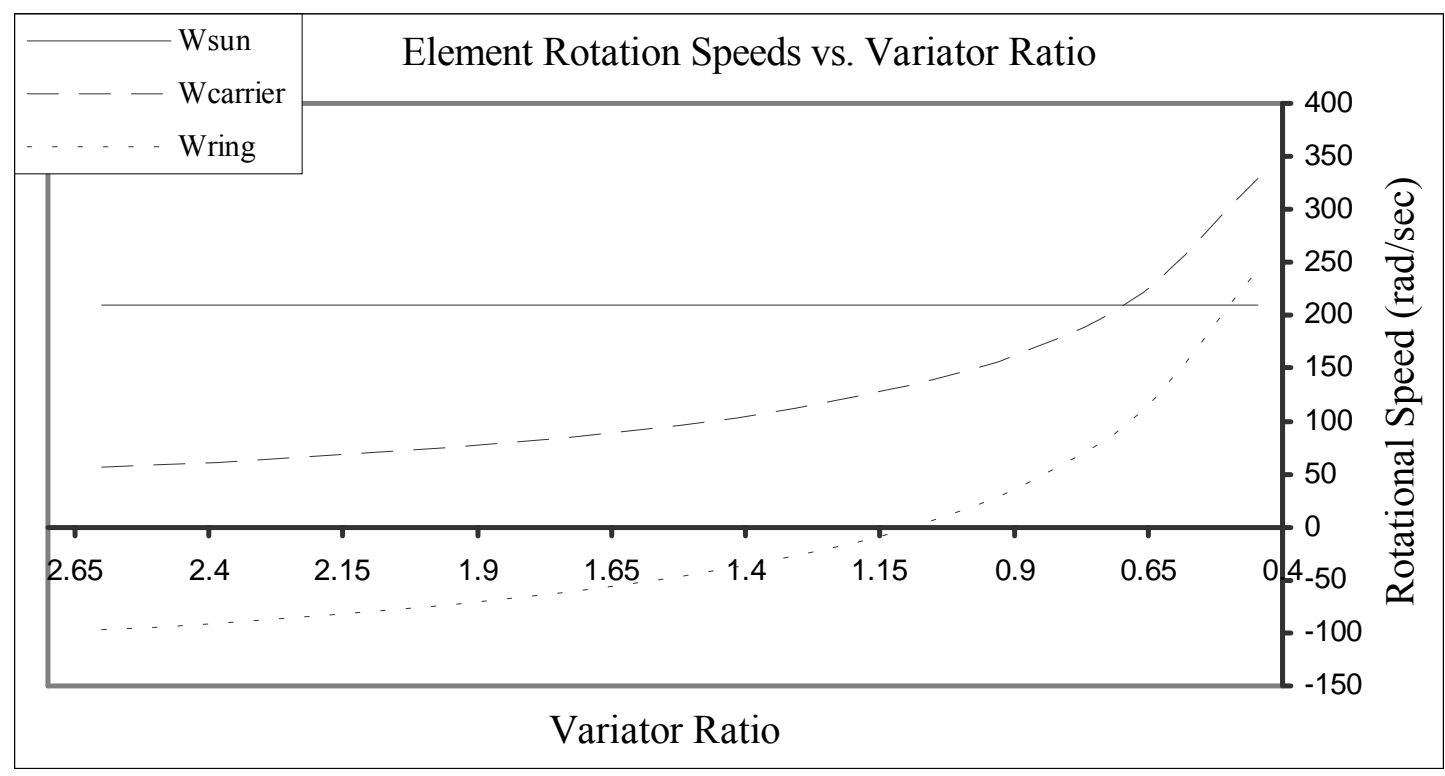

Figure 3.2.1.6: Planetary Geartrain Component Rotation Speed as a Function of Variator Ratio

\section{Type 4:}

The fourth combination analyzed has the engine connected to both the sun and planetary carrier and does not employ an idler between the variator and planetary carrier. The motor is connected to the ring gear. The system was studied with the engine rotating at a constant speed of $2000 \mathrm{rpm}$ while the variator ratio was changed. These relationships are shown in Figure 3.2.1.8. The variables $\gamma_{c}$, diameter of ring gear divided by diameter of the sun gear, and $\gamma_{\mathrm{g}}$, the output rotational speed of the CVT divided by rotational speed of the ring gear, were also varied to find the effect on component rotational speeds. By varying variator ratio, $\gamma_{\mathrm{c}}$, and $\gamma_{\mathrm{g}}$ individually, general performance trends were identified. It was determined that as $\gamma_{c}$ increases, motor speed increases opposite in rotation to the engine rotation and lower total gear reduction is achieved. Further, $\gamma_{\mathrm{g}}$ has an inverse relationship with the motor speed: as $\gamma_{\mathrm{g}}$ decreases the motor 
speed increases. This combination also has the desirable characteristic of motor speed and variator ratio being proportional. While at lower vehicle speeds the motor turns slowly and as speed increases so does motor speed.

- $\gamma_{\mathrm{g}}=$ Ratio of ring gear to the sun gear $\left(\mathrm{N}_{\mathrm{r}} / \mathrm{N}_{\mathrm{s}}\right)$

- $\gamma_{\mathrm{c}}=\mathrm{CVT}$ output to planetary carrier ratio $\left(\mathrm{W}_{\mathrm{c}} / \mathrm{W}_{\mathrm{o}}\right)$

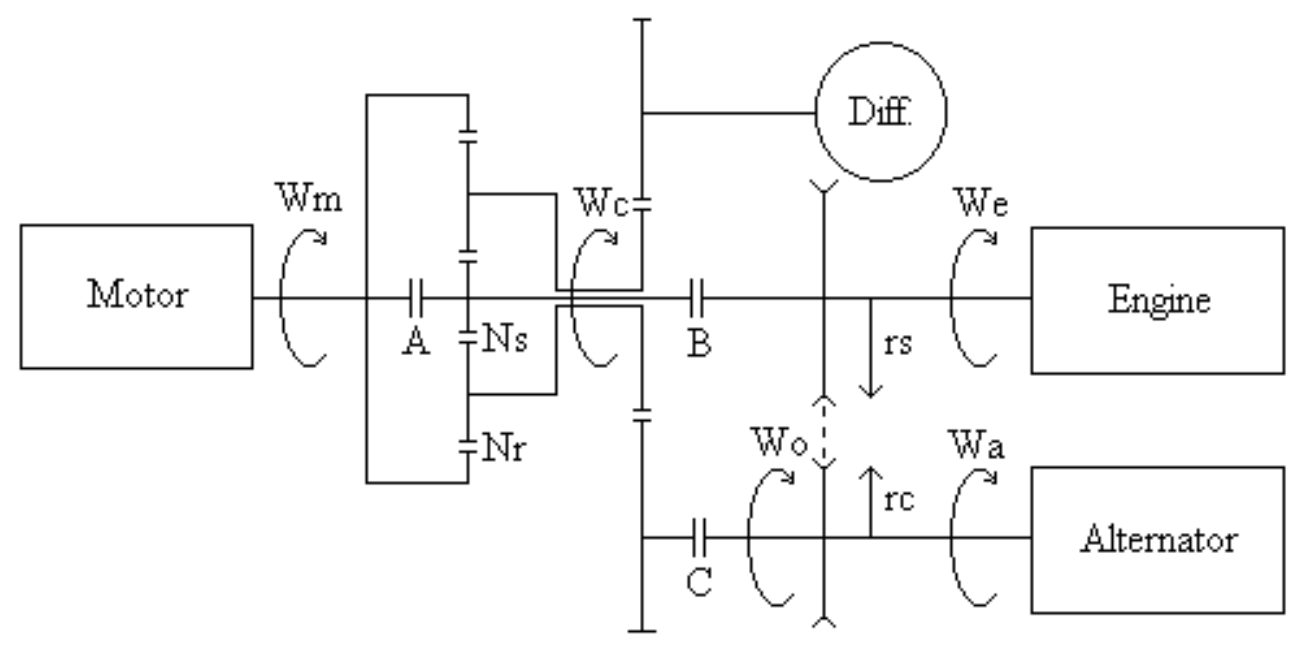

Figure 3.2.1.7: Component Schematic for Type 4 Analysis 


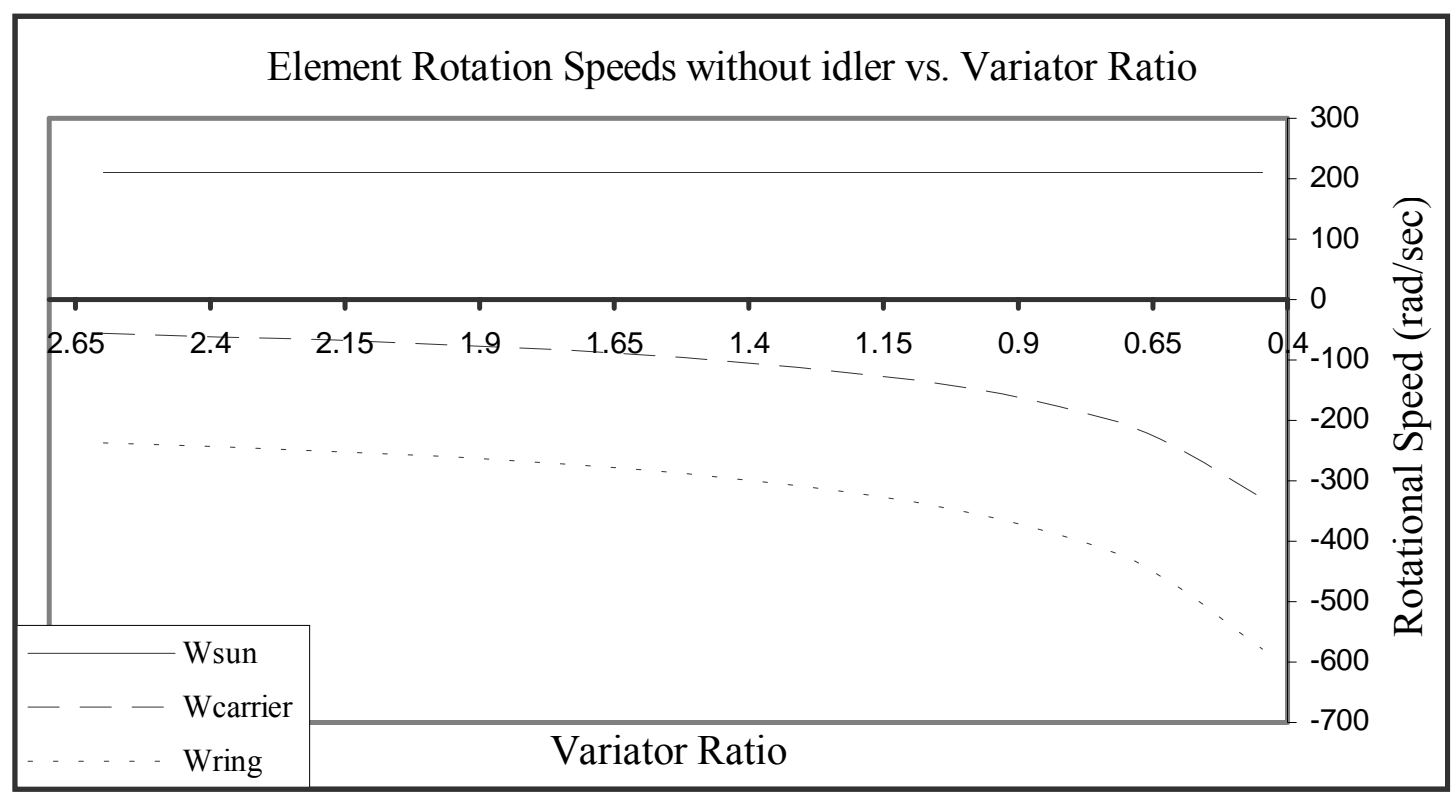

Figure 3.2.1.8: Planetary Geartrain Component Rotation Speed as a Function of Variator Ratio

\section{Type 5:}

The fifth combination analyzed has the engine connected to both the ring gear and planetary carrier and employs an idler between the variator and ring gear. The motor is connected to the sun gear. The system was studied with the engine rotating at a constant speed of $2000 \mathrm{rpm}$ while the variator ratio was changed. These relationships are shown in Figure 3.2.1.10. The variables $\gamma_{c}$, diameter of ring gear divided by diameter of the sun gear, and $\gamma_{\mathrm{g}}$, the output rotational speed of the CVT divided by rotational speed of the ring gear, were also varied to find the effect on component rotational speeds. By varying variator ratio, $\gamma_{\mathrm{c}}$, and $\gamma_{\mathrm{g}}$ individually, general performance trends were identified. It was determined that as $\gamma_{c}$ increases, motor speed decreases and higher total gear reduction is negligible. Furthermore, the lower the value of $\gamma_{\mathrm{g}}$, the lower the motor speed. This combination also has the characteristic of motor speed and variator ratio 
being inversely proportional. This is undesirable because while at lower speeds the motor has higher rotational speeds and as vehicle speed increases motor rotation slows.

- $\gamma_{\mathrm{g}}=$ Ratio of ring gear to the sun gear $\left(\mathrm{N}_{\mathrm{r}} / \mathrm{N}_{\mathrm{s}}\right)$

- $\gamma_{\mathrm{c}}=$ CVT output to ring gear ratio $\left(\mathrm{W}_{\mathrm{c}} / \mathrm{W}_{\mathrm{o}}\right)$

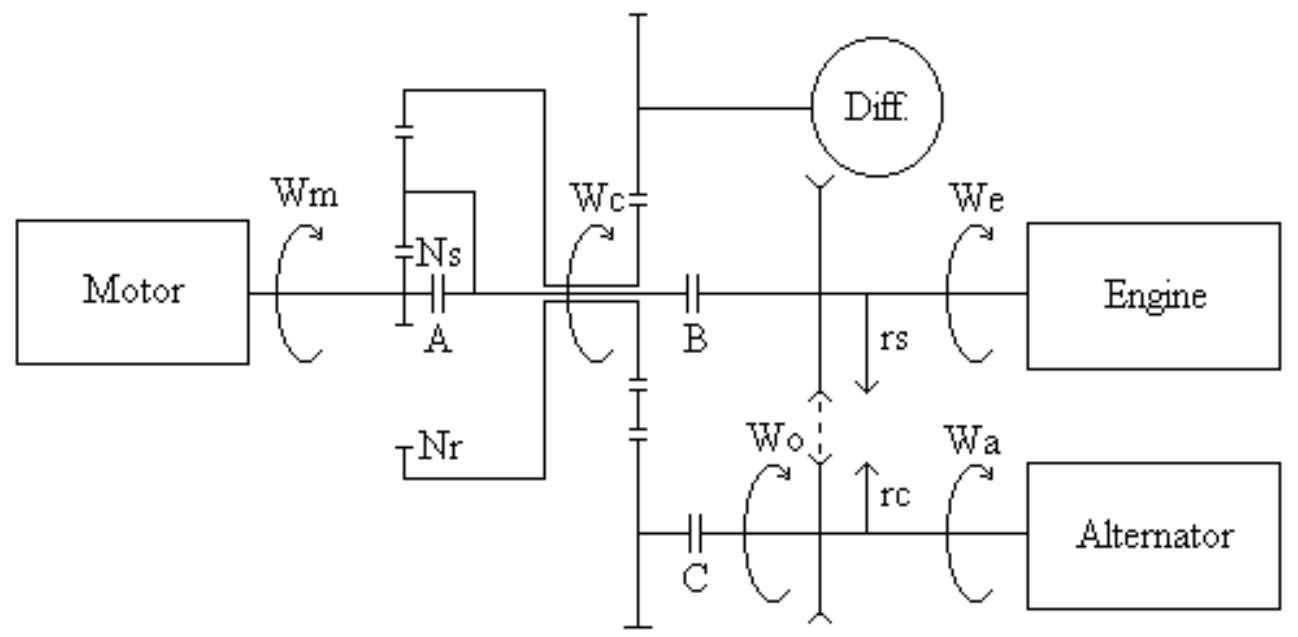

Figure 3.2.1.9: Component Schematic for Type 5 Analysis

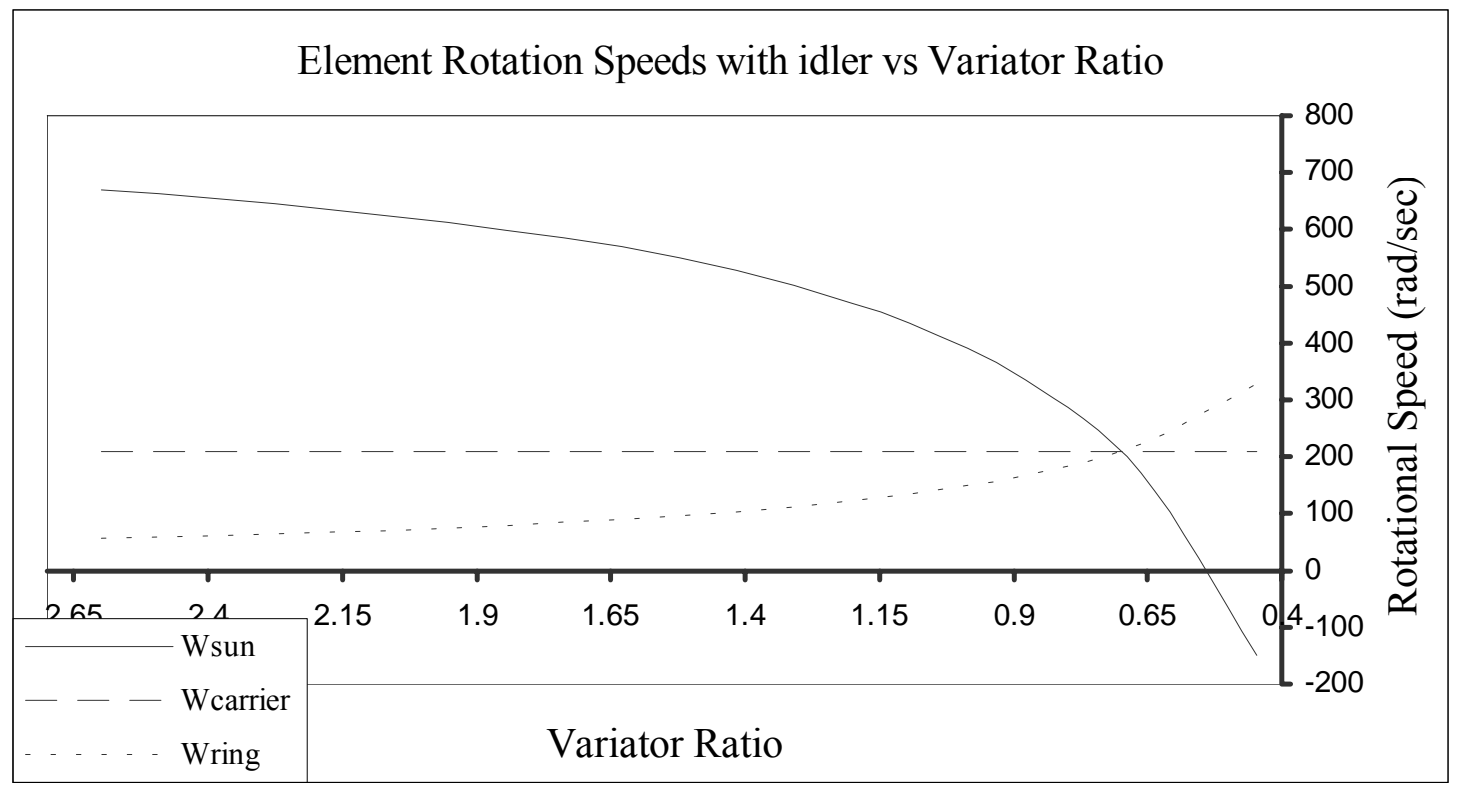

Figure 3.2.1.10: Planetary Geartrain Component Rotation Speed as a Function of Variator Ratio 


\section{Type 6:}

The final combination analyzed has the engine connected to both the planetary carrier and ring gear and does not employ an idler between the variator and ring gear.

The motor is connected to the sun gear. The system was studied with the engine rotating at a constant speed of $2000 \mathrm{rpm}$ while the variator ratio was changed. These

relationships are shown in Figure 3.2.1.12. The variables $\gamma_{c}$, diameter of ring gear divided by diameter of the sun gear, and $\gamma_{\mathrm{g}}$, the output rotational speed of the CVT divided by rotational speed of the ring gear, were also varied to find the effect on component rotational speeds. By varying variator ratio, $\gamma_{\mathrm{c}}$, and $\gamma_{\mathrm{g}}$ individually, general performance trends were identified. It was determined that as $\gamma_{\mathrm{c}}$ increases, motor speed increases opposite in rotation to the engine rotation and lower total gear reduction is negligible. Further, by decreasing the value of $\gamma_{\mathrm{g}}$, the speed of the motor is lowered. This is necessary to keep the motor under a fixed upper limit that is typically near 9000 rpm for permanent magnet motors. This combination also has the desirable characteristic of motor speed and variator ratio being proportional. While at lower vehicle speeds the motor turns slowly and as speed increases so does motor speed.

- $\gamma_{\mathrm{g}}=$ Ratio of ring gear to the sun gear $\left(\mathrm{N}_{\mathrm{r}} / \mathrm{N}_{\mathrm{s}}\right)$

- $\gamma_{\mathrm{c}}=$ CVT output to ring gear ratio $\left(\mathrm{W}_{\mathrm{c}} / \mathrm{W}_{\mathrm{o}}\right)$ 


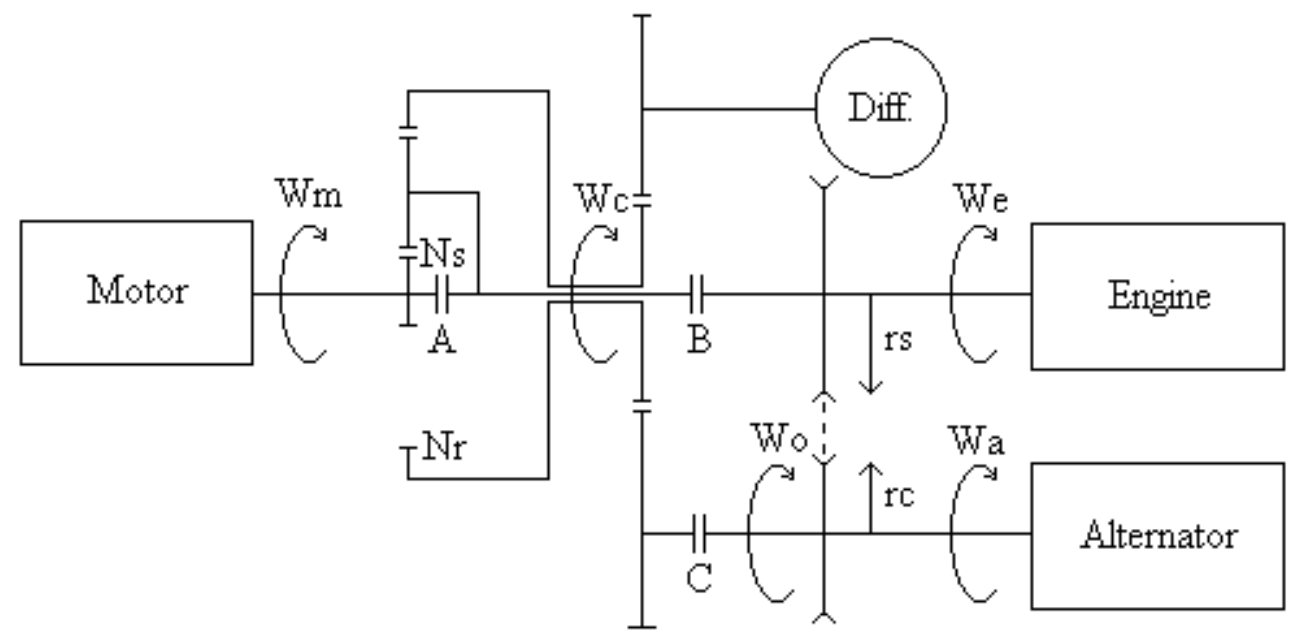

Figure 3.2.1.11: Component Schematic for Type 6 Analysis

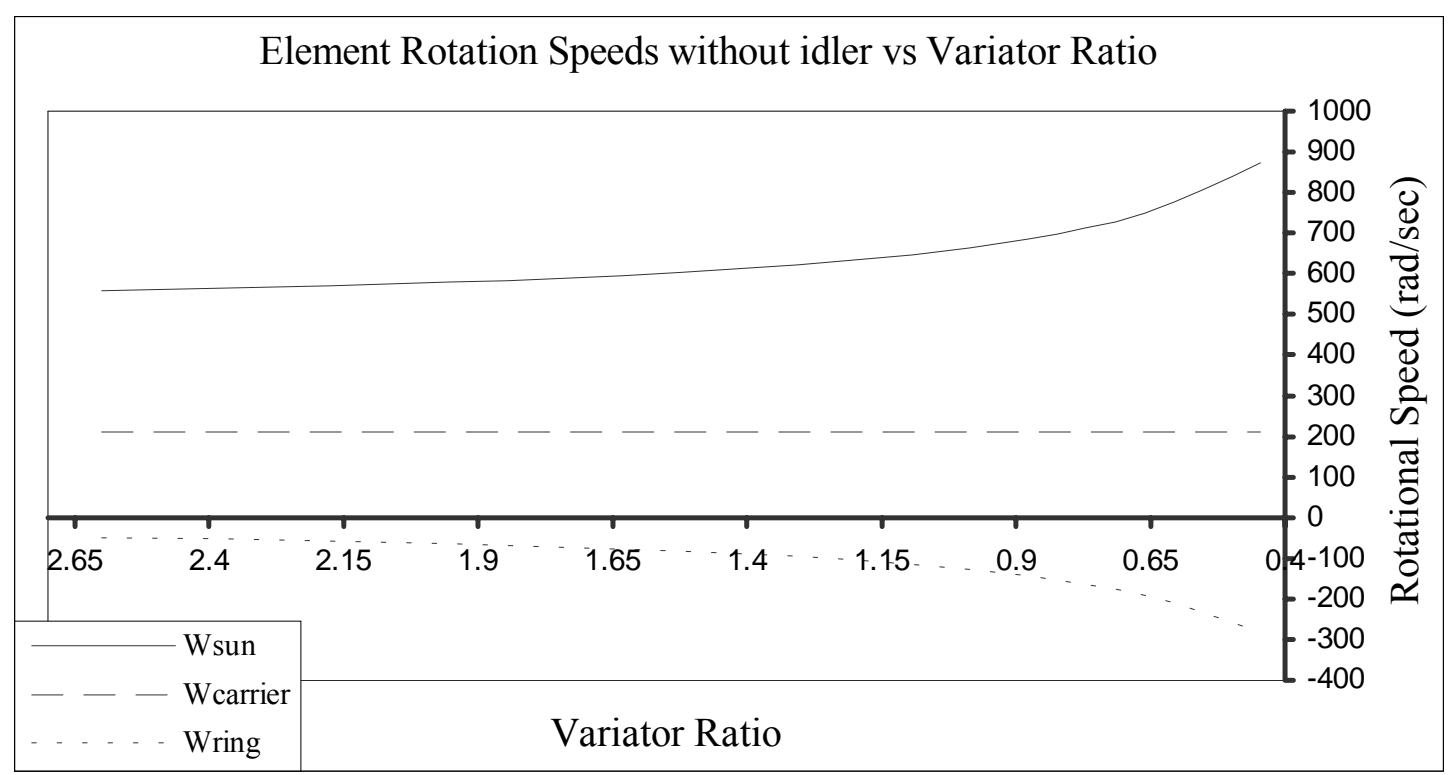

Figure 3.2.1.12: Planetary Geartrain Component Rotation Speed as a Function of Variator Ratio

\subsubsection{Comparison of Optimization Types}

Table 3.2.2.1 below provides the specific geared connections for each of the six types examined. Each of these types provides distinctly different operating 
characteristics. It is these characteristics that were evaluated to decide which of the six types was most suited for an automotive application. The advantages and disadvantages are stated below in Table 3.2.2.2.

\begin{tabular}{|l|l|l|l|l|}
\hline Configuration & Ring Gear & Sun Gear & Planetary Carrier & Idler \\
\hline Type 1. & Engine & Engine & Motor & yes \\
\hline Type 2. & Engine & Engine & Motor & no \\
\hline Type 3. & Motor & Engine & Engine & yes \\
\hline Type 4. & Motor & Engine & Engine & no \\
\hline Type 5. & Engine & Motor & Engine & yes \\
\hline Type 6. & Engine & Motor & Engine & no \\
\hline
\end{tabular}

Table 3.2.2.2: Component Connection for Each Type Examined

\begin{tabular}{|l|c|c|c|c|}
\hline Configuration & Operating Range & $\begin{array}{l}\text { Engine Cruising } \\
\text { Speed }\end{array}$ & Motor Rotation & Ease of Control \\
\hline Type 1. & ++ & ++ & ++ & ++ \\
\hline Type 2. & ++ & ++ & -- & -- \\
\hline Type 3. & ++ & ++ & -- & -- \\
\hline Type 4. & ++ & ++ & + & ++ \\
\hline Type 5. & ++ & ++ & -- & - \\
\hline Type 6. & ++ & ++ & + & ++ \\
\hline
\end{tabular}

Note: ++: Excellent, +: Good, -: Fair, - -: Poor

Table 3.2.3.2: Advantages and Disadvantages of Each Type Examined

Comparisons drawn from Table 3.2.2.2 above indicate performance available by each type while operating in Parallel HEV variate 1. This was assumed to be the main mode of operation for the drivetrain. Operating range is the total range of gear reduction available through the transmission. All six TSCT types are capable of operation from an underdrive ratio of 3:1 to an overdrive of 0.6:1. Engine speed was the variable that was fixed to allow equal comparison between types. The engine speed was held at $2000 \mathrm{rpm}$ while the variator ratio was changed. This method was used to simulate an automobile undergoing an acceleration at a medium rate from standstill to $65 \mathrm{mph}$. By simulating this acceleration, the speed and rotation direction necessary for the motor could be 
determined. Motor rotation is the combination of both speed of the motor and the necessity of the motor to change directions depending on variator ratio. Types 2,3 , and 5 require that lower numerical ratios in the transmission force the motor slow to a stop and then reverse direction and increase speed. This type of operation if more difficult from a control aspect due to speed and torque of the motor must now be controlled in two directions. Ease of control describes qualitatively how easily the control strategy of the motor may be implemented.

From Table 3.2.2.2, it becomes obvious that Types 1, 4, and 6 have the most desirable characteristics with Type 1 being the best choice. However, this table is only based on one mode of operation. All three types are capable of all modes of operation, but Types 4 and 6 must reverse motor rotation compared to all other modes of operation to accomplish a geared neutral. This significantly compromises the usefulness of a geared neutral as it would be no longer possible to switch from this mode to another mode once the vehicle was moving. It is for this reason the Type 1 was chosen as the best mode and fully evaluated henceforth.

\subsubsection{Desired Input/Output Relationships}

Design of the Torque and Speed Control Transmission required a transmission capable of utilizing two different power sources and also provide the capability of multiple power outputs (drive wheels and an alternator). For this drivetrain to function as a conventional, electric, series hybrid electric, and parallel hybrid electric vehicle the components necessary are an electric motor, alternator, and an engine. All three of these components can act as power sources. However, the alternator only functions as a 
power sink in the TSCT while the motor sometimes behaves as a sink while the vehicle undergoes regenerative braking. This configuration has a total of two power sources, engine and motor, and two outputs, the alternator and the wheels of the vehicle.

\begin{tabular}{|l|l|l|l|}
\hline Mode of Operation & Engine & Motor & Alternator \\
\hline Conventional & + & not used & not used \\
\hline Electric & not used & + & not used \\
\hline Series HEV & + & + & - \\
\hline Parallel HEV, variate 1 & + &,+- & not used \\
\hline Parallel HEV, variate 2 & + &,+- & not used \\
\hline
\end{tabular}

Note: +: Source, -: Sink

Table 3.2.3.4: Required Components and Function for Each Mode of Operation

\subsubsection{Desired CVT Operating Range}

CVT operation in the TSCT is modeled after the Ford CTX continuously variable transmission. The CTX transmission was chosen because the vehicle application and power requirements are similar to the intended usage in the TSCT. This transmission is a first generation CVT built in the early 1990's by Ford of Europe. The transmission is of the push belt type and employs a clutch and planetary geartrain for reverse gear operation. Current application of this transmission is in compact passenger cars with four cylinder engines.

Since this is a feasibility study, the performance variables of the Ford CTX transmission such as variator efficiency or total system efficiency are not taken into account. Only the physical operation of the variator, the push belt and both variable pulleys, is modeled. The ratios possible with this variator range from a reduction of 2.60:1 to an overdrive of $0.445: 1$. This is a broad range with nearly a six-fold change in ratios that exceeds other transmission designs. Production automotive transmissions 
usually have an operating range no greater than 4.5:1. These are the extremes used to characterize operation of the CVT within the TSCT during operation in all modes.

\section{Modes of TSCT Operation}

\subsection{Conventional Vehicle Operation}

Conventional vehicle operation is achieved in the TSCT using engine only operation with direct gearing through the planetary geartrain and variable gearing through the CVT. The planetary geartrain provides a fixed gear reduction while the CVT provides a variable gear ratio. Clutches $\mathrm{B}$ and $\mathrm{C}$ are closed while clutch $\mathrm{A}$ is open. The engine drives both the sun gear and the CVT. This electronically controlled continuously variable operation provides seamless power transmission and allows for engine operation in more efficient regions of the speed and load map. Under light load conditions engine operating speed can be lowered for decreased fuel usage and quickly raised back to peak power should load increase. 
Equations of Motion for Conventional Vehicle Operation:

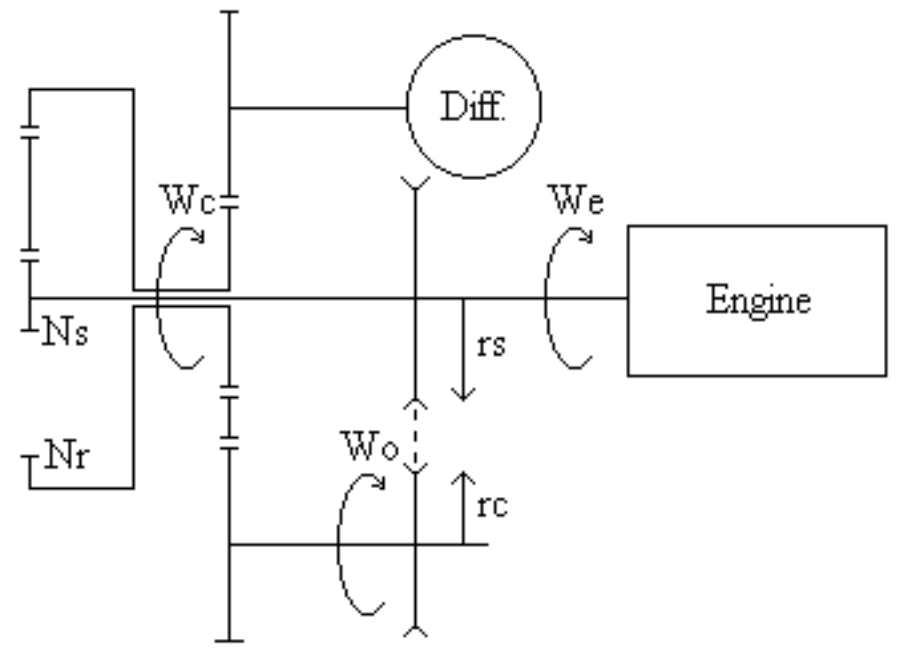

Figure 4.1.1: Conventional Vehicle Operation

- $\gamma_{\mathrm{g}}=$ Ratio of ring gear to the sun gear $\left(\mathrm{N}_{\mathrm{r}} / \mathrm{N}_{\mathrm{s}}\right)$

- $\gamma_{\mathrm{c}}=\mathrm{CVT}$ to ring gear ratio $\left(\mathrm{W}_{\mathrm{c}} / \mathrm{W}_{\mathrm{o}}\right)$

- $\int_{\mathrm{v}}=$ Instantaneous CVT ratio $\left(\mathrm{W}_{\mathrm{e}} / \mathrm{W}_{\mathrm{o}}\right)$

- $\mathrm{W}_{\mathrm{e}}=$ Engine speed $(\mathrm{rad} / \mathrm{sec})$

- $\mathrm{T}_{\mathrm{e}}=$ Engine torque $(\mathrm{Nm})$

$\mathrm{W}_{\mathrm{o}}=\frac{\mathrm{W}_{\mathrm{e}}}{\int_{\mathrm{v}}}$

$\mathrm{W}_{\mathrm{c}}=\mathrm{W}_{\mathrm{e}} \frac{\gamma_{\mathrm{c}}}{\int_{\mathrm{v}}}$

$\mathrm{W}_{\text {out }} \mathrm{T}_{\text {out }}=\mathrm{W}_{\mathrm{e}} \mathrm{T}_{\mathrm{e}}$

Power $_{\text {out }}=\frac{2 \pi \mathrm{W}_{\mathrm{e}} \mathrm{T}_{\mathrm{e}}}{60000} \mathrm{~kW}$ 


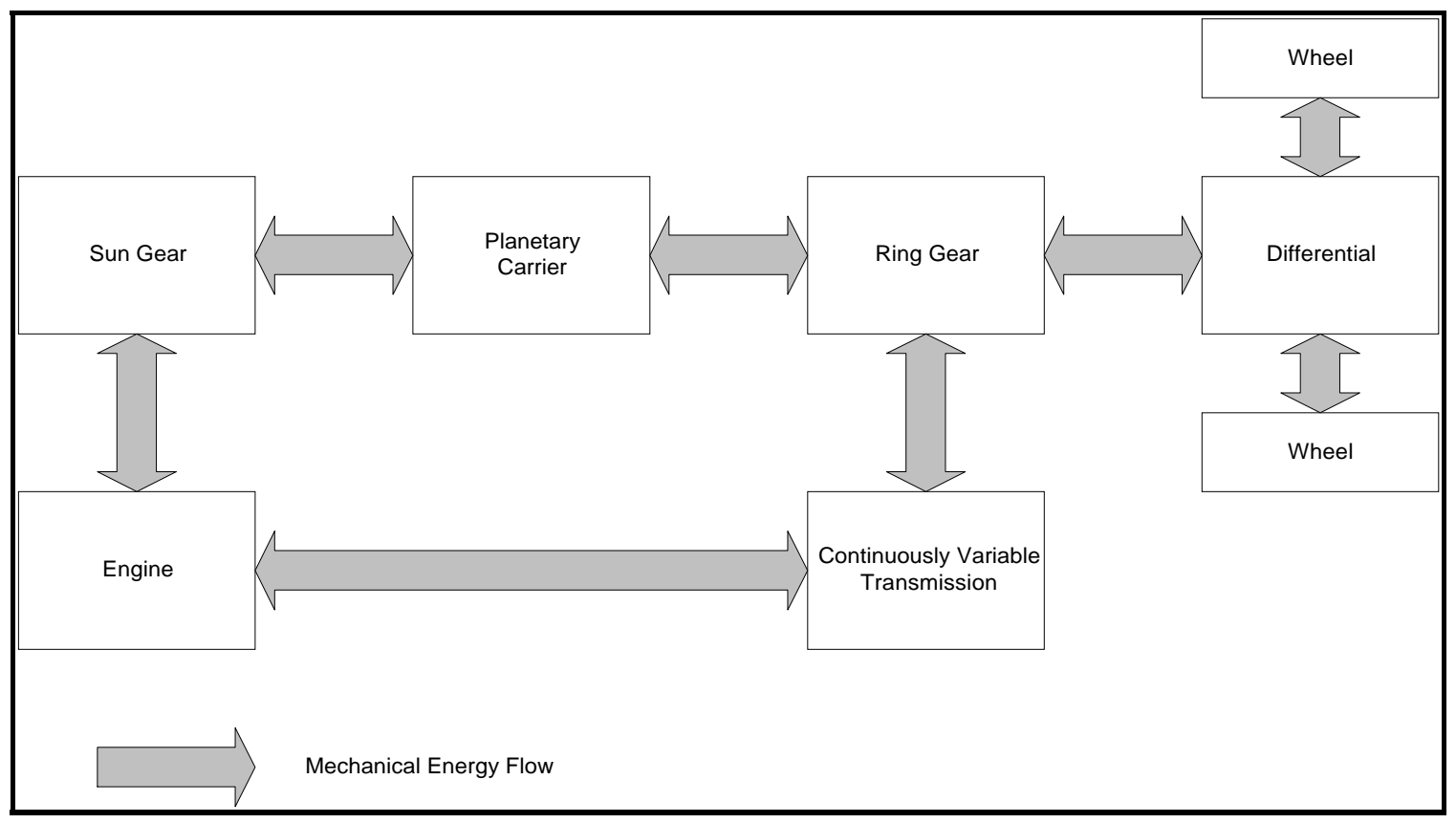

Figure 4.1.2: Power Flow Diagram for Conventional Vehicle Operation

\subsection{Electric Vehicle Operation}

The electric traction motor (powered by the battery pack, not shown) drives the wheels (a geared connection to the ring gear) through the planetary gear carrier and the sun gear. Clutch $\mathrm{A}$ is closed and clutches $\mathrm{B}$ and $\mathrm{C}$ are open removing the CVT and engine from operation. Locking the carrier and sun together with clutch A requires the ring to rotate at the speed of the motor. The motor effectively has a direct connection to the differential. Reverse operation is permissible through reversing the direction of rotation of the motor. This removes the requirement for a separate reverse gear on the vehicle. 
Equations of Motion for Electric Vehicle Operation:

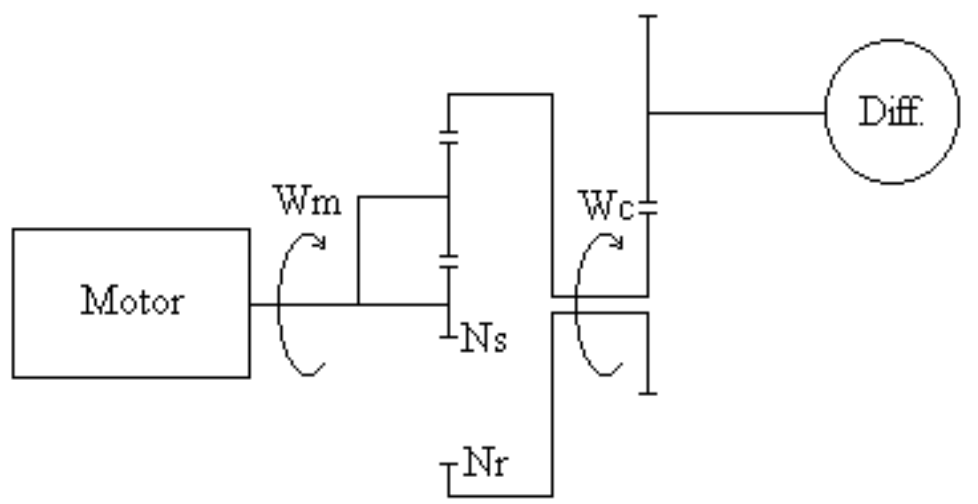

Figure 4.2.1: Electric Vehicle Mode

- $\gamma_{\mathrm{g}}=$ Ratio of ring gear to the sun gear $\left(\mathrm{N}_{\mathrm{r}} / \mathrm{N}_{\mathrm{s}}\right)$

- $\mathrm{W}_{\mathrm{m}}=$ Motor speed $(\mathrm{rad} / \mathrm{sec})$

- $\mathrm{T}_{\mathrm{m}}=$ Motor torque $(\mathrm{Nm})$

$\mathrm{W}_{\mathrm{m}}=\mathrm{W}_{\mathrm{c}}$

$\mathrm{W}_{\text {out }} \mathrm{T}_{\text {out }}=\mathrm{W}_{\mathrm{m}} \mathrm{T}_{\mathrm{m}}$

Power $_{\text {out }}=\frac{2 \pi \mathrm{W}_{\mathrm{m}} \mathrm{T}_{\mathrm{m}}}{60000} \mathrm{~kW}$ 


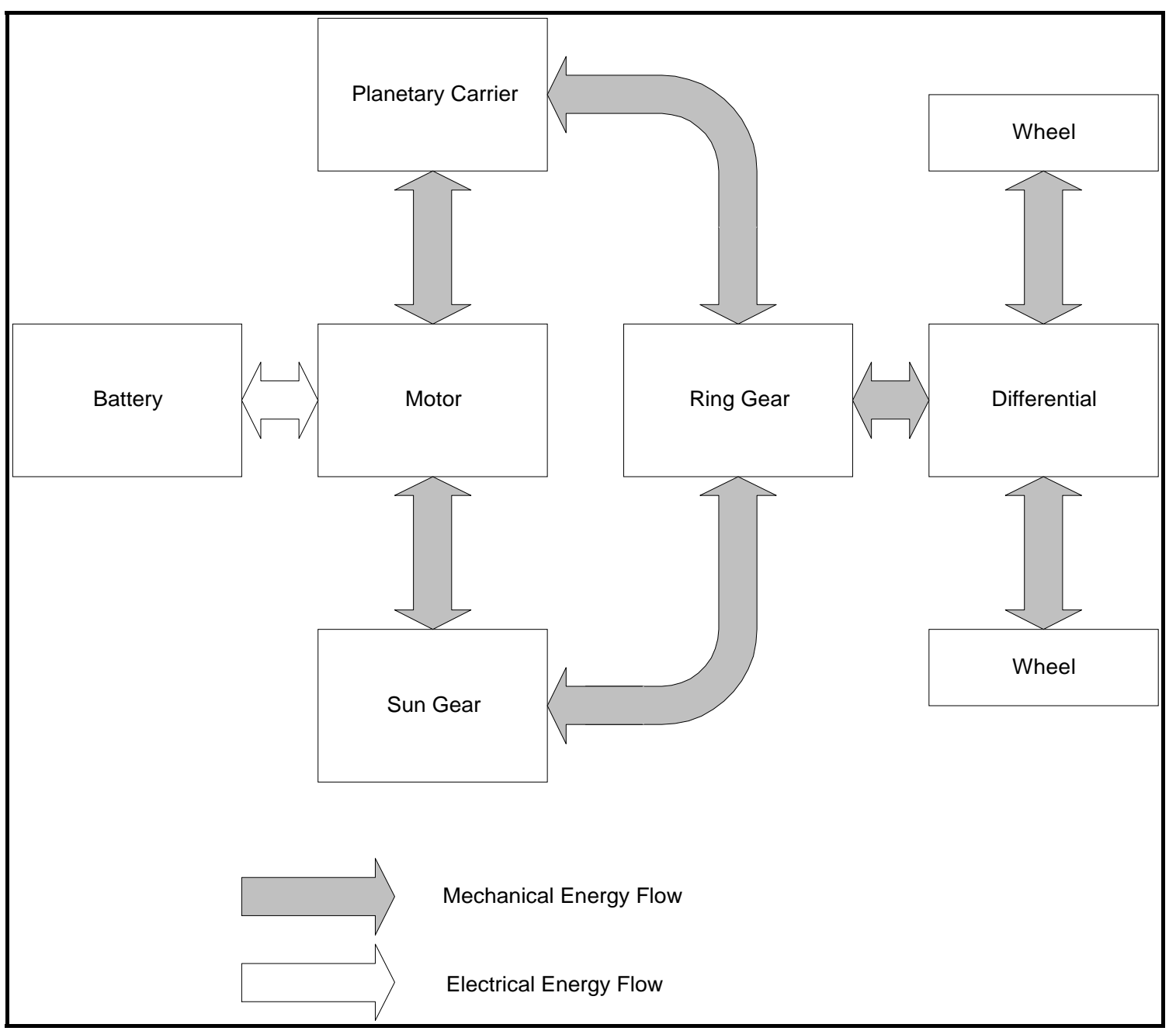

Figure 4.2.2: Power Flow Diagram for Electric Vehicle Operation

\subsection{Series Hybrid Electric Operation}

Series HEV operation occurs by breaking the connection between the CVT and the planetary geartrain. The combination of the engine, alternator, and CVT then becomes decoupled from the final drive that receives power from the electric motor. This is accomplished by closing Clutch $\mathrm{A}$ and opening clutches $\mathrm{B}$ and $\mathrm{C}$. The engine drives the alternator through the CVT allowing variable speed output to the alternator while engine speed is constant. This feature allows for constant engine speed as state of charge increases in the battery pack requiring higher alternator speed. The alternator is 
connected electrically to the drive motor and to the battery pack (not shown) that acts as a load-leveling device allowing for intermittent engine and alternator operation.

Equations of Motion for Series Hybrid Electric Operation:

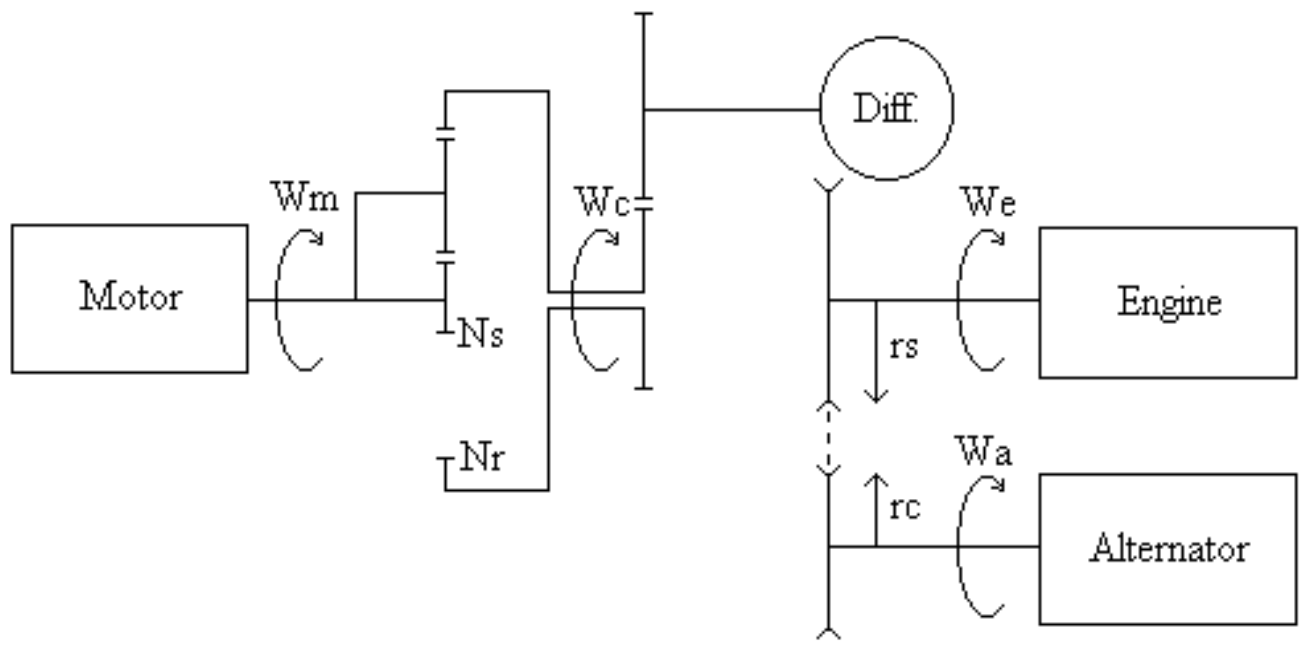

Figure 4.3.1: Series HEV Operation

- $\gamma_{\mathrm{g}}=$ Ratio of ring gear to the sun gear $\left(\mathrm{N}_{\mathrm{r}} / \mathrm{N}_{\mathrm{s}}\right)$

- $\gamma_{\mathrm{c}}=$ CVT to ring gear ratio $\left(\mathrm{W}_{\mathrm{c}} / \mathrm{W}_{\mathrm{a}}\right)$

- $\int_{\mathrm{v}}=$ Instantaneous CVT ratio $\left(\mathrm{W}_{\mathrm{e}} / \mathrm{W}_{\mathrm{a}}\right)$

- $\mathrm{W}_{\mathrm{e}}=$ Engine speed $(\mathrm{rad} / \mathrm{sec})$

- $\mathrm{T}_{\mathrm{e}}=$ Engine torque $(\mathrm{Nm})$

- $\mathrm{W}_{\mathrm{m}}=$ Motor speed $(\mathrm{rad} / \mathrm{sec})$

- $\mathrm{T}_{\mathrm{m}}=$ Motor torque $(\mathrm{Nm})$

$\mathrm{W}_{\mathrm{m}}=\mathrm{W}_{\mathrm{c}}$

$\mathrm{W}_{\mathrm{a}}=\frac{\mathrm{W}_{\mathrm{e}}}{\int_{\mathrm{v}}}$ 


$$
\begin{aligned}
& \mathrm{W}_{\text {out }} \mathrm{T}_{\text {out }}=\mathrm{W}_{\mathrm{m}} \mathrm{T}_{\mathrm{m}} \\
& \text { Power }_{\text {out }}=\frac{2 \pi \mathrm{W}_{\mathrm{m}} \mathrm{T}_{\mathrm{m}}}{60000} \mathrm{~kW}
\end{aligned}
$$

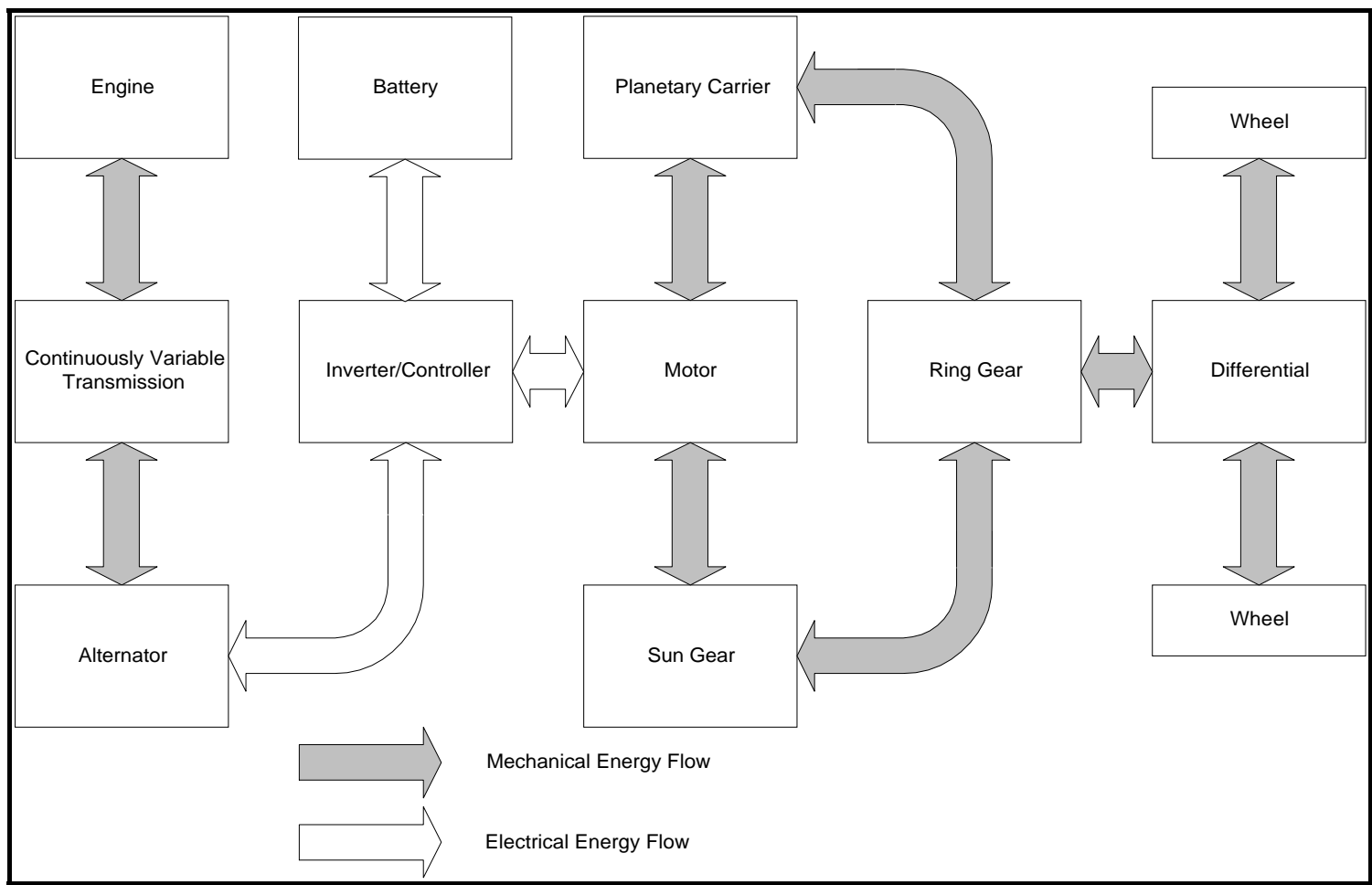

Figure 4.3.2: Power Flow Diagram for Series HEV Operation

\subsection{Parallel HEV, Variate 1 Operation}

Parallel HEV operation occurs in Variation 1 with the use of both the planetary geartrain and the CVT. Clutch A is open and clutches B and C are closed. This configuration allows a power split between the CVT and geared connection increasing system efficiency under motor regeneration conditions. The motor speed is prescribed by the engine speed and total power output is a function of engine speed, engine torque, and motor torque. 
Equations of Motion for Parallel HEV, Variate 1 Operation:

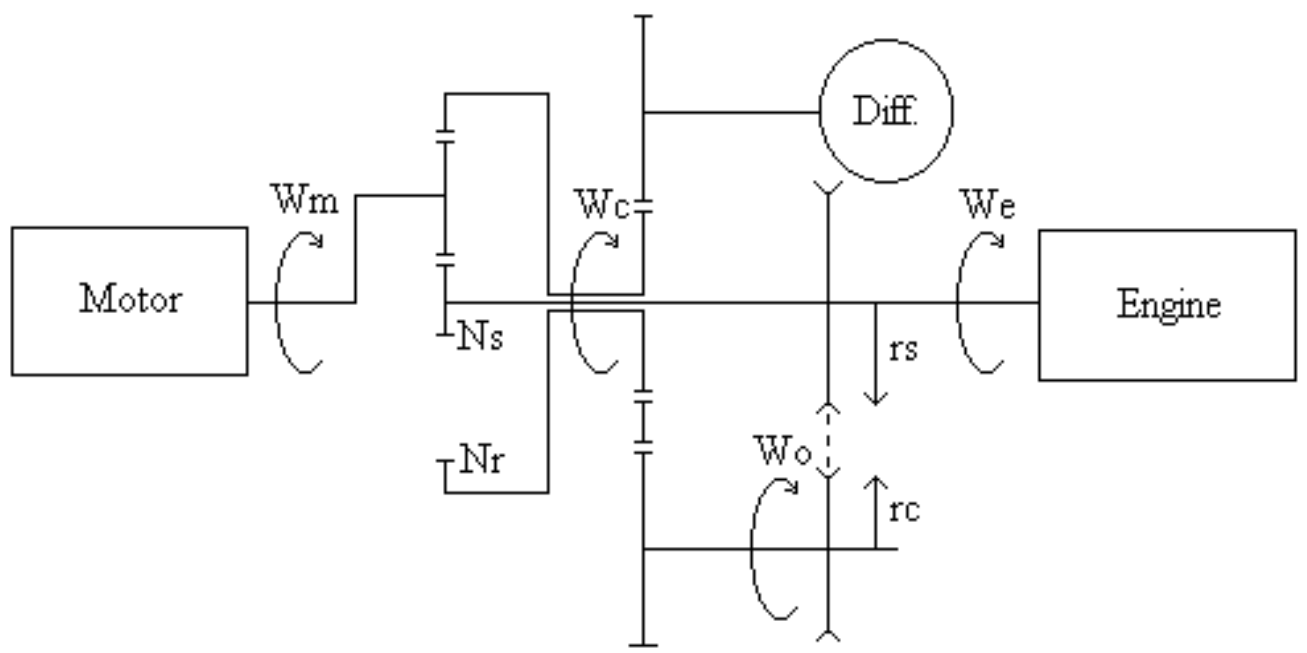

Figure 4.4.1: Parallel HEV, Variate 1

- $\gamma_{\mathrm{g}}=$ Ratio of ring gear to the sun gear $\left(\mathrm{N}_{\mathrm{r}} / \mathrm{N}_{\mathrm{s}}\right)$

- $\gamma_{\mathrm{c}}=\mathrm{CVT}$ to ring gear ratio $\left(\mathrm{W}_{\mathrm{c}} / \mathrm{W}_{\mathrm{o}}\right)$

- $\int_{\mathrm{v}}=$ Instantaneous CVT ratio $\left(\mathrm{W}_{\mathrm{e}} / \mathrm{W}_{\mathrm{o}}\right)$

- $\mathrm{W}_{\mathrm{e}}=$ Engine speed $(\mathrm{rad} / \mathrm{sec})$

- $\mathrm{T}_{\mathrm{e}}=$ Engine torque $(\mathrm{Nm})$

- $\mathrm{W}_{\mathrm{m}}=$ Motor speed $(\mathrm{rad} / \mathrm{sec})$

- $\mathrm{T}_{\mathrm{m}}=$ Motor torque $(\mathrm{Nm})$

$$
\begin{aligned}
& \mathrm{W}_{\mathrm{o}}=\mathrm{W}_{\mathrm{e}} \frac{\mathrm{r}_{\mathrm{s}}}{\mathrm{r}_{\mathrm{c}}} \\
& \mathrm{W}_{\mathrm{o}}=\frac{\mathrm{W}_{\mathrm{e}}}{\int_{\mathrm{v}}} \\
& \mathrm{W}_{\mathrm{c}}=\frac{\mathrm{W}_{\mathrm{e}}}{\int_{\mathrm{v}}} \gamma_{\mathrm{c}}=\mathrm{W}_{\mathrm{e}} \frac{\gamma_{\mathrm{c}}}{\int_{\mathrm{v}}}
\end{aligned}
$$




$$
\begin{aligned}
& \frac{\mathrm{W}_{\mathrm{e}}-\mathrm{W}_{\mathrm{m}}}{\mathrm{W}_{\mathrm{e}} \frac{\gamma_{\mathrm{c}}}{\int_{\mathrm{v}}}-\mathrm{W}_{\mathrm{m}}}=-\gamma_{\mathrm{g}} \\
& \mathrm{W}_{\mathrm{e}}-\mathrm{W}_{\mathrm{m}}=\gamma_{\mathrm{g}} \mathrm{W}_{\mathrm{m}}-\mathrm{W}_{\mathrm{e}} \frac{\gamma_{\mathrm{c}} \gamma_{\mathrm{g}}}{\int_{\mathrm{v}}} \\
& \mathrm{W}_{\mathrm{e}}-\mathrm{W}_{\mathrm{m}}=\gamma_{\mathrm{g}}\left(\mathrm{W}_{\mathrm{m}}-\mathrm{W}_{\mathrm{e}} \frac{\gamma_{\mathrm{c}}}{\int_{\mathrm{v}}}\right) \\
& \mathrm{W}_{\mathrm{e}}\left(1-\frac{\gamma_{\mathrm{c}} \gamma_{\mathrm{g}}}{\int_{\mathrm{v}}}\right)=\mathrm{W}_{\mathrm{m}}\left(1+\gamma_{\mathrm{g}}\right) \\
& \mathrm{W}_{\mathrm{m}}=\mathrm{W}_{\mathrm{e}} \frac{1+\frac{\gamma_{\mathrm{c}} \gamma_{\mathrm{g}}}{\int_{\mathrm{v}}}}{1+\gamma_{\mathrm{g}}} \\
& \mathrm{W}_{\mathrm{c}}=\mathrm{W}_{\mathrm{e}} \frac{\gamma_{\mathrm{c}}}{\int_{\mathrm{v}}} \\
& \mathrm{W}_{\text {out }} \mathrm{T}_{\text {out }}=\mathrm{W}_{\mathrm{e}} \mathrm{T}_{\mathrm{e}}+\mathrm{W}_{\mathrm{m}} \mathrm{T}_{\mathrm{m}} \\
& \mathrm{W}_{\text {out }} \mathrm{T}_{\text {out }}=\mathrm{W}_{\mathrm{e}} \mathrm{T}_{\mathrm{e}}+\left(\mathrm{W}_{\mathrm{e}} \frac{1+\frac{\gamma_{\mathrm{c}} \gamma_{\mathrm{g}}}{\int_{\mathrm{v}}}}{1+\gamma_{\mathrm{g}}}\right) \mathrm{T}_{\mathrm{m}} \\
& 2 \pi \mathrm{W}_{\mathrm{e}}\left(\mathrm{T}_{\mathrm{e}}+\left(\frac{1+\frac{\gamma_{\mathrm{c}} \gamma_{\mathrm{g}}}{\int_{\mathrm{v}}}}{1+\gamma_{\mathrm{g}}}\right) \mathrm{T}_{\mathrm{m}}\right) \\
& 60000 \\
& \mathrm{~kW}
\end{aligned}
$$




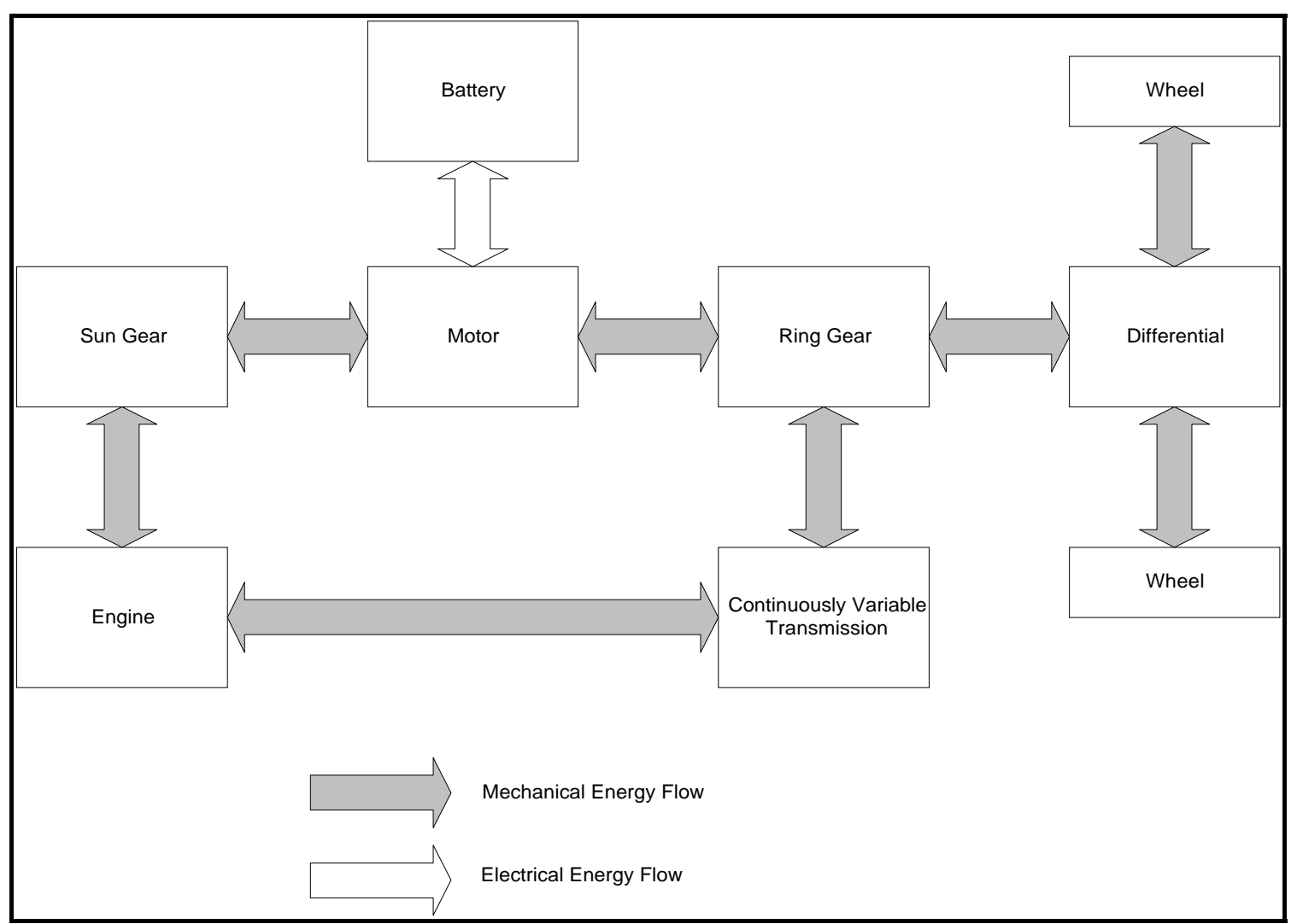

Figure 4.4.2: Power Flow Diagram for Parallel HEV, Variate 1 Operation

\subsection{Parallel HEV, Variate 2 Operation}

Parallel HEV operation requires only the use of the CVT. Clutch B is opened and clutches $\mathrm{A}$ and $\mathrm{C}$ are closed. By closing clutch $\mathrm{A}$ the planetary geartrain rotates as a single unit. This occurs because the rotation of the motor now prescribes both the motion of the planetary carrier and the sun gear. This configuration requires all engine power to be transmitted through the CVT. Variation of the CVT ratio allows for the overall range of gear ratios necessary to match engine output to power required at the wheels. The motor speed is prescribed by the engine speed and CVT ratio total power output is a function of engine speed, engine torque, and motor torque. 
Equations of Motion for Parallel HEV, Variate 2 Operation:

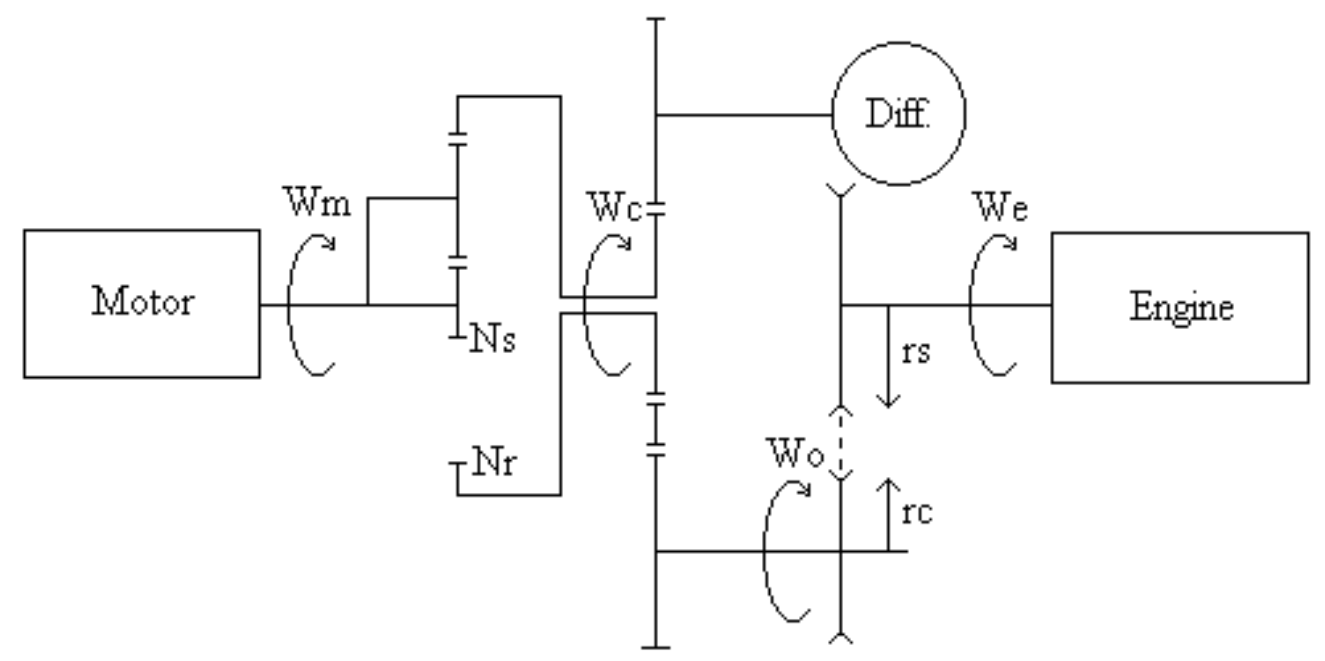

Figure 4.5.1: Parallel HEV, Variate 2

- $\gamma_{\mathrm{g}}=$ Ratio of ring gear to the sun gear $\left(\mathrm{N}_{\mathrm{r}} / \mathrm{N}_{\mathrm{s}}\right)$

- $\gamma_{\mathrm{c}}=$ CVT to ring gear ratio $\left(\mathrm{W}_{\mathrm{c}} / \mathrm{W}_{\mathrm{o}}\right)$

- $\int_{\mathrm{v}}=$ Instantaneous CVT ratio $\left(\mathrm{W}_{\mathrm{e}} / \mathrm{W}_{\mathrm{o}}\right)$

- $\mathrm{W}_{\mathrm{e}}=$ Engine speed $(\mathrm{rad} / \mathrm{sec})$

- $\mathrm{T}_{\mathrm{e}}=$ Engine torque $(\mathrm{Nm})$

- $\mathrm{W}_{\mathrm{m}}=$ Motor speed $(\mathrm{rad} / \mathrm{sec})$

- $\mathrm{T}_{\mathrm{m}}=$ Motor torque $(\mathrm{Nm})$

$$
\begin{aligned}
& \mathrm{W}_{\mathrm{o}}=\mathrm{W}_{\mathrm{e}} \frac{\mathrm{r}_{\mathrm{s}}}{\mathrm{r}_{\mathrm{c}}} \\
& \mathrm{W}_{\mathrm{o}}=\frac{\mathrm{W}_{\mathrm{e}}}{\int_{\mathrm{v}}} \\
& \mathrm{W}_{\mathrm{c}}=\frac{\mathrm{W}_{\mathrm{e}} \gamma_{\mathrm{c}}}{\int_{\mathrm{v}}}
\end{aligned}
$$




$$
\begin{aligned}
& \mathrm{W}_{\mathrm{m}}=\mathrm{W}_{\mathrm{c}} \\
& \mathrm{W}_{\mathrm{m}}=\frac{\mathrm{W}_{\mathrm{e}} \gamma_{\mathrm{c}}}{\int_{\mathrm{v}}} \\
& \mathrm{W}_{\text {out }} \mathrm{T}_{\text {out }}=\mathrm{W}_{\mathrm{e}} \mathrm{T}_{\mathrm{e}}+\mathrm{W}_{\mathrm{m}} \mathrm{T}_{\mathrm{m}} \\
& \mathrm{W}_{\text {out }} \mathrm{T}_{\text {out }}=\left(\frac{\mathrm{W}_{\mathrm{e}} \gamma_{\mathrm{c}}}{\int_{\mathrm{v}}}\right) \mathrm{T}_{\mathrm{m}}+\mathrm{W}_{\mathrm{e}} \mathrm{T}_{\mathrm{e}} \\
& \mathrm{W}_{\text {out }} \mathrm{T}_{\text {out }}=\mathrm{W}_{\mathrm{e}}\left(\frac{\mathrm{T}_{\mathrm{m}} \gamma_{\mathrm{c}}}{\int_{\mathrm{v}}}+\mathrm{T}_{\mathrm{e}}\right) \\
& \text { Power }_{\text {out }}=\frac{2 \pi \mathrm{W}_{\mathrm{e}}\left(\frac{\mathrm{T}_{\mathrm{m}} \gamma_{\mathrm{c}}}{\int_{\mathrm{v}}}+\mathrm{T}_{\mathrm{e}}\right)}{60000} \mathrm{~kW}
\end{aligned}
$$

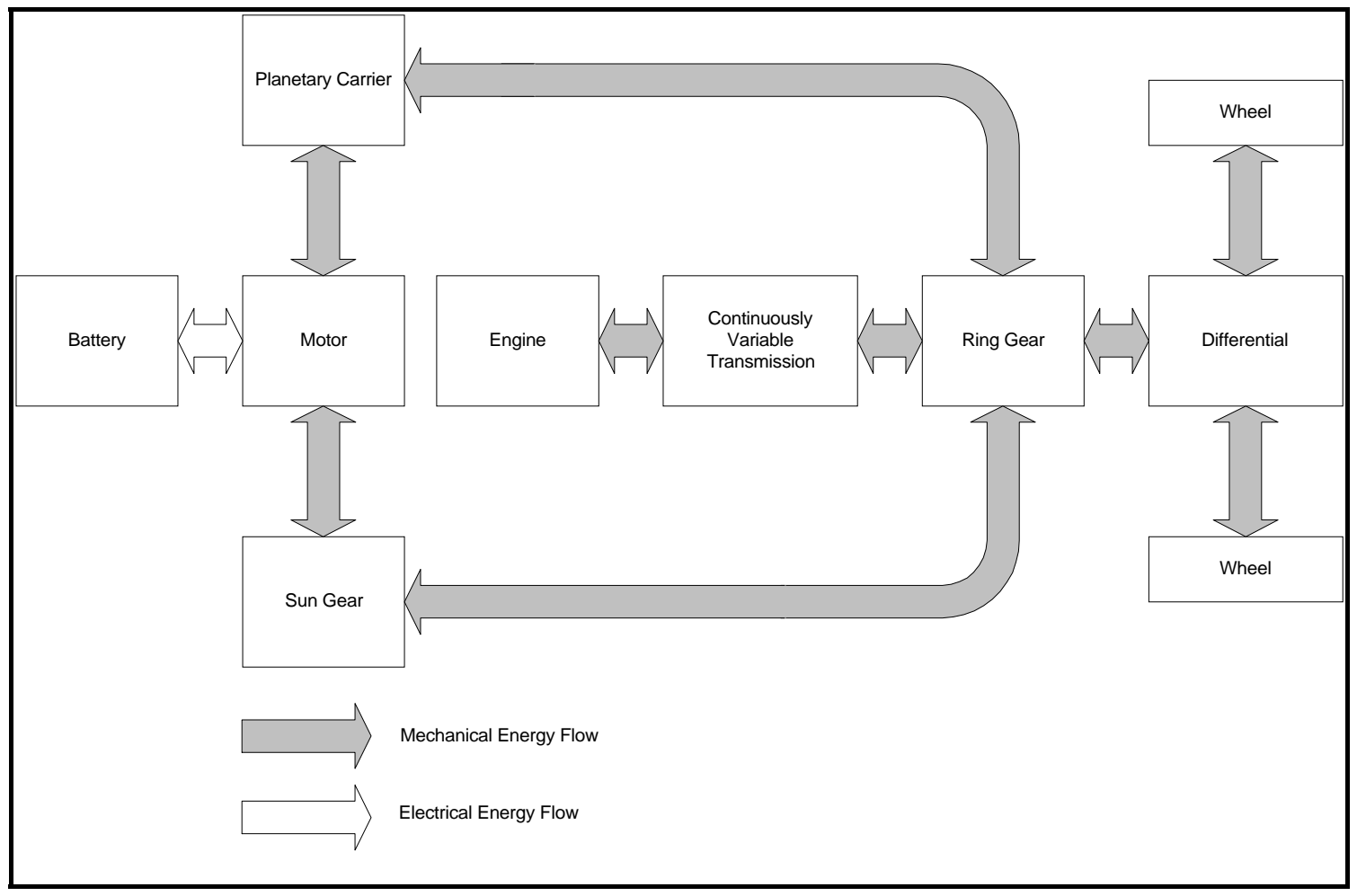

Figure 4.5.2: Power Flow Diagram for Parallel HEV, Variate 2 Operation 


\subsection{Geared Neutral Operation}

Geared neutral operation, the engine rotating with the drivetrain totally engaged without slippage and the drive wheels being motionless, occurs with only the use of the planetary gear train. Clutches A and C are opened and clutch B is closed. Output speed to the differential is a function of both engine and motor speed. By reversing the rotation of the motor, a geared neutral is possible. By further increasing the speed of the reverse motor rotation reverse operation is possible. This removes the requirement for a separate reverse gear in the transmission. This mode also provides an alternative means of starting vehicle motion with the engine running and engaged without slipping a clutch.

Equations of Motion for Geared Neutral Operation:

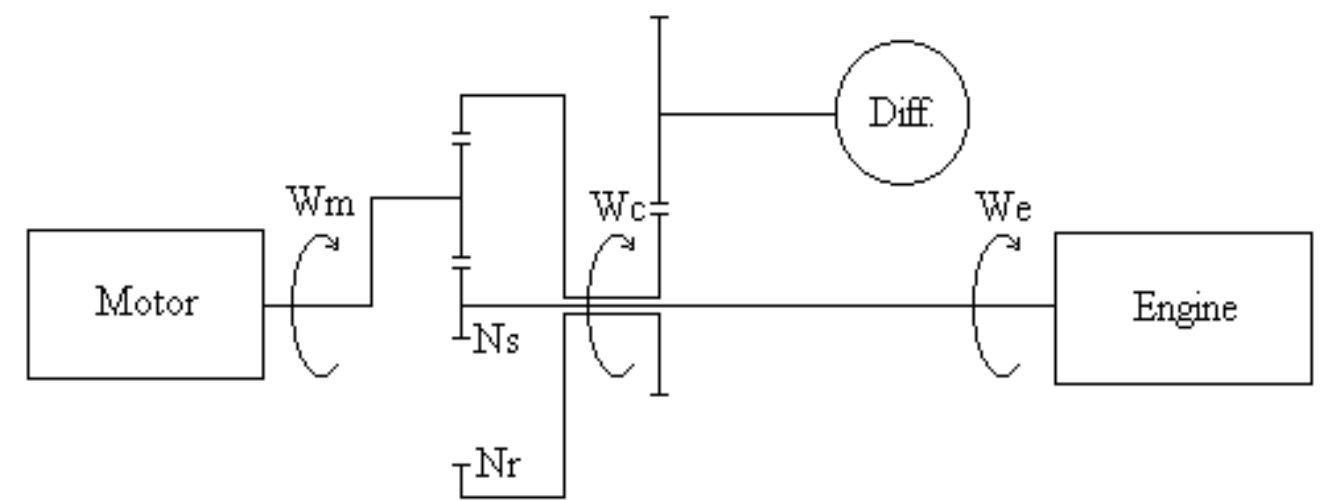

Figure 4.6.1: Geared Neutral Operation

- $\gamma_{\mathrm{g}}=$ Ratio of ring gear to the sun gear $\left(\mathrm{N}_{\mathrm{r}} / \mathrm{N}_{\mathrm{s}}\right)$

- $\mathrm{W}_{\mathrm{e}}=$ Engine speed $(\mathrm{rad} / \mathrm{sec})$

- $\quad \mathrm{T}_{\mathrm{e}}=$ Engine torque $(\mathrm{Nm})$

- $\mathrm{W}_{\mathrm{m}}=$ Motor speed $(\mathrm{rad} / \mathrm{sec})$ 
- $\mathrm{T}_{\mathrm{m}}=$ Motor torque $(\mathrm{Nm})$

$\mathrm{W}_{\mathrm{c}}=\frac{\mathrm{W}_{\mathrm{e}}}{\gamma_{\mathrm{g}}}-\frac{\mathrm{W}_{\mathrm{m}}}{\gamma_{\mathrm{g}}+1}$

$\mathrm{W}_{\text {out }} \mathrm{T}_{\text {out }}=\mathrm{W}_{\mathrm{m}} \mathrm{T}_{\mathrm{m}}+\mathrm{W}_{\mathrm{e}} \mathrm{T}_{\mathrm{e}}$

$\mathrm{W}_{\text {out }} \mathrm{T}_{\text {out }}=\frac{\mathrm{W}_{\mathrm{e}}\left(\gamma_{\mathrm{g}}+1\right)}{\gamma_{\mathrm{g}}} \mathrm{T}_{\mathrm{m}}+\mathrm{W}_{\mathrm{e}} \mathrm{T}_{\mathrm{e}}$

$\mathrm{W}_{\text {out }} \mathrm{T}_{\text {out }}=\mathrm{W}_{\mathrm{e}}\left(\frac{\mathrm{T}_{\mathrm{m}}\left(\gamma_{\mathrm{g}}+1\right)}{\gamma_{\mathrm{g}}}+\mathrm{T}_{\mathrm{e}}\right)$

Power $_{\text {out }}=\frac{2 \pi \mathrm{W}_{\mathrm{e}}\left(\frac{\mathrm{T}_{\mathrm{m}}\left(\gamma_{\mathrm{g}}+1\right)}{\gamma_{\mathrm{g}}}+\mathrm{T}_{\mathrm{e}}\right)}{60000} \mathrm{~kW}$

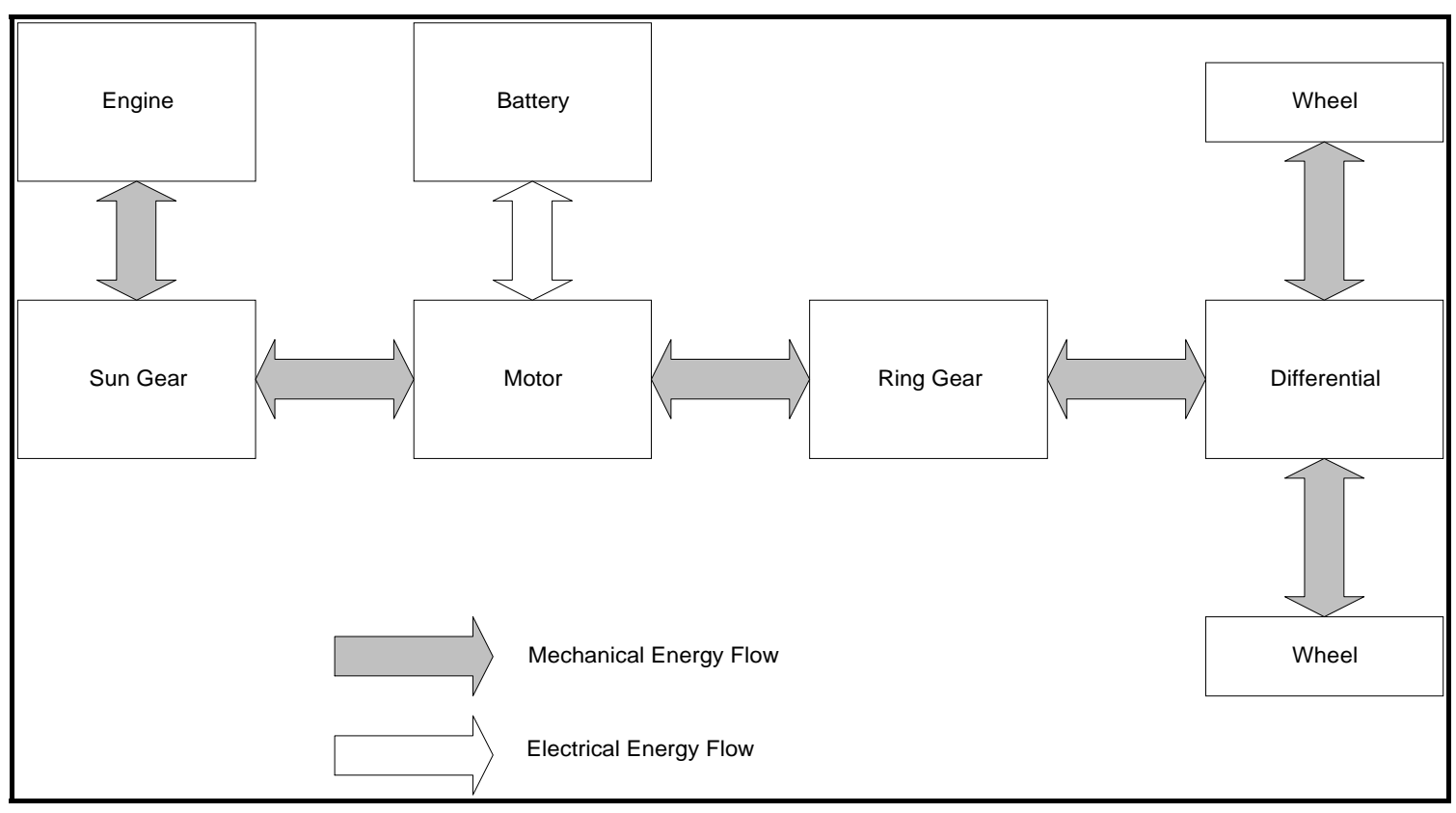

Figure 4.6.2: Power Flow Diagram for Geared Neutral Operation 


\subsection{Power Split Operation}

Operation of the Torque and Speed Control Transmission in Parallel HEV, Variate 1 is the only mode that utilizes both the CVT and planetary geartrain and has a split of engine power. In Parallel HEV, Variate 1 operation, the motor that is attached to the planetary gear train through the carrier and creates a torque on the sun gear. This torque is in the same direction as the torque of the engine that is attached to the other end of the sun shaft. These two torques are additive while the motor is acting as a power source. However, when the motor is used to charge the batteries either through regenerative braking or to increase the load on the engine for more efficient engine operation, the torque due to the motor changes direction. This is when power split of the engine occurs.

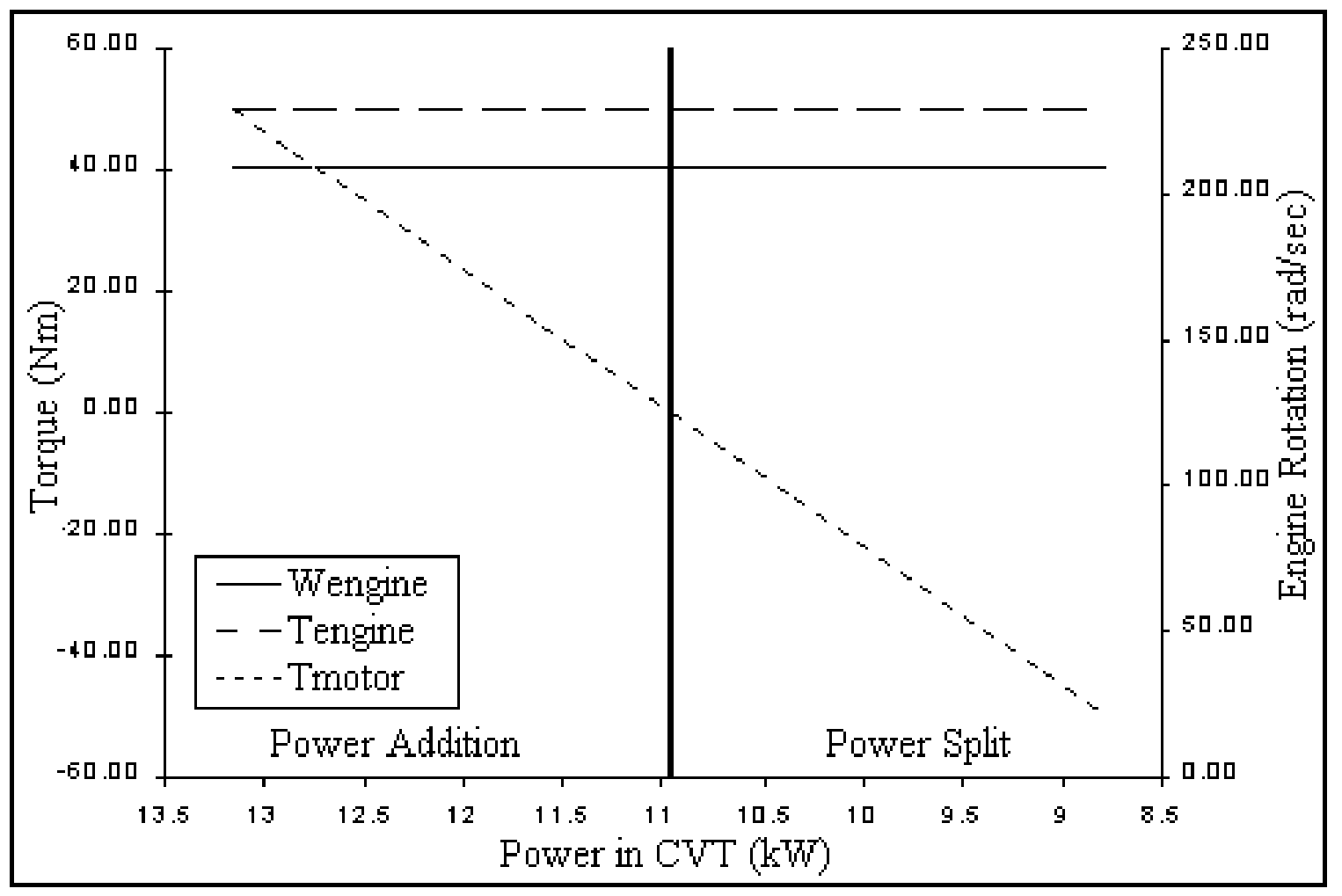

Figure 4.7.1: Power Split in CVT as a Function of Motor Torque 
The power addition/power split function of the TSCT is solely dependent upon the operation of the motor. Figure 4.7.1 illustrates this power addition/power split operation of the TSCT during one specific point of operation. The engine operation is held at a constant speed of $2000 \mathrm{rpm}$ and a constant torque of $50 \mathrm{Nm}$ (power is $10.9 \mathrm{~kW}$ ). The motor is then allowed to sweep from producing power, $50 \mathrm{Nm}$ at $1040 \mathrm{rpm}$, to sinking power, $-50 \mathrm{Nm}$ at $1040 \mathrm{rpm}$. It is this change in motor torque that alters the engine power flow through the CVT belt.

On the left side of the figure, motor torque is positive which is the same direction as the torque created by the engine. The vertical line denotes the point of operation where the motor is not adding power to the system. To the right of this line is the area of operation where the TSCT has a power split between the CVT and the planetary geartrain. The fraction of power sent through the CVT is the torque of the engine minus the torque on the sun gear due to the motor.

To find the power split through the transmission an analysis using free body diagrams is required. This is necessary to find the force in the belt of the CVT. Once the force is known, the torque on the output shaft of the CVT can be found. With the speed and torque of the CVT, the power can then be determined. This derivation is shown below with the CVT output power, Power ${ }_{\mathrm{CVT}}$, being the end result.

$$
\begin{aligned}
& \mathrm{r}_{\mathrm{arm}}=\frac{\mathrm{N}_{\mathrm{R}}+\mathrm{N}_{\mathrm{s}}}{2} \\
& \mathrm{~T}_{\text {motor }}=\mathrm{F}_{\mathrm{a}} \mathrm{r}_{\mathrm{a}} \\
& \mathrm{F}_{\mathrm{a}}=\frac{\mathrm{T}_{\mathrm{m}}}{\mathrm{r}_{\mathrm{a}}}=\frac{\frac{\mathrm{T}_{\mathrm{m}}}{\mathrm{N}_{\mathrm{R}}+\mathrm{N}_{\mathrm{S}}}}{2}=\frac{2 \mathrm{~T}_{\mathrm{m}}}{\mathrm{N}_{\mathrm{R}}+\mathrm{N}_{\mathrm{S}}}
\end{aligned}
$$




$$
\begin{aligned}
& \frac{F_{a}}{2}=\frac{T_{m}}{N_{R}+N_{S}} \\
& \left(\frac{\mathrm{T}_{\mathrm{m}}}{\mathrm{N}_{\mathrm{R}}+\mathrm{N}_{\mathrm{S}}}\right) \mathrm{N}_{\mathrm{S}}+\mathrm{T}_{\mathrm{e}}=\mathrm{F}_{\mathrm{b}} \mathrm{r}_{\mathrm{s}} \\
& F_{b}=\frac{\frac{T_{m} N_{s}}{N_{R}+N_{S}}+T_{e}}{r_{s}}=\frac{T_{m} N_{s}}{r_{s}\left(N_{R}-N_{s}\right)}+\frac{T_{e}}{r_{s}} \\
& \mathrm{~T}_{\mathrm{o}}=\mathrm{F}_{\mathrm{b}} \mathrm{r}_{\mathrm{c}}=\frac{\mathrm{T}_{\mathrm{m}} \mathrm{N}_{\mathrm{s}} \mathrm{r}_{\mathrm{c}}}{\mathrm{r}_{\mathrm{s}}\left(\mathrm{N}_{\mathrm{R}}+\mathrm{N}_{\mathrm{S}}\right)}+\frac{\mathrm{T}_{\mathrm{e}} \mathrm{r}_{\mathrm{c}}}{\mathrm{r}_{\mathrm{s}}} \\
& \mathrm{T}_{\mathrm{o}}=\frac{\mathrm{T}_{\mathrm{m}} \mathrm{N}_{\mathrm{S}} \int_{\mathrm{v}}}{\mathrm{N}_{\mathrm{R}}+\mathrm{N}_{\mathrm{S}}}+\mathrm{T}_{\mathrm{e}} \int_{\mathrm{v}} \\
& \mathrm{T}_{\mathrm{o}}=\int_{\mathrm{v}}\left(\frac{\mathrm{T}_{\mathrm{m}} \mathrm{N}_{\mathrm{S}}}{\mathrm{N}_{\mathrm{R}}+\mathrm{N}_{\mathrm{S}}}+\mathrm{T}_{\mathrm{e}}\right) \\
& \mathrm{W}_{\mathrm{o}}=\frac{\mathrm{W}_{\mathrm{e}}}{\int_{\mathrm{v}}} \\
& \text { Power }_{\mathrm{CVT}}=\left(\mathrm{W}_{\mathrm{o}} \mathrm{T}_{\mathrm{o}}\right) \frac{2 \pi}{60000}=\left(\frac{\mathrm{W}_{\mathrm{e}}}{\int_{\mathrm{v}}} \int_{\mathrm{v}}\left(\frac{\mathrm{T}_{\mathrm{m}} \mathrm{N}_{\mathrm{S}}}{\mathrm{N}_{\mathrm{R}}+\mathrm{N}_{\mathrm{S}}}+\mathrm{T}_{\mathrm{e}}\right)\right) \frac{2 \pi}{60000} \mathrm{~kW} \\
& \text { Power }_{\mathrm{CVT}}=\left(\mathrm{W}_{\mathrm{e}}\left(\frac{\mathrm{T}_{\mathrm{m}} \mathrm{N}_{\mathrm{s}}}{\mathrm{N}_{\mathrm{R}}+\mathrm{N}_{\mathrm{S}}}+\mathrm{T}_{\mathrm{e}}\right)\right) \frac{2 \pi}{60000} \mathrm{~kW} \\
& \text { Power }_{\mathrm{CVT}}=\left(\frac{\mathrm{W}_{\mathrm{e}} \mathrm{T}_{\mathrm{m}} \mathrm{N}_{\mathrm{s}}}{\mathrm{N}_{\mathrm{R}}+\mathrm{N}_{\mathrm{S}}}+\mathrm{W}_{\mathrm{e}} \mathrm{T}_{\mathrm{e}}\right) \frac{2 \pi}{60000} \mathrm{~kW}
\end{aligned}
$$

\section{Results and Discussion}

This study was conducted to determine the feasibility of creating a multiple input/multiple output transmission that was a combination of a planetary geartrain and a CVT. This combination of two different types of transmissions was selected because 
combining a CVT with a planetary geartrain allows for a power split under certain operating conditions. A power split is beneficial because it allows the amount of power flowing through the CVT belt to varied independently of the power output from the source connected to the transmission. This can be beneficial in terms of increasing the efficiency of the CVT and also the total power handling capability of the system.

Six different variations of the TSCT design were studied to find the optimum configuration. This configuration was based on ease of control and desired component rotations and velocities. These six variations are described in Section 3.2.1 as Type 1 though Type 6. Type 1 was chosen as outlined in Section 3.2.2. This was the TSCT configuration that was fully evaluated.

Once the mechanical layout of the TSCT was decided, the necessary gear ratio within the planetary geartrain had to be chosen as well as the gear ratio of the connection of the ring gear to the CVT output shaft. These gear ratios selected were $\gamma_{\mathrm{g}}$, the number of teeth of the ring gear divided by the number of teeth of the sun gear, and $\gamma_{c}$, the velocity ratio of the ring gear to the output of CVT. Through a numerical analysis of steady-state performance of the TSCT, a value of 0.7 was chosen for $\gamma_{c}$. As the value of $\gamma_{c}$ becomes numerically smaller, the more the total gear reduction that is possible within the system. However, a compromise must be made such that engine speed at highway speeds is not excessively high which lowers fuel economy due to throttling losses. The value of 0.7 chosen for $\gamma_{c}$ allows for a gear reduction of $3.714: 1$ and an overdrive of 0.636:1 before the differential. Figure 5.1 below illustrates the dynamic ability of the TSCT versus a currently produced five speed manual transmission the Nissan Maxima. 


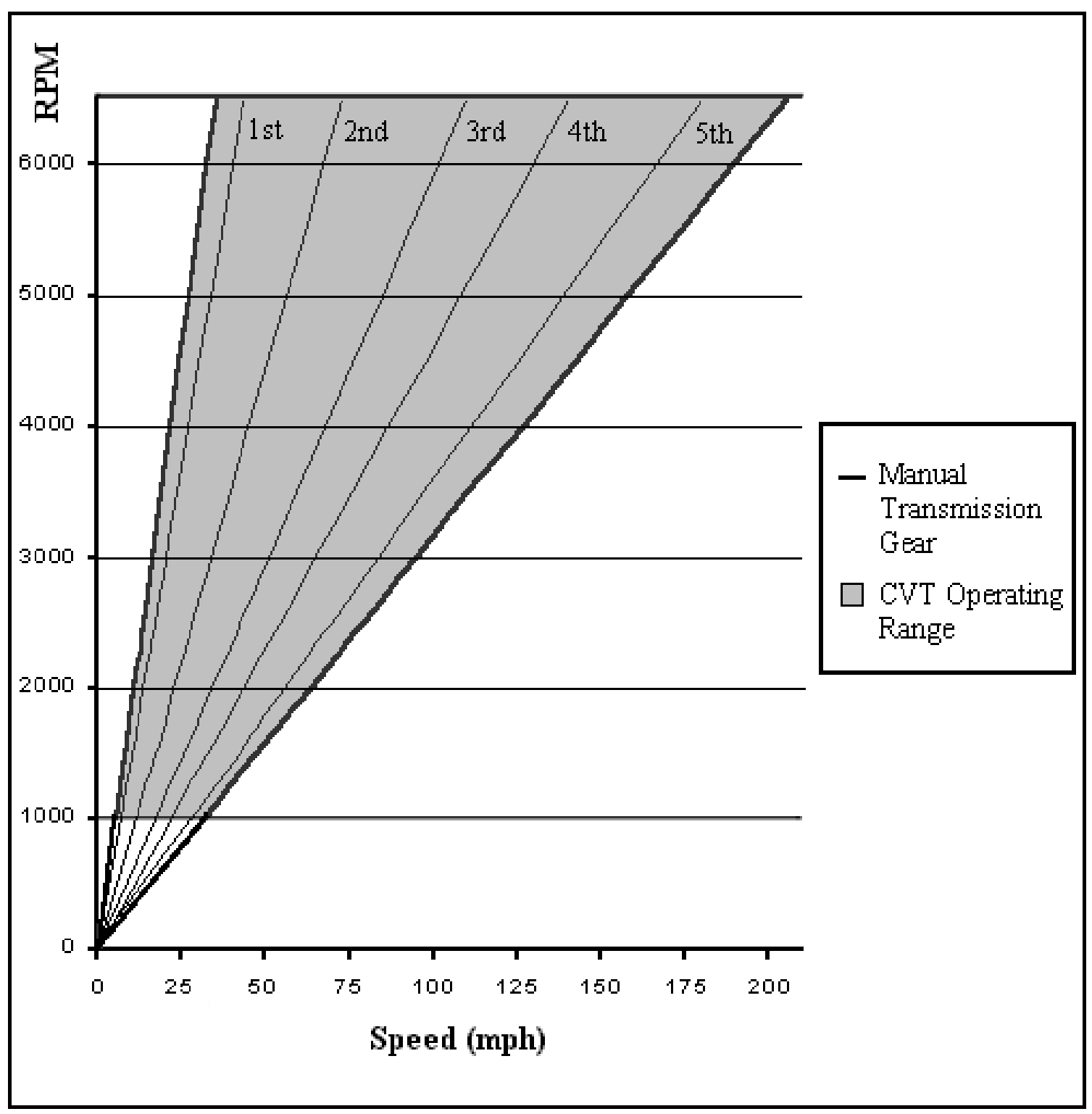

Figure 5.1: TSCT Operation vs Manual Transmission

The mechanical response of the TSCT to the variation in $\gamma_{\mathrm{g}}$ was also evaluated numerically under steady-state conditions in Parallel HEV variate 1 and Geared Neutral modes. These two modes require the conditions where the planetary geartrain is not spinning as a solid unit. An increase in the value of $\gamma_{\mathrm{g}}$ provides a slight increase in motor speed in both modes. This is beneficial because motor operation is moved to a slightly more efficient area in the speed versus torque map. However, increasing the 
value of $\gamma_{\mathrm{g}}$ also creates the need to either make the ring gear larger or reduce the size of the sun gear. Increasing the size of the ring gear is a disadvantage as it creates a larger component that needs to be housed under the hood of vehicles that are becoming increasing more component dense. Furthermore, decreasing the size of the sun gear reduces the strength of the gear as less surface area is in contact with the planetary gears. Therefore, the value of 4.0 was chosen for $\gamma_{\mathrm{g}}$. This creates a planetary geartrain with values consistent with those in automotive production and provides acceptable motor speeds during operation.

With the values of $\gamma_{c}$ and $\gamma_{\mathrm{g}}$ chosen, the velocity relationships for all modes of operation are prescribed. The first mode simulated is a conventional vehicle mode. Figure 5.2 below illustrates the operating range of an engine connected to the TSCT. Once the initial vehicle movement has begun by slipping a clutch, the entire boxed area of engine operation is possible. The minimum and maximum operating speeds of the engine were assumed to be $1000 \mathrm{rpm}$ and $5500 \mathrm{rpm}$ respectively. Speed can be increased from the bottom left corner of the figure in two directions. Either the engine speed can be raised (moving vertically up the figure), or the CVT ratio may be increased. Increasing the CVT ratio to a numerically higher value (lower total gear reduction) moves operation horizontally across the figure. 


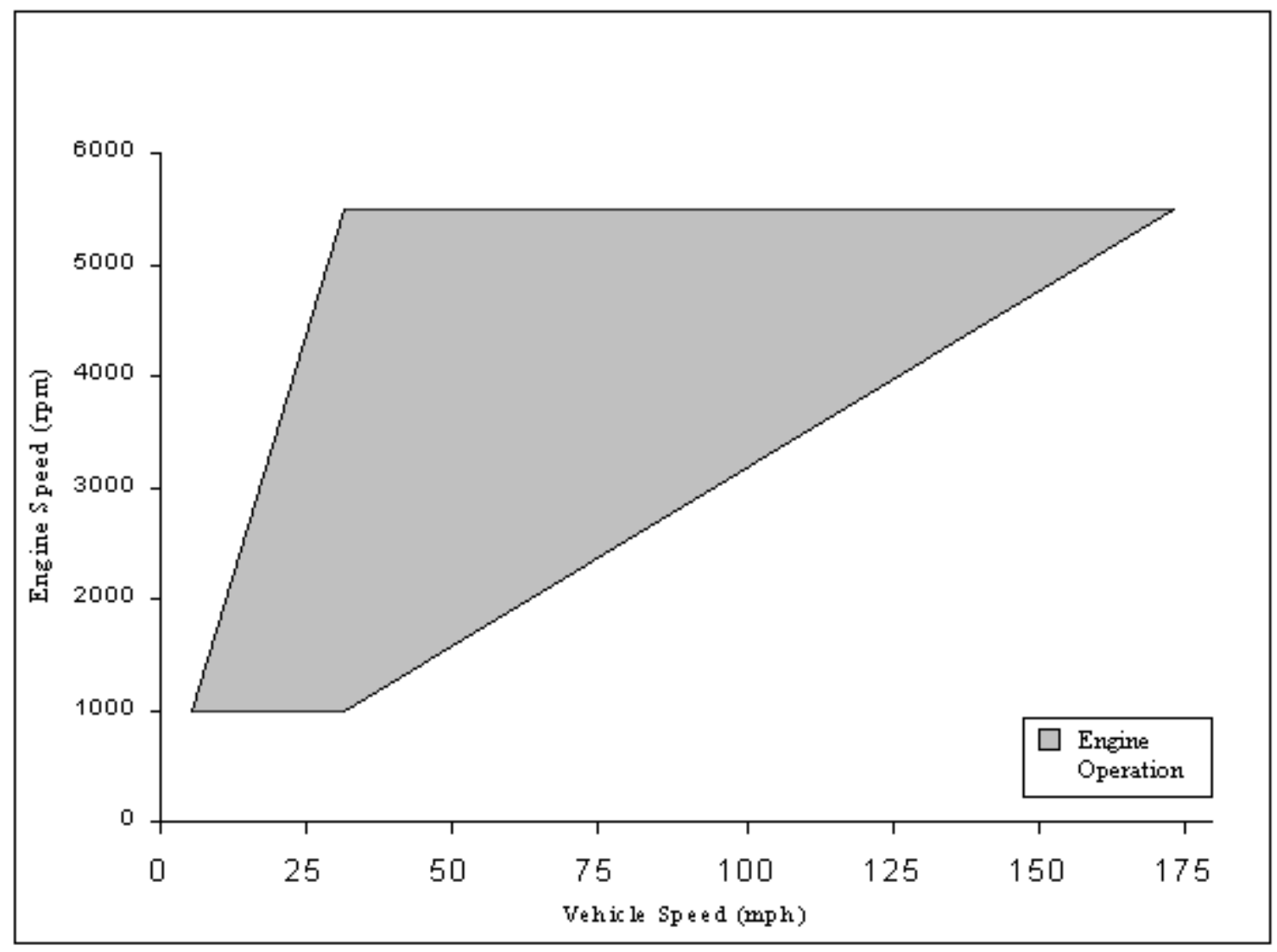

Figure 5.2: Engine Operation as a Function of Vehicle Speed and Variator Ratio

The next modes of operation simulated are all identical in terms of the planetary geartrain operation. In Electric Vehicle, Series HEV, and Parallel HEV, Variate 2 modes, all three elements of the planetary geartrain rotate at the same speed. This motion is due to a clutch being engaged between the planetary carrier and the ring gear. The speed of the planetary geartrain is dictated solely by the speed of the motor in the case of EV and Series HEV operation and by the speed of the vehicle (due to the engine) in Parallel HEV, Variate 2 operation.

For EV and Series HEV operation, all propulsive power for the vehicle is supplied by the electric motor connected to the planetary carrier. Figure 5.3 below illustrates the linear relationship of vehicle speed due to motor rotation. The motion of all three 
planetary components is the same and lies along this one line of operation. This direct drive from the motor takes advantage of electric machine's inherently high torque at lower speeds. This characteristic allows the TSCT to operate without the CVT.

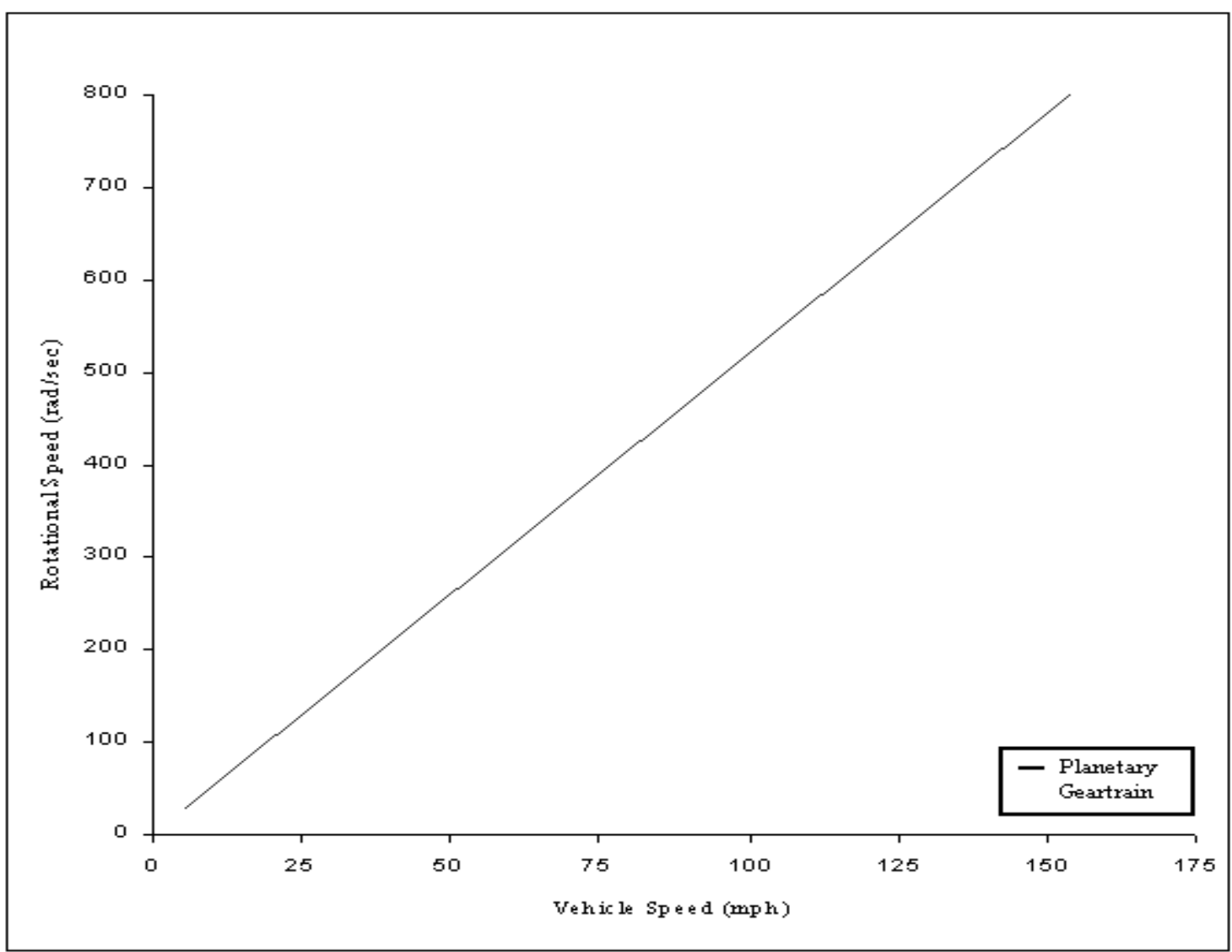

Figure 5.3: Planetary Geartrain Rotation as a Function of Vehicle Speed

While the TSCT is functioning in Series HEV mode, the electric drive motor provides all propulsive power for the vehicle and the CVT is decoupled from the planetary geartrain. The CVT is still coupled directly to the engine however. The engine then operates intermittently to power an alternator connected to the output of the CVT. The electrical energy created by the alternator powers the electric motor or is stored in the battery pack. 
For Parallel HEV, Variate 2, drivetrain operation is very similar to conventional vehicle operation except that the motor adds or subtracts power. The planetary geartrain operation is identical to that illustrated in Figure 5.2. The motor may add torque into the planetary geartrain under heavy load or act as an alternator under light load. This addition load created by the motor creates a higher torque on the engine in turn raising the engine efficiency because of lower throttling losses and charges the batteries assuming that the $\mathrm{SoC}$ is not 100 percent. The engine and planetary geartrain speeds are shown below in Figure 5.4. As with Figure 5.2, vehicle speed is increased by raising engine speed, (vertical movement on the figure), or by utilizing higher numeric CVT ratios, (horizontal movement on the figure). This figure is created by superimposing Figures 5.2 and 5.3. 


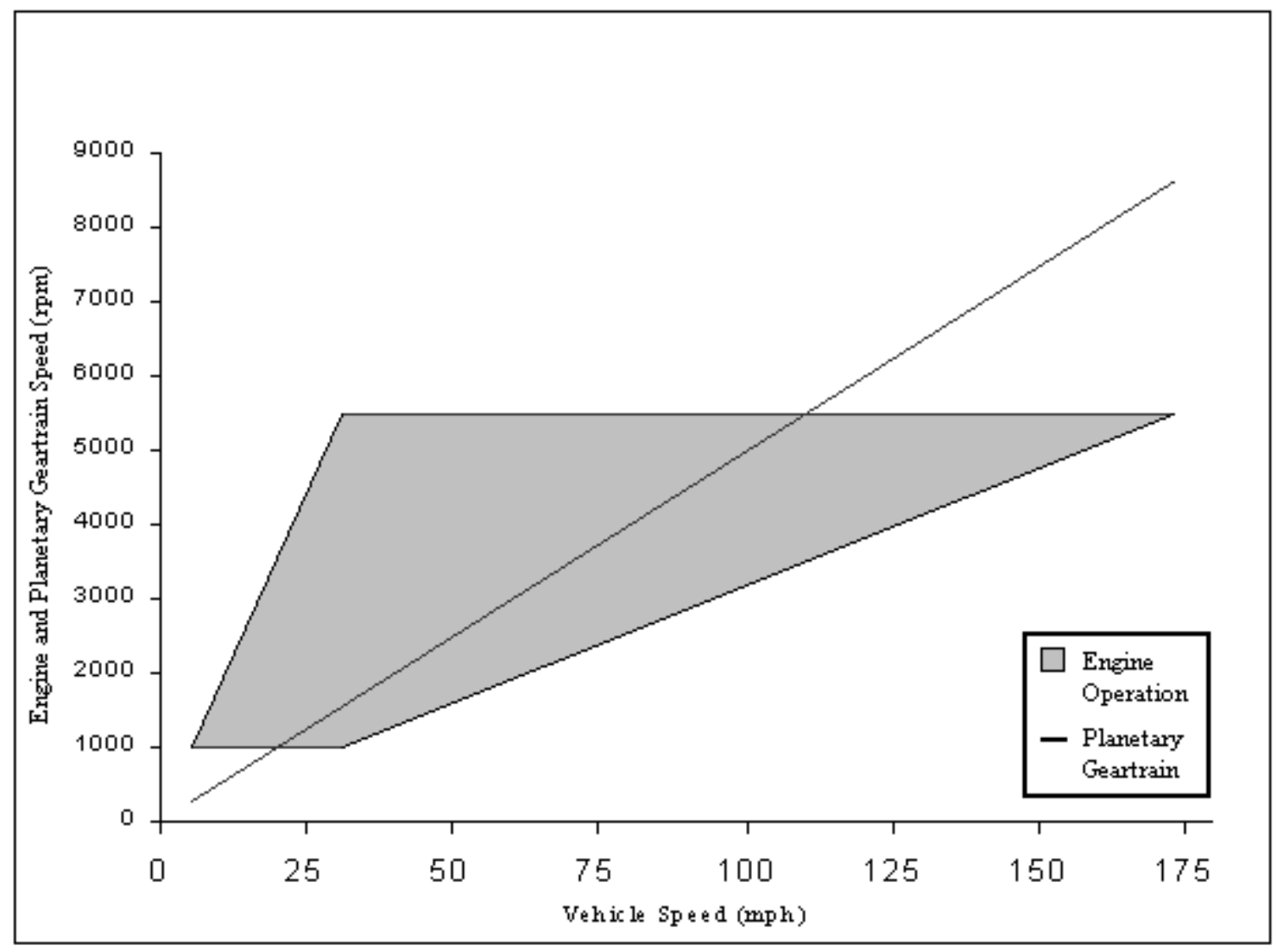

Figure 5.4: Engine and Planetary Geartrain Speed vs Vehicle Speed

Parallel HEV, Variate 1 was simulated next. This mode builds on the types of operation in Conventional and Parallel HEV, Variate 2 modes. Engine operation is the same as in previous modes, but the motor now operates in a larger speed vs torque regime. This is due to the clutch between the sun gear and planetary carrier being opened. Opening this clutch removes the restraint from the planetary geartrain that all elements rotate together. The engine now provides both degrees-of-freedom for the system through direct connection to the sun gear and the second output to the ring gear that varies in speed due to the use of the CVT. As the CVT ratio varies, the motor speed also changes. Increasing the ratio of the CVT to a higher numerical value raises the operating speed of the motor. This trend may be noted below in Figure 5.5. 


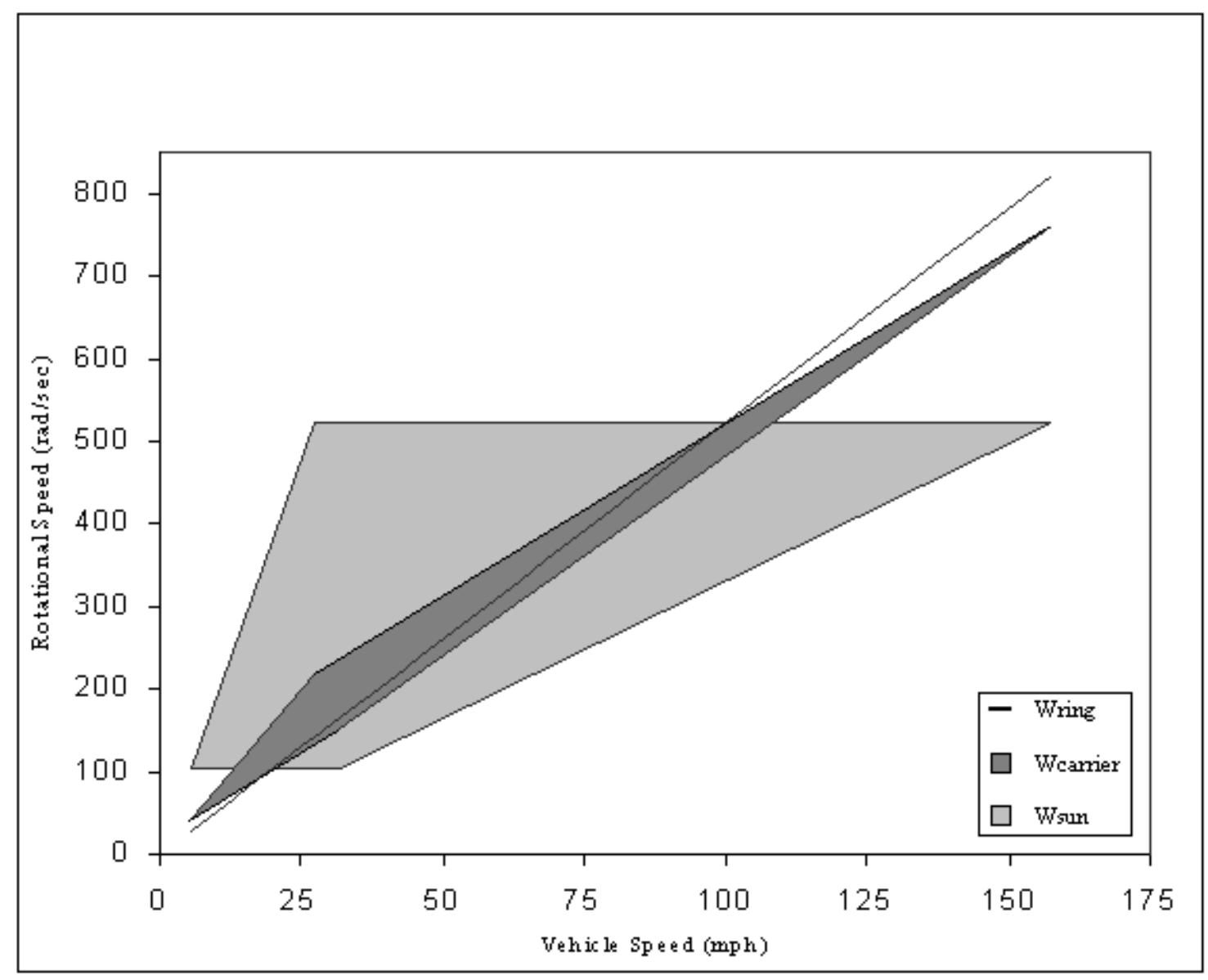

Figure 5.5: Planetary Geartrain Speeds vs Vehicle Speed

The final mode of operation of the TSCT is a Geared Neutral mode. In this mode the engine is connected only to the sun gear. The motor is then connected to the planetary carrier and the output to the drive wheels is taken from the ring gear. This mode of operation differs from the other parallel HEV modes because there is no CVT operation. Vehicle speed is a function of both engine and motor speed. This operation allows the engine to operate while the vehicle is stationary and the drivetrain is engaged. This is possible because the motor spins in a reverse rotational direction compared to the engine. For the vehicle to initiate forward movement, the motor adds torque into the planetary geartrain that slows the motion of the planetary carrier to zero. The planetary 
carrier then reverses direction. It is after this reversal of direction that Figure 5.6 applies. The Geared Neutral mode allows the engine to operate at any speed between 1000 and $5500 \mathrm{rpm}$ for any vehicle speed between zero and a theoretical top speed of $150+\mathrm{mph}$. The only requirement is that the engine must produce enough torque not to be stalled by the torque of the electric motor.

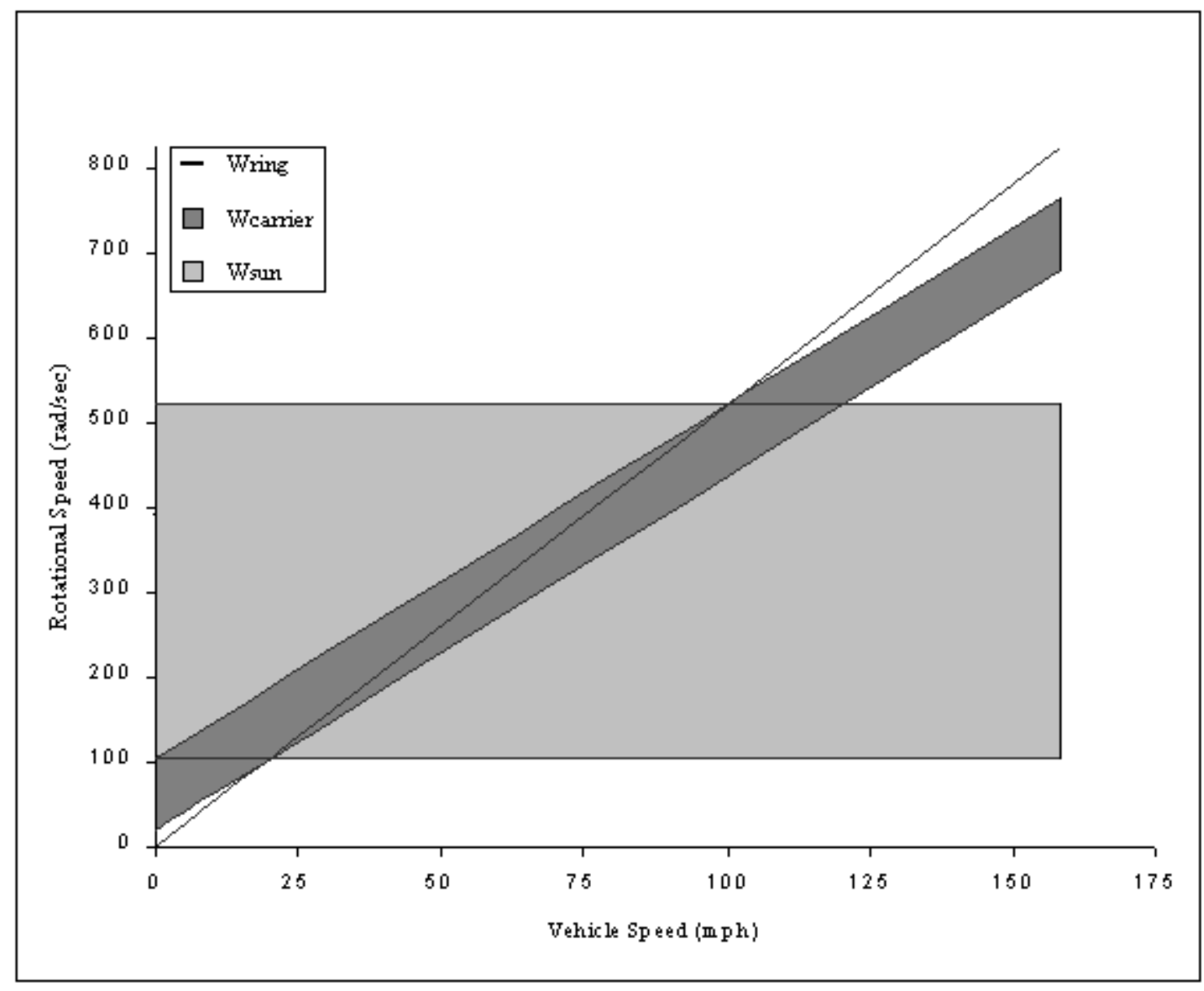

Figure 5.6: Planetary Geartrain Speeds vs Vehicle Speed 


\section{Conclusions}

This study was conducted to determine the feasibility of creating a multiple input/multiple output transmission. This transmission, the Torque and Speed Control Transmission, is combination of a planetary geartrain and a continuously variable transmission. This combination of transmission technologies allows for six distinct different operating modes. These six modes are Conventional, Electric Vehicle, Series HEV, Parallel HEV ,Variate 1, Parallel HEV ,Variate 2, and Geared Neutral. Each of these modes has specific efficiency benefits during vehicle operation and the TSCT operation can switch between modes on the fly. This type of operation allows for a transmission that is significantly more flexible than current automotive transmissions.

By combining these two power transmission technologies, a hybrid electric automotive transmission is created that has provisions for an engine, electric drive motor, high power alternator, and the drive wheels. The engine attached to the TSCT functions only as a power source while the electric motor and alternator may act as power sources or sinks. This transmission is revolutionary in function because of the interaction of the CVT with the planetary geartrain. The engine may send power to the drive wheels directly through the planetary geartrain, through the CVT and planetary geartrain simultaneously, or through the CVT. This flexibility in power transmission allows engine to have a much broader dynamic operating range than possible with an automatic, manual, or continuously variable transmission.

The results of this study show a transmission that is capable of efficient operation under a wide variety of circumstances. These types of operation are illustrated in Figures 5.1 through 5.6. The design of this transmission is also successful due to the 
creation of a design that does allow for multiple input/multiple output power connections. By further analyzing this design in respect to the mechanical efficiencies of the CVT and geared connections, a viable alternative could possibly be created for implementation into the next generation of hybrid vehicles. 


\section{References}

1. Thiesen, Frank J., and Davis N. Dales, Automotive Drive Trains, Reston Publishing Company, Reston VA, 1984

2. Lu, Zhijian, "Acceleration Simulation of a Vehicle with a Continuously Variable Power Split Transmission”, MSME Thesis, West Virginia University, 1998

3. Chowanietz, Eric, Automobile Electronics ed. 1, Society of Automotive Engineers, Warrendale PA, 1995

4. Dietrich, Philipp, "Results of the ETH Hybrid III-Vehicle Project", SAE Paper No. 1999-01-0920, 1999

5. Moore, Stephen and Mehrdad Ehsani, "A Charge Sustaining Parallel HEV Application of the Transmotor", SAE Paper No. 1999-01-0919, 1999

6. Hattori, Noboru, Shunichi Aoyama, Shinichiro Kitada, and Isaya Matsuo - Nissan Motor Company, "Functional Design of a Motor Integrated CVT for a Parallel HEV Nissan Parallel HEV”, SAE Paper No. 1999-01-0753, 1999

7. Mucino, Victor H., James E. Smith, Ben Cowan, and Marek Kmicikiewicz, "A Continuously Variable Power Split Transmission for Automotive Applications", SAE Paper No. 970687, 1997

8. EPA420-R-98-006, "Evaluation of a Toyota Prius Hybrid System (THS)", United States Environmental Protection Agency, 1998

9. "Strategies in Electric and Hybrid Vehicle Design", SAE Special Publication No. 1156,1996

10. General Motors Corporation, “Two-mode, Input-split, Parallel, Hybrid Transmission”, US Patent 5,558,588, 1996

11. Toyota Motor Corporation, Toyota Prius Technical Specifications, http://www.toyota.com.au/env_tech/prius/hybrid/9specs.html, 1999 


\section{Bibliography}

Kellermeyer, William F. III, Development and Validation of a Modular Hybrid Electric Vehicle Simulation Model, MSME Thesis, West Virginia University, May 1998

Mucino, Victor H., James E. Smith, Ben Cowan, and Marek Kmicikiewicz, "A Continuously Variable Power Split Transmission for Automotive Applications”, SAE Paper No. 970687, 1997

Sharma, Pradeep K., Design and Analysis of a Planetary Gear Continuously Variable Transmission, MSME Thesis, West Virginia University, 1994

Yamaguchi, Kozo, “Advancing the hybrid system”, Equos Research Co. Ltd., Japan, 1996

“Toyota Hybrid System”, Toyota Press Information '97, Toyota Motor Corporation, 1997

Bagot, Nick, Editor, Electric \& Hybrid Vehicle Technology '98, UK \& International Press, Surrey UK, 1998

Information from electronic archive: $\underline{\text { www.epa.gov }}$ 